\title{
WestVirginiaUniversity
}

THE RESEARCH REPOSITORY @ WVU

Graduate Theses, Dissertations, and Problem Reports

2002

\section{Evaluation of strut-and-tie modeling for bridge pier applications}

Thomas Nicholas II

West Virginia University

Follow this and additional works at: https://researchrepository.wvu.edu/etd

\section{Recommended Citation}

Nicholas, Thomas II, "Evaluation of strut-and-tie modeling for bridge pier applications" (2002). Graduate Theses, Dissertations, and Problem Reports. 1893.

https://researchrepository.wvu.edu/etd/1893

This Thesis is protected by copyright and/or related rights. It has been brought to you by the The Research Repository @ WVU with permission from the rights-holder(s). You are free to use this Thesis in any way that is permitted by the copyright and related rights legislation that applies to your use. For other uses you must obtain permission from the rights-holder(s) directly, unless additional rights are indicated by a Creative Commons license in the record and/ or on the work itself. This Thesis has been accepted for inclusion in WVU Graduate Theses, Dissertations, and Problem Reports collection by an authorized administrator of The Research Repository @ WVU. For more information, please contact researchrepository@mail.wvu.edu. 
Evaluation of Strut-and-Tie Modeling for

Bridge Pier Applications

\title{
Thomas Nicholas II
}

Thesis submitted to the College of Engineering and Mineral Resources at West Virginia University in partial fulfillment of the requirements for the Degree of

\author{
Masters of Science \\ in \\ Civil Engineering
}

\author{
Dr. Karl E. Barth, Chair \\ Dr. John P. Zaniewski \\ Dr. Anthony L. Brizendine, UNCC \\ Department of Civil and Environmental Engineering
}

\author{
Morgantown, West Virginia \\ 2002
}

Keywords: Reinforced Concrete, Strut-and-Tie Modeling, Hammerhead Piers 


\section{ABSTRACT \\ Evaluation of Strut-and-Tie Modeling for Bridge Pier Applications}

\section{Thomas Nicholas II}

Strut-and-tie modeling is an analysis and design tool for reinforced concrete elements which assumes that internal stresses are transferred through a truss type mechanism. The tensile ties and compressive struts serve as truss members connected by nodal zones. The internal truss idealized by the strut-and-tie model implicitly accounts for the distribution of both flexure and shear.

In 1998, the AASHTO LRFD Bridge Specifications (1998) incorporated the strutand-tie modeling procedure for the analysis and design of deep reinforced concrete members where sectional design approaches are not valid. In most instances, hammerhead piers can be defined as deep reinforced concrete members and therefore, should be designed using the strut-and-tie modeling approach. However, little has been done to develop a consistent approach to the design of hammerhead pier caps employing the strut-and-tie modeling method.

The present study is focused on developing a uniform design procedure for applying the strut-and-tie modeling method to hammerhead piers. In addition to developing a design procedure, a survey of all fifty State Transportation Departments was conducted to ascertain the degree of implementation of the AASHTO LRFD Bridge Specifications for substructure design.

A design study was conducted using four hammerhead piers that were previously designed using the strength design method specified by the AASHTO Standard Specifications in order to evaluate strut-and-tie modeling procedures. The four pier caps were designed using the strut-and-tie modeling procedure and the results compared to the results of the sectional design method. For each hammerhead pier cap, the strut-and-tie method required more flexural steel than the sectional method. Based on the design studies, a well-defined procedure for designing a hammerhead pier utilizing the strut-andtie model was established that may be used by bridge engineers. 


\section{ACKNOWLEDGEMENTS}

I would like to express my deepest gratitude to my advisor Dr. Karl E. Barth for providing me the opportunity to pursue my graduate degree under his direction. His support, direction, and encouragement throughout the course of my graduate study made the completion of this work possible. His exemplary work ethic and commitment to excellence have made it a privilege to work with him. The tutelage and guidance I received under him have helped me to grow as an individual, educator, and engineer.

I would like to express my sincere gratitude to Dr. John Zaniewski for his willingness to serve on my graduate advisory committee.

I would like to thank Dr. Anthony L. Brizendine for serving on my committee and for his guidance and support throughout my professional and scholarly careers.

I would like to thank my family for their encouragement, support, and understanding throughout my graduate work.

Finally, I would like to thank my wife, Melissa. My graduate studies would not have been possible without her patience, support, and love. 


\section{TABLE OF CONTENTS}

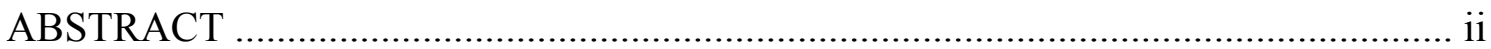

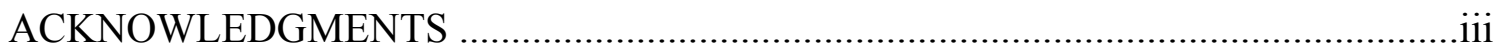

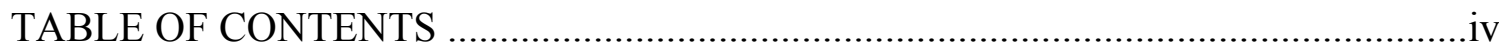

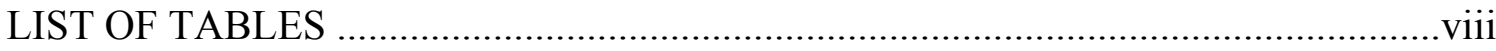

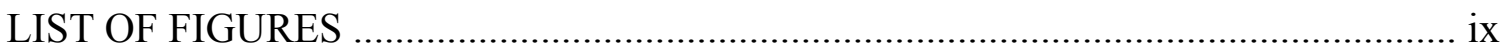

1. INTRODUCTION

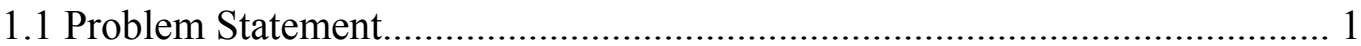

1.2 Objectives and Scope of Study................................................................ 2

1.3 Organization of Thesis .......................................................................... 3

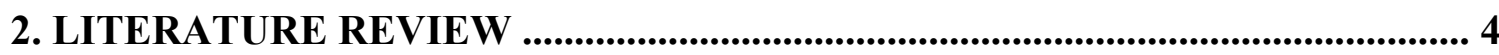

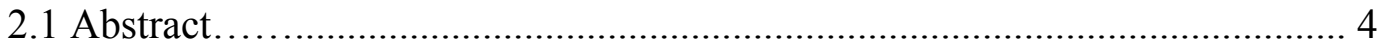

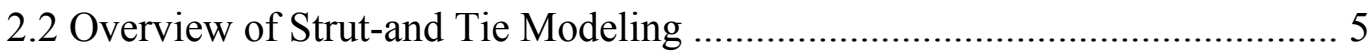

2.3 Adequate Selection of Truss Members ...................................................... 6

2.4 General Strength of Truss Members.............................................................. 9

2.4.1 Strength of Tensile Ties ........................................................... 9

2.4.2 Strength of Compressive Strut .................................................. 10

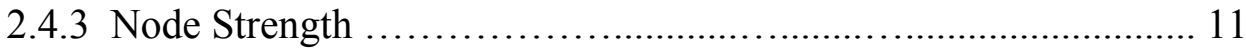

2.5 Shear Concerns in Strut-and-Tie Models ...................................................... 13

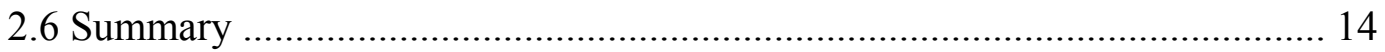

\section{AASHTO LFD AND LRFD SPECIFICATIONS AND DEPARTMENT OF}

HIGHWAYS SURVEY RESULTS .............................................................................. 26 
3.1 Introduction

3.2 AASHTO Standard Code Specifications for the Design of Reinforced

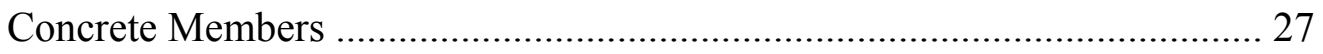

3.2.1 Design for Flexure ................................................ 29

3.2.2 Design for Shear .............................................. 33

3.3 AASHTO LRFD Code Specifications for the Design of Reinforced Concrete

Members using Strut-and-Tie Modeling ….......................................... 35

3.3.1 Compression Struts ........................................... 36

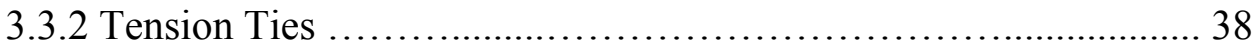

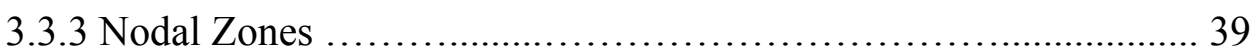

3.4 Survey of State Transportation Departments ............................................ 40

3.5 Survey Results ......................................................... 41

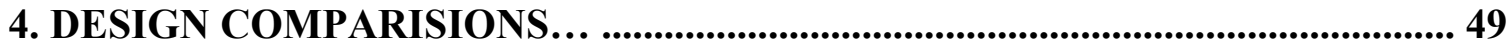

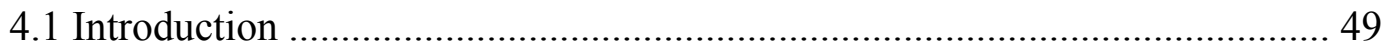

4.2 Description of Design Procedures ......................................................... 50

4.2.1 Load Generation Procedure ............................................. 50

4.2.2 Strut-and-Tie Model Truss Background and Development for

Hammerhead Piers ........................................................ 51

4.2.2.1 Strut-and-Tie Model Background ................................ 51

4.2.2.2 Truss Definition Procedure for Hammerhead Pier Caps

54

4.2.3 Pier Design Procedure .................................................. 55

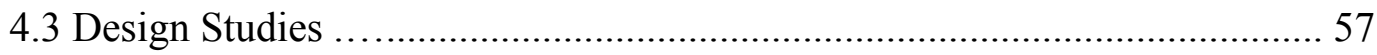


4.3.1 Barboursville Bridge Hammerhead Pier Design Example 57

4.3.1.1 Project Description ........................................... 57

4.3.1.2 Original Analysis/Design................................. 58

4.3.1.3 Strut-and-Tie Analysis/Design............................. 59

4.3.2 South Madison Bridge Hammerhead Pier Design Example .......... 60

4.3.2.1 Project Description .......................................... 60

4.3.2.2 Original Analysis/Design................................... 61

4.3.2.3 Strut-and-Tie Analysis/Design............................ 62

4.3.3 Clear Fork Bridge Hammerhead Pier Design Example .............. 63

4.3.3.1 Project Description .......................................... 63

4.3.3.2 Original Analysis/Design..................................... 64

4.3.3.3 Strut-and-Tie Analysis/Design............................. 65

4.3.4 Shepherd Bridge Hammerhead Pier Design Example .............. 66

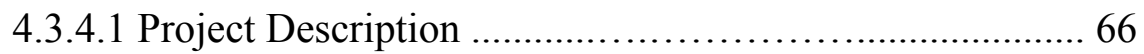

4.3.4.2 Original Analysis/Design................................ 67

4.3.4.3 Strut-and-Tie Analysis/Design.............................. 68

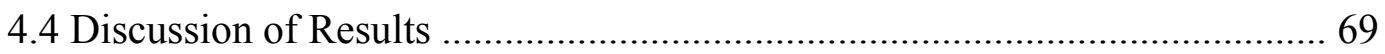

5. DESIGN RECOMMENDATIONS........................................................ 104

5.1 Recommended Strut-and-Tie Design Procedure For Hammerhead Piers.... 104

5.1.1 Determination of Loads........................................................ 104

5.1.2 Defining the Truss Model....................................................... 105

5.1.3 Dimensioning of Tensile Ties, Compressive Struts, and Nodal

Zones

106 
6. SUMMARY AND CONCLUSIONS...................................................... 110

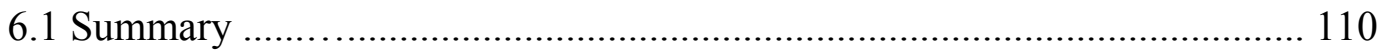

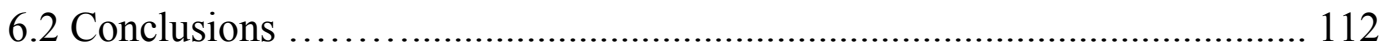

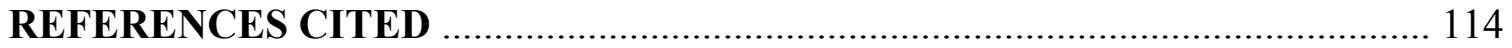
APPENDICES

Appendix A: STATE TRANSPORTATION DEPARTMENT SURVEY .....................117

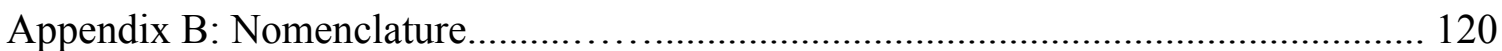




\section{LIST OF TABLES}

Table 2.1 Effective Stress Levels in Nodal Zones. Adapted from Yun and Rameriz (1996) 15

Table 4.1 Tensile Reinforcement Calculations and Concrete Compression

Requirements - Barboursville Bridge ..................................... 70

Table 4.2 Tensile Reinforcement Calculations and Concrete Compression

Requirements - South Madison Bridge ............................................. 71

Table 4.3 Tensile Reinforcement Calculations and Concrete Compression

Requirements - Clear Fork Bridge ................................ 72

Table 4.4 Tensile Reinforcement Calculations and Concrete Compression

Requirements - Shepherd Bridge ............................................... 73

Table 4.5 Comparison between LFD and Strut-and-Tie Modeling Results 


\section{LIST OF FIGURES}

Figure 2.1 Typical truss model for a deep beam. Adapted from MacGregor, 1997 16

Figure 2.2 Examples of the basic types of hydrostatic nodes: (a) Compression-

Compression-Tension-nodes. (b) Compression-Compression-

Compression-nodes. Adapted from Schlaich et. al., 1997 ............... 17

Figure 2.3 Example strut-and-tie models. (a) An Acceptable Model (b) A Poor

Model. Adapted from Schlaich et. al., 1997...........................................18

Figure 2.4 Hammerhead Pier Cap with Acceptable Truss Model............................... 19

Figure 2.5 Hammerhead Pier Cap with Alternate Truss Model................................ 20

Figure 2.6 Topology Optimization History (a) Topology at iteration 20, (b) topology at iteration 40, (c) Optimum topology at iteration 49. Adapted from

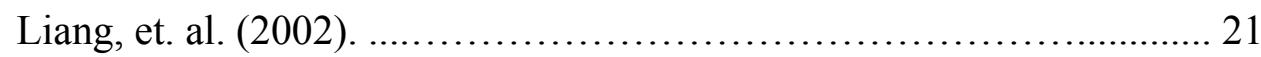

Figure 2.7 Final Strut-and-Tie Model from Topology Optimization Procedure.

Adapted from Liang, et. al. (2002). ........................................... 22

Figure 2.8 Types of Compression Struts. (a) Prismatic Strut (b) Bottle Shaped Strut

(c) Strut-and-Tie Model for Bottle Shaped Strut. Adapted from

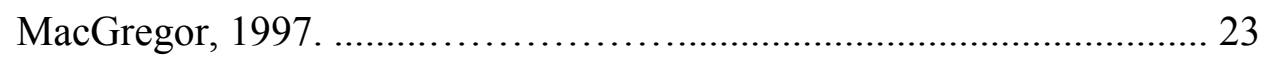

Figure 2.9 (a) Typical singular nodes, (b) Typical smeared nodes. Adapted from

Schlaich et. al., 1997 ............................................... 24

Figure 2.10 Predicted and observed strengths of concrete beams tested by Kani, (1979) 
Figure 3.1 Rectangular Section with Tension Reinforcement Only ................... 44

Figure 3.2 Rectangular Section with Compression and Tension Reinforcement....... 45

Figure 3.3 Flanged Section with Tension Reinforcement Only............................. 46

Figure 3.4 Compressive Strut anchorages (Collins and Mitchell, 1991)

Figure 3.5 United States Map of Responding State Transportation Departments....48

Figure 4.1 HL-93 Reaction Calculation Configuration .............................. 75

Figure $4.2 \quad$ Illustration of Wheel Placement ...................................... 76

Figure 4.3 Illustration of Lane Loading Placement ................................ 77

Figure 4.4 Steps for defining a truss model. (Collins and Mitchell, 1991)............... 78

Figure 4.5 Hammerhead Pier Cap with Truss Model .................................. 79

Figure 4.6 Bridge Elevation - Barboursville Bridge .............................. 80

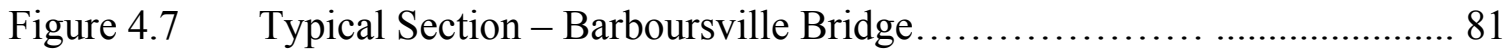

Figure 4.8 Barboursville Pier Cap LFD Design ................................... 82

Figure 4.9 Barboursville Truss Model Dimensions and Solutions........................ 83

Figure 4.10 Effective Depth Calculation for Barboursville Bridge Pier Cap............. 84

Figure 4.11 Barboursville Bridge Strut-and-Tie Modeling Reinforcing Details........ 85

Figure 4.12 Bridge Elevation - South Madison Bridge ................................ 86

Figure 4.13 Typical Section - South Madison Bridge................................ 87

Figure 4.14 South Madison Bridge Pier Cap LFD Design............................... 88

Figure 4.15 South Madison Truss Model Dimensions and Solutions....................... 89

Figure 4.16 Effective Depth Calculation for South Madison Bridge Pier Cap........... 90

Figure 4.17 South Madison Bridge Strut-and-Tie Modeling Reinforcing Details....... 91 
Figure 4.18 Bridge Elevation - Clear Fork Bridge ...................................... 92

Figure 4.19 Typical Section - Clear Fork Bridge..................................... 93

Figure 4.20 Clear Fork Bridge Pier Cap LFD Design...................................... 94

Figure 4.21 Clear Fork Truss Model Dimensions and Solutions.............................. 95

Figure 4.22 Effective Depth Calculation for Clear Fork Bridge Pier Cap................... 96

Figure 4.23 Clear Fork Bridge Strut-and-Tie Modeling Reinforcing Details.............. 97

Figure 4.24 Bridge Elevation - Shepherd Bridge ….................................... 98

Figure 4.25 Typical Section - Shepherd Bridge ........................................ 99

Figure 4.26 Shepherd Bridge Pier Cap LFD Design ..................................... 100

Figure 4.27 Shepherd Bridge Truss Model Dimensions and Solutions .................... 101

Figure 4.28 Effective Depth Calculation for Shepherd Bridge Pier Cap................... 102

Figure 4.29 Shepherd Bridge Strut-and-Tie Modeling Reinforcing Details.............. 103 


\section{Chapter 1}

\section{INTRODUCTION}

\subsection{Problem Statement}

Strut-and-tie modeling is an analysis and design tool for reinforced concrete elements in which it may be assumed that internal stresses are transferred through a truss mechanism. The tensile ties and compressive struts serve as truss members connected by nodal zones. The internal truss, idealized by the strut-and-tie model, implicitly account for the distribution of both flexure and shear.

In 1998, the AASHTO LRFD Bridge Specifications (1998) incorporated the strutand-tie modeling procedure for the analysis and design of deep reinforced concrete members where sectional design approaches are not valid. In most instances, hammerhead piers can be defined as deep reinforced concrete members and therefore, should be designed using the strut-and-tie modeling approach.

However, most bridge designers have not embraced the strut-and-tie model due to the unfamiliarity with the design procedure, the inability to check the truss model's validity (without laboratory tests or a finite element model), and the time it takes to complete the strut-and-tie model analysis and design. Therefore, it is likely that, with the formulation of a well-defined strut-and-tie modeling procedure, practicing engineers will 
become more comfortable with the design method and therefore, employ the method more often and consistently.

\subsection{Objectives and Scope of Study}

The specific objectives of the study are:

- To ascertain the degree of strut-and-tie modeling implementation in State Transportation Departments,

- To compare the flexure and shear reinforcing requirements for typical hammerhead type bridge piers using both strut-and-tie modeling and standard sectional design practices, and

- To develop a uniform design procedure for employing strut-and-tie modeling for hammerhead piers.

A survey of all fifty State Transportation Departments was conducted to ascertain the implementation of the AASHTO LRFD Bridge Specifications and the strut-and-tie method for bridge substructures in their respective states. The survey consisted of two questions and follow-ups were performed via email and telephone.

The design study utilizes four hammerhead piers that were previously designed using the strength design method specified by the AASHTO Standard Specifications. The four pier caps are designed using the strut-and-tie modeling procedure and the results compared to the results of the sectional design method. By comparing the results, the reduction or increase in the flexural steel and the shear steel can be quantified. 
Lastly, a well-defined procedure for designing a hammerhead pier utilizing the strut-and-tie model saw established that may be used by bridge engineers.

\subsection{Organization of Thesis}

The thesis is organized in six chapters. The first chapter presents the background, objectives and scope of the project. Chapter 2 presents a review of previous work on the development of strut-and-tie models in deep reinforced concrete sections. Chapter three presents the state transportation department survey and the governing specifications for the design of reinforced concreted in bridges. Chapter four discusses the design comparisons between the strength design method and the strut-and-tie method. Chapter five provides design recommendations for strut-and-tie modeling of hammerhead piers. Lastly, chapter six presents a summary and conclusions of the current study and describes potential directions for future work. 


\section{Chapter 2}

\section{LITERATURE REVIEW}

\subsection{Abstract}

Over the past several decades considerable research has been conducted on the analysis, strength and behavior of various reinforced concrete sections designed using the strut-and-tie approach. Initial work was conducted by Ritter (1899) and later Morsch (1920) whom first used a truss type analogy to model the internal load carrying mechanism in a reinforced concrete beam. Later, Schlaich et al. (1987) worked to combine individual research conducted on various reinforced concrete elements in such a fashion that strut-and-tie modeling could be used for the entire structure.

Strut-and-tie modeling is an analysis and design tool for reinforced concrete elements in which it may be assumed that both flexural and shearing stresses are transferred internally in a truss type member comprised of concrete compressive struts and steel reinforcing tension ties. It should be noted that while the shear design is theoretically coupled with the truss model, in most instances designers perform a separate check for providing additional stirrup type shear reinforcement.

During the past few years design codes, ACI (2001) and AASHTO LRFD (1998),

have adopted strut-and-tie principles for the design of deep beam members. The 
definition of deep sections provided by these specifications classifies most hammerhead piers as deep sections.

This chapter provides a brief overview of previous work that has been conducted on strut-and-tie modeling specifically as it relates to the design of sections such as hammerhead piers.

\subsection{Overview of Strut-and-Tie Modeling}

Previous researchers focused on understanding the internal distribution of forces in a reinforced concrete structure and have defined two specific regions; B-Regions and D-Regions. The B-Regions of a structure (where B stands for a region where Bernoulli Beam theory may be employed) have internal states of stress that are easily derived from the sectional forces e.g. bending, shear, etc. For structural members that do not exhibit plane strain distribution, e.g. the strain distribution is non-linear, the sectional force approach in not applicable. These regions are called D-Regions (where D stands for discontinuity, disturbance, or detail). The D-Regions of a structure are normally corners, corbels, deep sections, and areas near concentrated loads. When D-Regions crack the treatments used such as "detailing," "past experience," and "good practice" often prove inadequate and inconsistent (Schlaich et al., 1987).

Figure 2.1 provides a simple strut-and-tie model applied to a simply supported deep beam. In this figure, the lighter shaded regions represent concrete compressive struts, the steel reinforcing bar represents a tensile tie, and the dark shared regions represent nodal zones. 
The tension ties in the truss model may represent one or several layers of flexural reinforcement in the deep section. The locations of the tension ties normally are defined at the centroid of reinforcing mat. The compressive struts are concrete compressive stress fields with the prevailing compression in the direction of the strut (Kuchma and Tjhin, 2001). As previously stated, nodal zones are the truss joints in the strut-and-tie model. Nodal zones are formed where tension ties, compression struts, and exterior loads intersect. Figure 2.2 shows the two types of hydrostatic nodal zones.

For further in-depth information on the general application of strut-and-tie modeling for general structures, the reader is referred to Schlaich, et., al. (1987); Collins and Mitchell (1991); Adebar and Zhou (1996); and MacGregor (1997). It should be noted while research has been widely performed on the various parts of a structure, Schlaich et al. (1987) combined the individual pieces of the structure to allow for the entire structure to be modeled using the strut-and-tie approach.

\subsection{Adequate Selection of Truss Members}

Adequate representation of the truss model requires a level of skill and engineering judgment and typically requires an iterative procedure to produce an adequate reinforcement pattern for a given member. The process of defining the truss begins by defining the flow of forces in the member and locating the nodal zones at points where the external loads act and the loads are transferred between structural members, e.g. the pier cap to pier column or at the supports. The tension ties and compression struts can then be located once the nodal zones have been defined. The 
tension ties are located at the assumed centroid of tensile reinforcing beginning and terminating at nodal zones. The compression struts are defined to coincide with the compressive field and, as with the tensile ties, begin and terminate at the nodal zones (Collins and Mitchell, 1991).

The truss should exhibit equilibrium at each node and should portray an acceptable truss model. Figure 2.3 illustrates the difference between an acceptable model and a poor model. The truss model represented by Fig. $2.3 \mathrm{~b}$ is classified as poor due to the larger number of tension ties and the truss members cross. Furthermore, it is helpful to realize that loads try to use the path with the least forces and deformations. Since reinforced ties are much more deformable than concrete struts, the model with the least and shortest ties should provide the most favorable model. Schlaich et al., proposes a simple criterion for optimizing a model that derived from the principle of minimum strain energy for linear elastic behavior of the struts and ties after cracking. The contribution of the concrete struts can generally be omitted because the strains of the struts are usually much smaller than those of the steel ties. The minimum number of ties required for the model can be found by the following equation:

$$
\sum F_{i} l_{i} \in_{m i}=\text { Minimum }
$$

where

$F_{i}=$ force in strut or tie $\mathrm{i}$

$l_{i}=$ length of member i

$\epsilon_{m i}=$ mean strain of member i 
The selection of the truss model dictates the prevailing internal forces and behavior of the reinforced concrete member. Figure 2.4 and Figure 2.5 present two different truss models for the same hammerhead pier cap. Figure 2.4 represents the final model used in the design of the hammerhead piers in the design studies of chapter 4. Based on minimizing the number of tensile ties, the truss model in Fig. 2.4 provides a less stiff model than the truss in Fig. 2.5.

Liang, et al. (2002) developed a performance-based strut-and-tie modeling procedure for reinforced concrete citing the inefficiency of the trial-and-error iterative process that is based on the designer's intuition and past experience. Their optimization procedure consists of eliminating the most lowly stressed portions from the structural concrete member to find the actual load path. Liang, et al., proposes that minimizing the strain energy is equivalent to maximizing the overall stiffness of a structure and that the strut-and-tie system should be based on system performance (overall stiffness) instead of component performance (compression struts and tension ties).

The topology optimization employed by Liang et al., is performed by defining a design space, performing a linear elastic finite element analysis, calculating the strain energy densities, and removing the elements with the lowest strain energy densities. This process is repeated until the performance index, defined by Liang, et al., is less than unity. A strut-and-tie model can then be defined based on the final finite element model. A history of the topology optimization for a hammerhead pier is given by Fig. 2.6. The final strut-and-tie model produced by the topology procedure is illustrated in Fig. 2.7. 


\subsection{General Strength of Truss Members}

As previously stated, the truss model is comprised of tension ties, compression struts, and nodal zones. For the adequate design of the reinforced concrete member, the elements of the truss model must be sized. The following sections present the general strength of the tensile ties, compressive struts, and nodal zones.

\subsubsection{Strength of TensileTies}

One or several layers of reinforcement in the same direction represent a tension tie in a truss model. According to ACI, the tension tie can be designed with the straightforward approach of dividing the factored tie force by the yield strength of the reinforcing steel and is expressed as follows (Kuchma and Tjhin, 2001; ACI, 2001):

$$
A s>N_{u} / \phi f_{y}
$$

where

$N_{u}=$ the factored tie force

$f_{\mathrm{y}}=$ the tie yield strength

$\phi=$ resistance factor

$A_{S}=$ the required area of steel

However, the emphasis is not in the design of the tensile reinforcement but in the selection of how to distribute and anchor the reinforcement. This becomes apparent due 
to the ability of the joint or nodal zone to transfer forces between the strut-and-tie is dependent on the surface area of the reinforcement, the height over which it is distributed, the length of the node, and the type of anchorage method that is employed. ACI and AASHTO have provisions, which require the tie reinforcement be distributed over such a height that if the tie were anchored on the far side of the node that the nodal stress limit value will not be exceeded (Kuchma and Tjhin, 2001). AASHTO requirements for nodal stress limits can be found in Section 3.3 of this paper.

\subsubsection{Strength of Compressive Strut}

Struts represent one dimensional stress fields, which should not exceed the compressive strength of the concrete (Yun and Rameriz, 1996). Struts are often portrayed as prismatic or uniformly tapered members; however, struts can vary along their length and form what is known as a bottle-shape. Figure 2.8 shows several forms that may be used to represent internal compressive struts. Cracking may develop in bottle shaped elements if no crack control reinforcement is used.

ACI uses the following formula to limit the compressive stress in the strut (ACI, 2001).

$$
f_{c u}=0.85 \beta_{s} f_{c}^{\prime}
$$

where

$\beta_{s}=1.00$ for prismatic struts in uncracked compression zones

$\beta_{s}=0.40$ for struts in tension members 


$$
\begin{aligned}
& \beta_{s}=0.75 \text { when struts may be bottle shaped and crack control } \\
& \text { reinforcement is included } \\
& \beta_{s}=0.60 \text { when struts may be bottle shaped and crack control } \\
& \quad \text { reinforcement is not included } \\
& \beta_{s}=0.60 \text { for all other cases } \\
& f^{\prime} c=\text { concrete compressive strength }
\end{aligned}
$$

The ACI code equation accounts for when struts are prismatic, tapered, or bottle shaped and whether transverse reinforcement is or is not provided. ACI also gives the following equation for the required amount of crack control reinforcement:

$$
\sum \rho_{v i} \sin \gamma_{i} \geq 0.003
$$

where

$\rho_{v i}=$ steel ratio of the $i$-th layer of reinforcement crossing that strut $\gamma_{i}=$ angle between the axis of a strut and the bars

\subsubsection{Node Strength}

Nodal zones (the joints of the truss) are formed where tension ties, compression struts, and exterior loads intersect. To allow safe transfer of strut-and-tie forces through the nodal zones, concrete stress levels must be controlled. The strength of concrete in the nodal zones depends on (Yun and Rameriz, 1996): 
- The confinement of the zones by reactions, compression struts, anchorage plates for prestressing, reinforcement from the adjoining members and hoop reinforcement,

- The effects of strain discontinuities within the nodal zone when ties strained in tension are anchored in, or across, a compressed nodal zone, and

- The splitting stresses and hook-bearing stresses resulting from the anchorage of the reinforcing bars of a tension tie in or immediately behind a nodal zone.

When a node is introduced into a model it is implied that the internal forces change directions abruptly. In reality, the force changes directions over a certain length and width. This yields two types of nodes based on the length and width of the node; singular and smeared. Singular nodes are encountered when forces tend to be locally concentrated and the deviation of the forces tends to be locally concentrated. Conversely, if a strut or tie represents a wide stress field the node can be considered a smeared node. Figure 2.9 illustrates some typical examples of singular and smeared nodes (Schlaich et al., 1987).

A great deal of research has been done to determine the effective stress levels in nodal zones and is summarized in the third column of Table 2.1 (Yun and Rameriz, 1996). However, ACI gives the following equation for limiting the stresses in nodal zones: 


$$
f_{c u}=0.85 \beta_{n} f^{\prime}{ }_{c}
$$

where

$\beta_{n}=$ when nodes are bounded by struts and/or bearing areas

$\beta_{n}=0.80$ when nodes anchor only one tie

$\beta_{n}=0.60$ when nodes anchor more than one tie

$f^{\prime} c=$ concrete compressive strength

\subsection{Shear Concerns in Strut-and-Tie Models}

Truss models implicitly carry both flexure and shearing type forces through compressive and tensile axial force elements. Therefore, it is apparent that shear reinforcement could be omitted when employing the strut-and-tie model to reinforced concrete members, based on how the flexural and shearing stresses are treated by the truss model.

Kani et al., (1979) suggest that the shear behavior of a beam is dependent on the "shear span." The shear span is defined as the distance from the support of the structure to the load acting on the structure. A simply supported beam can resist high levels of shear closer to the support, which is illustrated in Figure 2.10 (Kani et al., 1979). The test showed that for span-to-depth ratios from 1 to 2.5 the shear is carried by strut-and-tie action; however, over the 2.5 ratio a sectional model transfers the shearing stress. The findings of Kani et al., (1979) would further support the ability of the truss model to transfer the shear in disturbed regions near supports and point loads. However, bridge designers are typically uncomfortable with the idea of not using shear reinforcement and 
therefore after a strut-and-tie has been developed most engineers have then also conducted a sectional analysis to detail additional shear reinforcement.

\subsection{Summary}

Throughout the past several years, researchers have sought to reliably and accurately predict the behavior of deep structural members consisting of D-Regions. For a number of years designers have been using "good" engineering judgment and "detailing" to handle theses situations. Now, due to the implementation of strut-and-tie modeling into the AASHTO LRFD Bridge Specifications and the ACI Design Code, designers have the tools to more accurately design these regions.

The truss model is constructed by defining the tension ties, compression struts, and nodal zones. The tensile ties represent the flexural reinforcement in the structural member, while the compressive struts represent the primary compressive stress paths. The nodal zones are defined where the external loads act on the structure; the intersection of compressive struts and tensile ties; and load paths between elements.

Truss model geometry and the detailing of the truss elements is an iterative and subjective process. However, when done by experienced engineers will provide a solution that is acceptable and more accurate than the traditional treatment of discontinuity regions. Where experience is insufficient, Liang, et al. (2002) provides the topology optimization procedure which consists of eliminating the underutilized portions from the structural concrete member to find the actual load path. The final load path is then used to define the truss model. 
Table 2.1 Effective Stress Levels in Nodal Zones. Adapted from Yun and Rameriz (1996)

\begin{tabular}{|c|c|c|}
\hline $\begin{array}{c}\text { Effective } \\
\text { stress level } \\
\text { (1) }\end{array}$ & $\begin{array}{l}\text { Nodes } \\
\text { (2) }\end{array}$ & $\begin{array}{l}\text { Proposed by } \\
\text { (3) }\end{array}$ \\
\hline $0.85 \mathrm{f}_{\mathrm{c}}$ & $\begin{array}{l}\text { Compression-compression- } \\
\text { compression nodes }\end{array}$ & $\begin{array}{l}\text { Schlaich et al. } \\
\text { (1987) }\end{array}$ \\
\hline $0.68 \mathrm{f}_{\mathrm{c}}$ & $\begin{array}{l}\text { Nodes where reinforcement } \\
\text { is anchored in or crossing } \\
\text { the node }\end{array}$ & $\begin{array}{l}\text { Schlaich et al. } \\
\text { (1987) }\end{array}$ \\
\hline $0.85 \mathrm{f}_{\mathrm{c}}$ & $\begin{array}{l}\text { Nodes bounded by } \\
\text { compressive struts and } \\
\text { bearing areas }\end{array}$ & MacGregor (1988) \\
\hline $0.65 \mathrm{f}_{\mathrm{c}}$ & $\begin{array}{l}\text { Nodes anchoring one } \\
\text { tension tie }\end{array}$ & MacGregor (1988) \\
\hline $0.50 \mathrm{f}_{\mathrm{c}}{ }_{\mathrm{c}}$ & $\begin{array}{l}\text { Nodes anchoring tension } \\
\text { ties in more than one } \\
\text { direction }\end{array}$ & MacGregor (1988) \\
\hline $\begin{array}{l}0.8 \mathrm{f}^{\prime}{ }_{\mathrm{c}} \text { for } \mathrm{f}^{\prime}{ }_{\mathrm{c}} \leq 27.6 \\
\mathrm{MPa}\end{array}$ & $\begin{array}{l}\text { Unconfined nodes without } \\
\text { bearing plates }\end{array}$ & $\begin{array}{l}\text { Bergmeister et al. } \\
\text { (1991) }\end{array}$ \\
\hline $\begin{array}{l}\left(0.9-0.25 \mathrm{f}^{\prime}{ } / 69\right) \mathrm{f}^{\prime}{ }_{c} \\
\text { for } 27.6 \leq \mathrm{f}^{\prime}{ }_{c} \leq 69 \\
\text { MPa }\end{array}$ & $\begin{array}{l}\text { Unconfined nodes without } \\
\text { bearing plates }\end{array}$ & $\begin{array}{l}\text { Bergmeister et al. } \\
\text { (1991) }\end{array}$ \\
\hline $\begin{array}{l}0.65 \mathrm{f}^{\prime} \text { for } \mathrm{f}_{\mathrm{c}} \geq 69 \\
\mathrm{MPa}\end{array}$ & $\begin{array}{l}\text { Unconfined nodes without } \\
\text { bearing plates }\end{array}$ & $\begin{array}{l}\text { Bergmeister et al. } \\
\text { (1991) }\end{array}$ \\
\hline $\begin{array}{l}\mathrm{v}\left(\mathrm{A} / \mathrm{A}_{\mathrm{b}}\right)^{0.5}+ \\
\alpha\left(\mathrm{A}_{\text {core }} / \mathrm{A}_{\mathrm{b}}\right) \mathrm{f}_{\mathrm{lat}}(1- \\
\mathrm{s} / \mathrm{d})^{2}\end{array}$ & Confined nodes & $\begin{array}{l}\text { Bergmeister et al. } \\
\text { (1991) }\end{array}$ \\
\hline $\mathrm{v} \mathrm{f}_{\mathrm{c}}\left(\mathrm{A} / \mathrm{A}_{\mathrm{b}}\right) 0.5$ & $\begin{array}{l}\text { Unconfined nodes with } \\
\text { bearing plates }\end{array}$ & $\begin{array}{l}\text { Bergmeister et al. } \\
\text { (1991) }\end{array}$ \\
\hline $2.5 \mathrm{f}_{\mathrm{c}}^{\prime}$ & Triaxially confined nodes & $\begin{array}{l}\text { Bergmeister et al. } \\
\text { (1991) }\end{array}$ \\
\hline
\end{tabular}

Note: $\mathrm{A}, \mathrm{A}_{\mathrm{b}}$, and $\mathrm{A}_{\text {core }}=$ area of confined concrete, bearing plate, and the confined strut, respectively; $\mathrm{f}_{\text {lat }}=$ lateral pressure $\left(2 \mathrm{f}_{\mathrm{y}} \mathrm{A}_{\mathrm{s}} /(\mathrm{ds})\right.$ for $\mathrm{f}_{\mathrm{c}}<48.3 \mathrm{MPa}$; $2 \mathrm{f}_{\mathrm{y}} \mathrm{A}_{\mathrm{s}} /(\mathrm{ds})$ for $\mathrm{f}_{\mathrm{c}}>48.3 \mathrm{MPa} ; \mathrm{s}=$ pitch or spacing of confining reinforcement; $\mathrm{d}$ $=$ diameter of confined core; $\alpha=$ parameter $(4.0$ for spiral confinement, 2.0 for square closed hoop confinement anchored with longitudinal reinforcement, and 1.0 for square closed hoop confinement without longitudinal reinforcement anchorage); and v $=0.5+1.25 / \sqrt{\mathrm{f}_{\mathrm{c}}}$. 


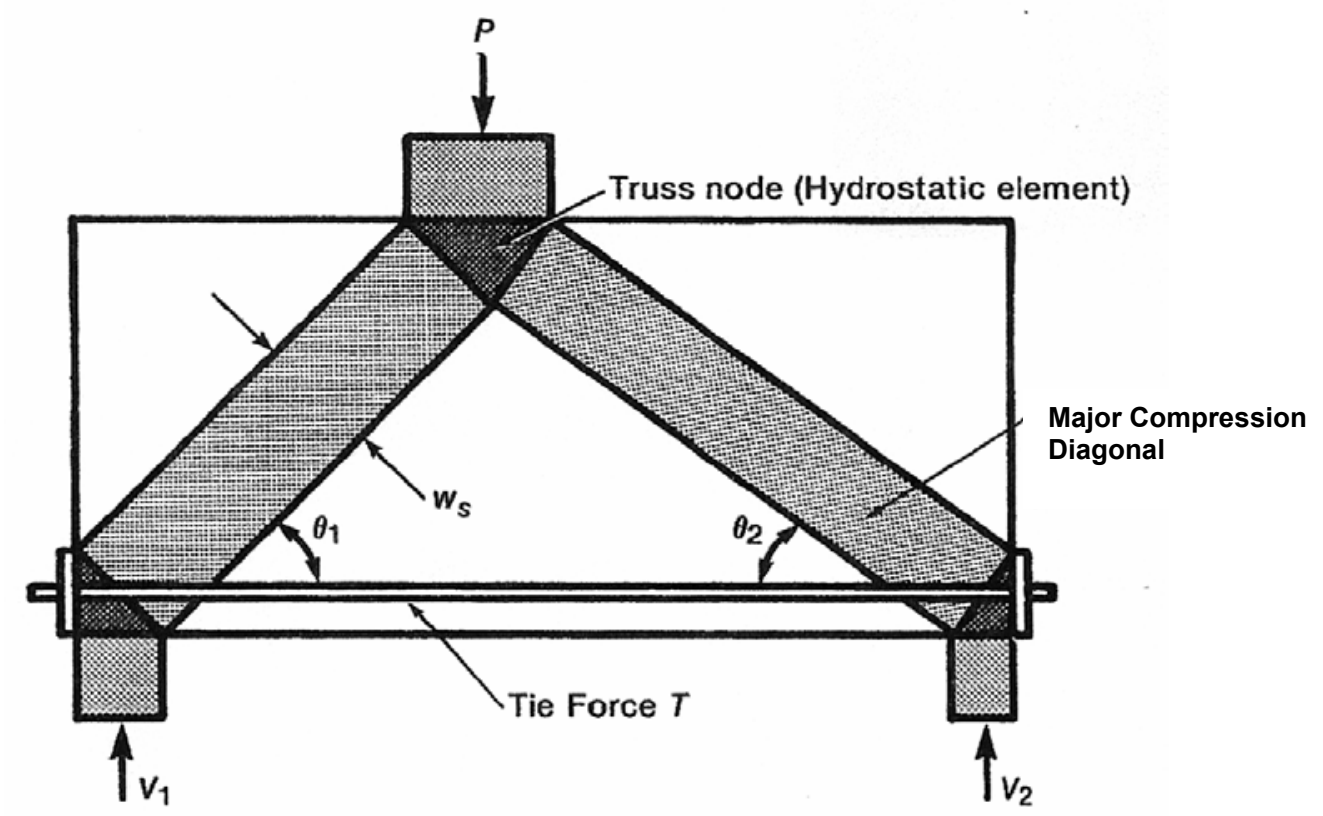

Figure 2.1 Typical truss model for a deep beam. Adapted from MacGregor, 1997 


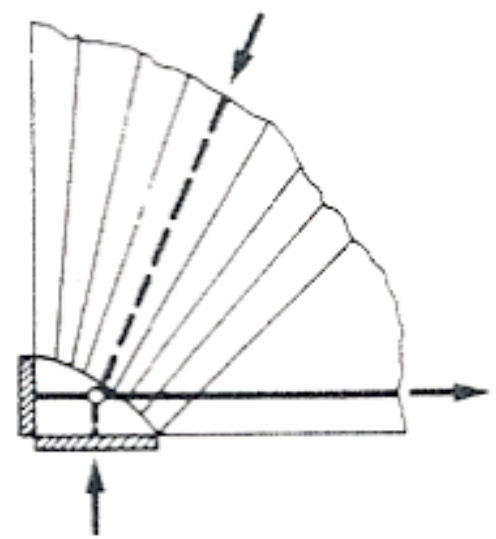

(a) CCT-node

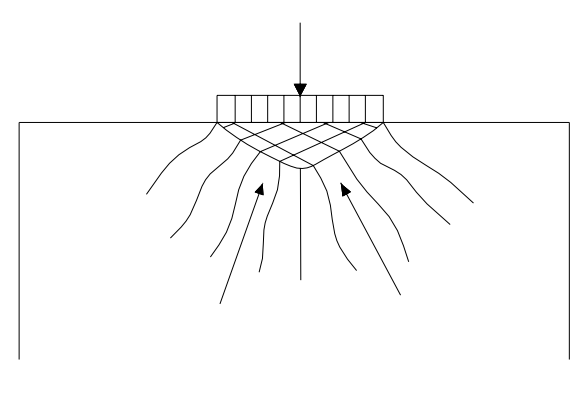

(b) CCC-node

Fig. 2.2 Examples of the basic types of hydrostatic nodes: (a) Compression-

Compression-Tension-nodes. (b) Compression-Compression-Compressionnodes. Adapted from Schlaich et. al., 1997 

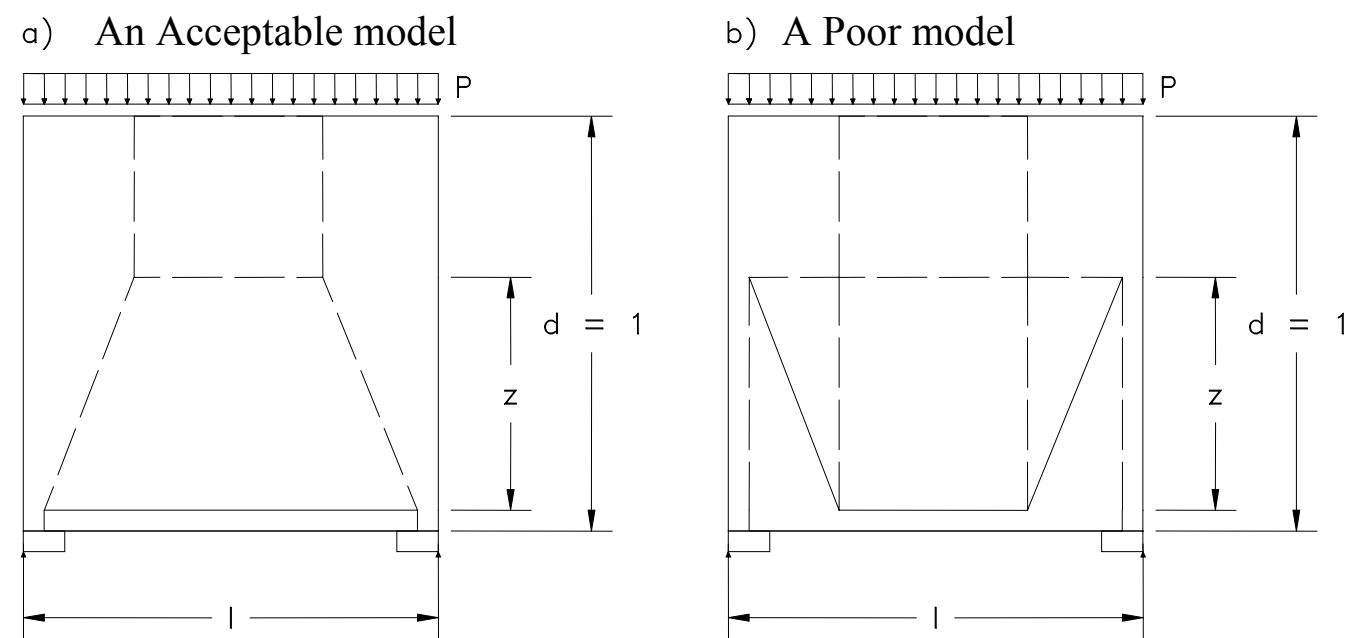

Figure 2.3. Example strut-and-tie models. (a) An Acceptable Model (b) A Poor Model. Adapted from Schlaich et. al., 1997 


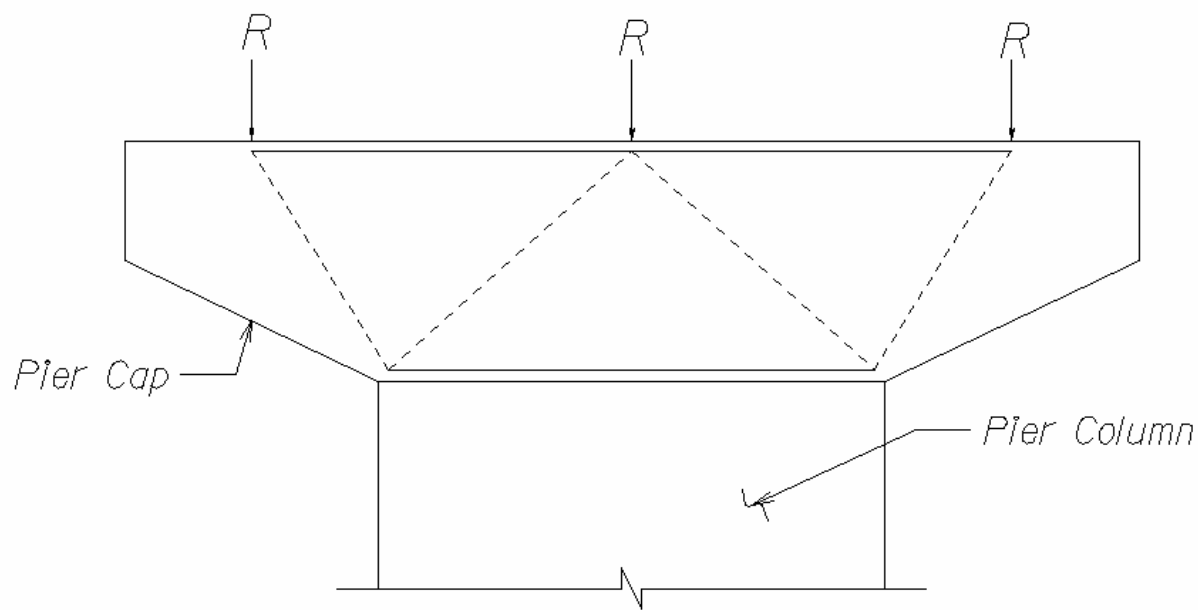

Figure 2.4. Hammerhead Pier Cap with Acceptable Truss Model 


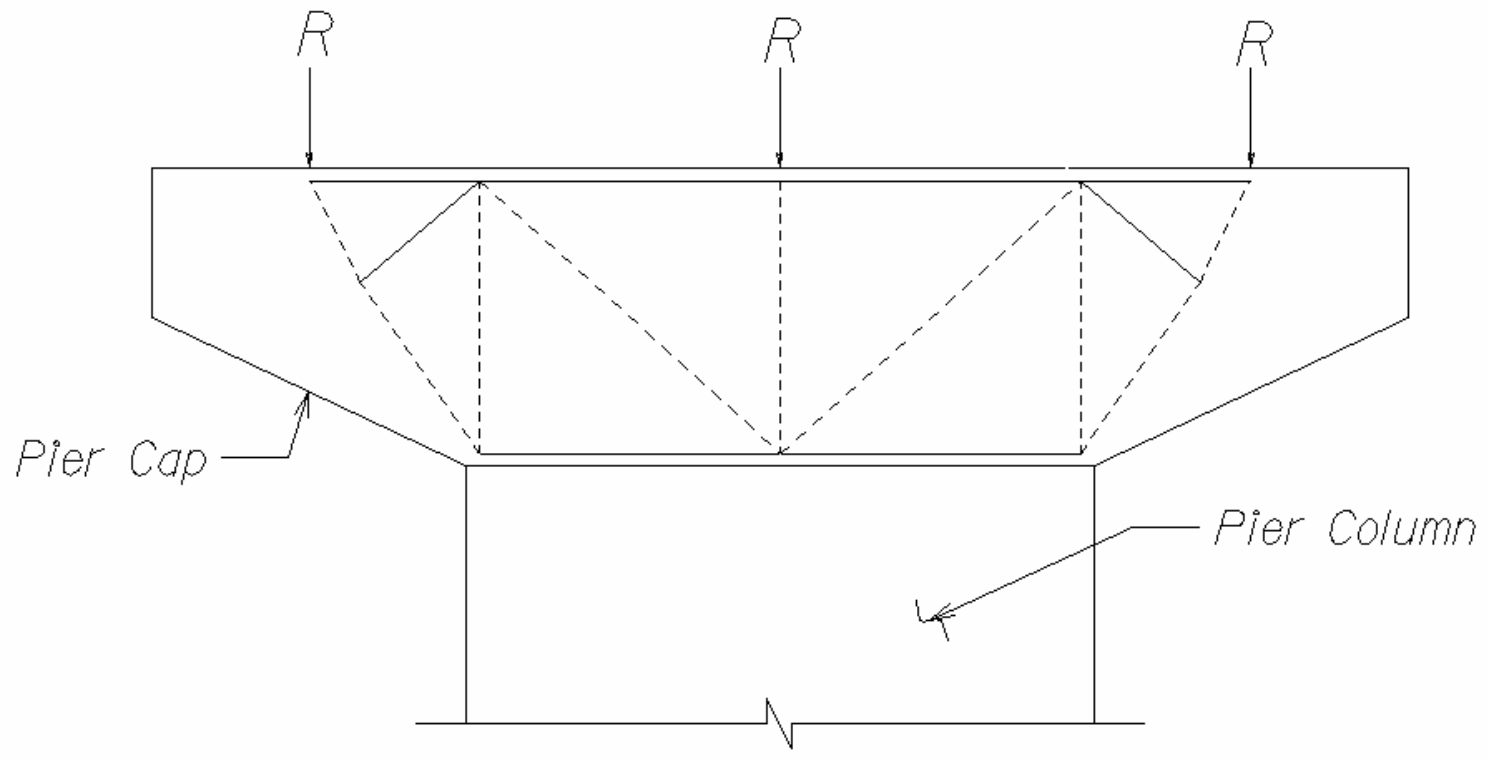

Figure 2.5. Hammerhead Pier Cap with Alternate Truss Model 


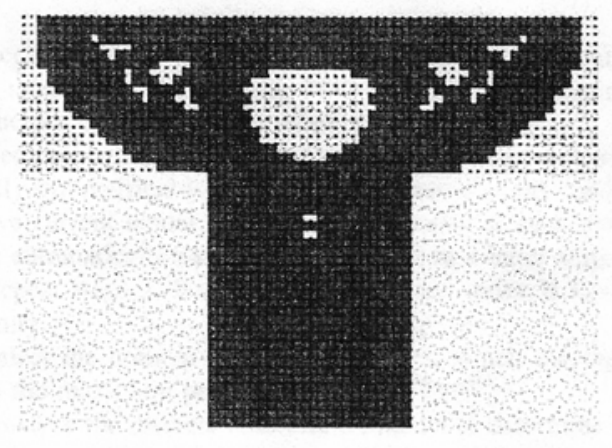

(a)

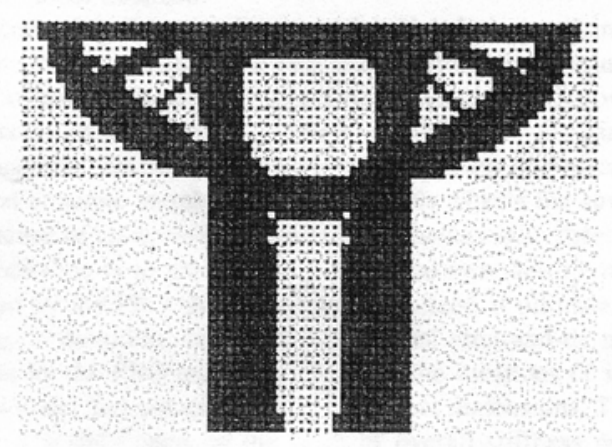

(b)

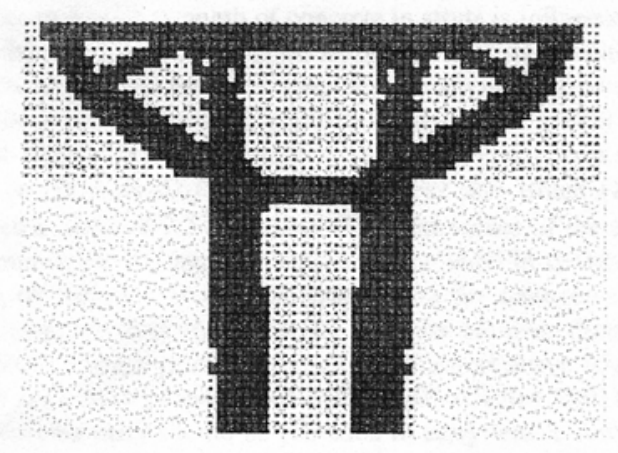

(c)

Figure 2.6. Topology Optimization History (a) Topology at iteration 20, (b) topology at iteration 40, (c) Optimum topology at iteration 49. Adapted from Liang, et. al. (2002) . 


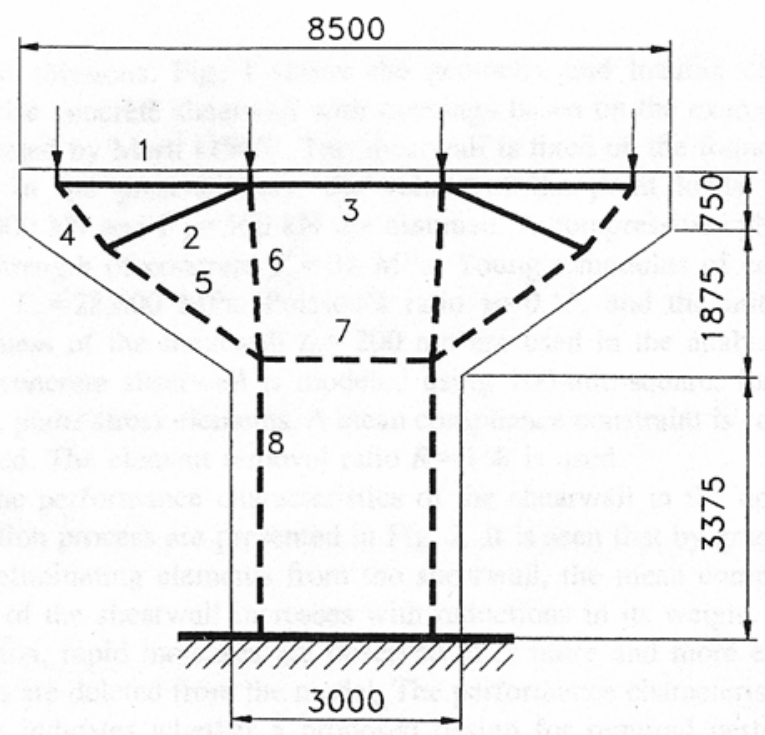

Figure 2.7. Final Strut-and-Tie Model from Topology Optimization Procedure. Adapted from Liang, et. al. (2002). 


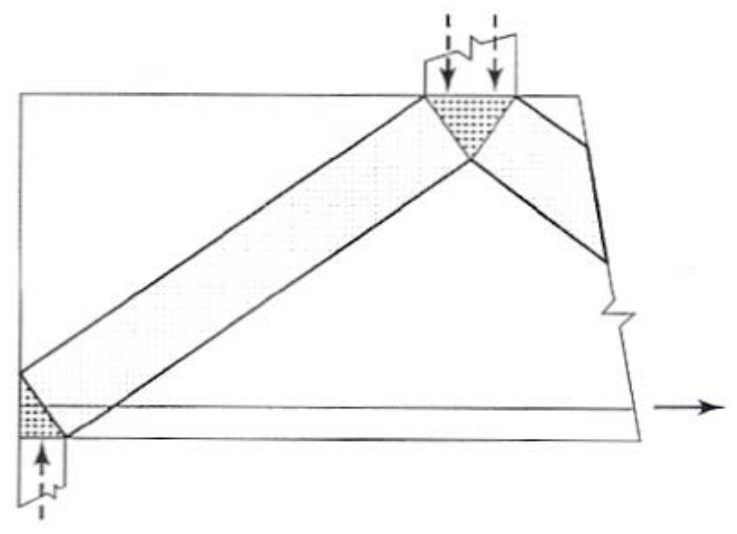

(a)

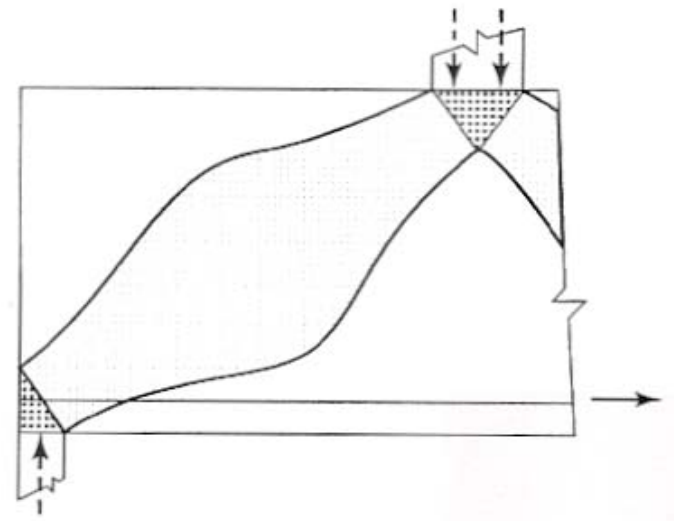

(b)

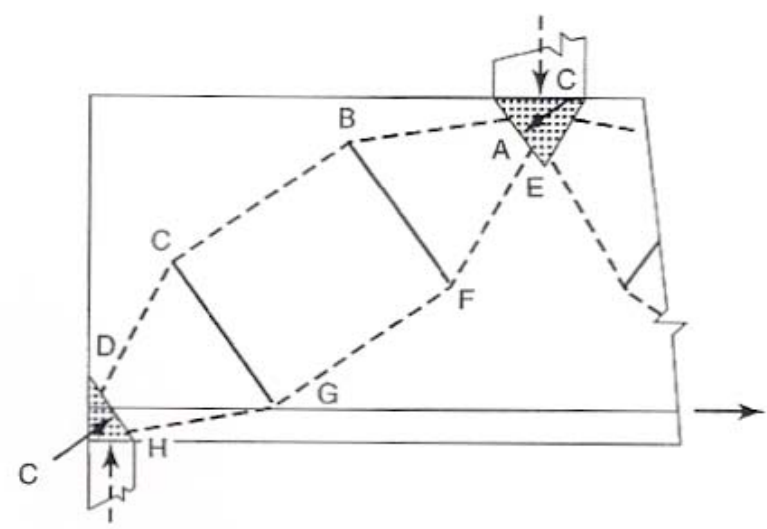

Figure 2.8. Types of Compression Struts. (a) Prismatic Strut (b) Bottle Shaped Strut (c) Strut-and-Tie Model for Bottle Shaped Strut. Adapted from MacGregor, 1997. 
a

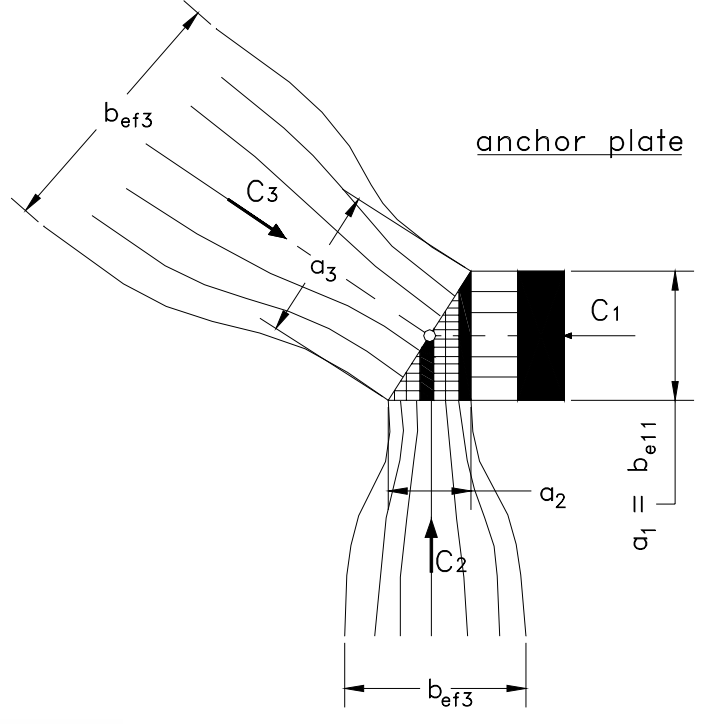

b
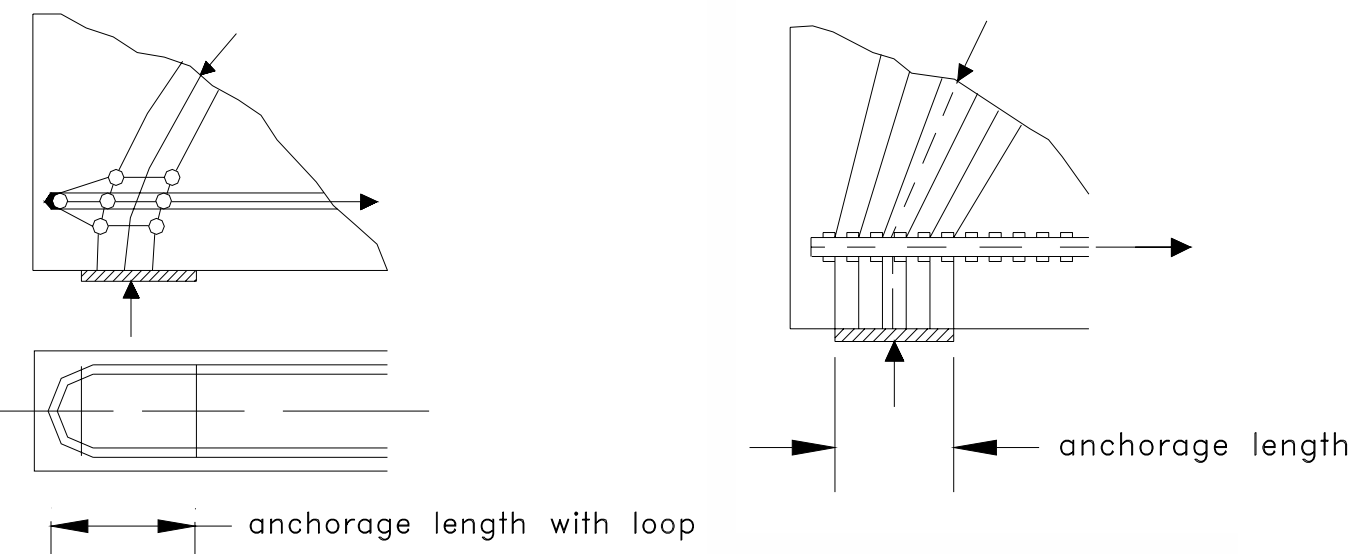

Figure 2.9. (a) Typical singular nodes, (b) Typical smeared nodes. Adapted from Schlaich et. al., 1997 


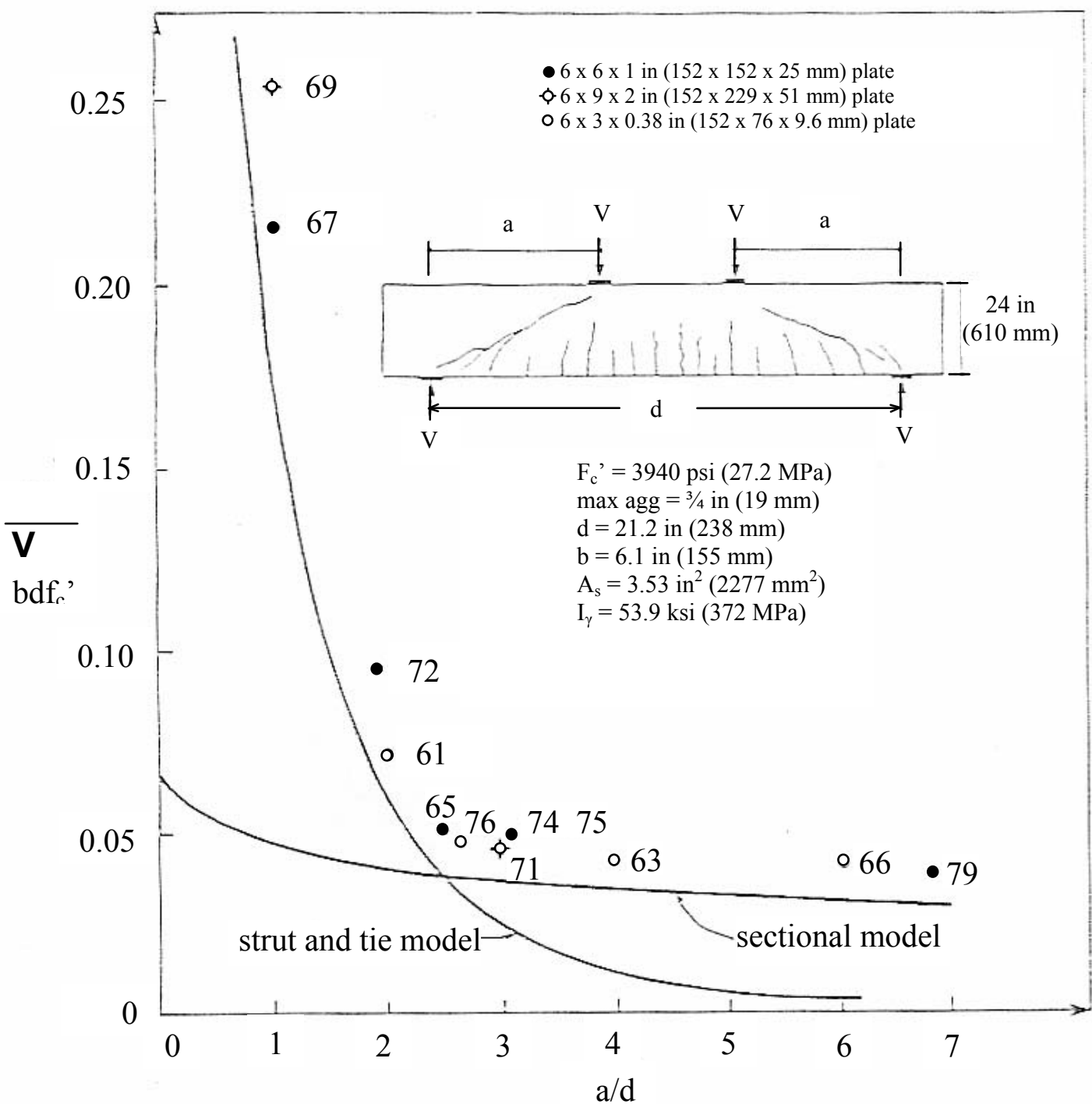

Figure 2.10. Predicted and observed strengths of concrete beams tested by Kani, (1979) 


\section{Chapter 3}

\section{AASHTO LFD AND LRFD SPECIFICATIONS AND DEPARTMENT OF HIGHWAYS SURVEY RESULTS}

\subsection{Introduction}

With the implementation of the AASHTO LRFD Bridge Specifications, bridge designers were presented with a new approach in the design of deep reinforced concrete sections, the strut-and-tie design method. While strut-and-tie modeling has been employed in the past for various reinforced concrete designs, the introduction of the AASHTO LFRD Specifications marks the first time it is presented as a suggested design procedure. This chapter outlines the procedures used in both the AASHTO Standard Specifications and the AASHTO LRFD Specifications for the design of deep concrete sections. Additionally, a survey of State Transportation Departments was conducted to determine design practice currently used for hammerhead type piers. Results of this survey are summarized in this chapter. 


\subsection{AASHTO Standard Code Specifications for the Design of Reinforced Concrete Members}

Generally, the design strength of a given member is in terms of moment, shear, or stress. In the strength design method, a nominal strength is calculated and then reduced by a factor normally expressed as $\phi$. Article 8.16.1.2.2 of the Standard Specifications gives the following strength-reduction factors (for shear and moment), $\phi$, shall be as follows (AASHTO, 1998):

(a)

Flexure

$\phi=0.90$

(b)

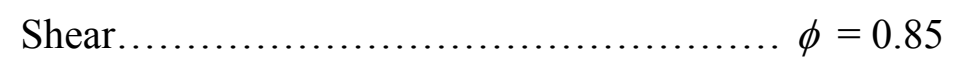

Section 8.16.2 presents several design assumptions used in the strength design method for reinforced concrete and are as follows:

- 8.16.2.1 The strength design of members for flexure and axial loads shall be based on the assumptions given in this Article, and on the satisfaction of the applicable conditions of equilibrium of internal stresses and compatibility of strains.

- 8.16.2.2 The strain in reinforcement and concrete is directly proportional to the distance from the neutral axis.

- 8.16.2.3 The maximum usable strain at the extreme concrete compression fiber is equal to 0.003 .

- 8.16.2.4 The stress in reinforcement below its specified yield strength, $f_{y}$, shall be $E_{s}$ times the steel strain. For strains greater than that 
corresponding to $f_{y}$, the stress in the reinforcement shall be considered independent of strain and equal to $f_{y}$.

- 8.16.2.5 The tensile strength of the concrete is neglected in flexural calculations.

- 8.16.2.6 The concrete compressive stress/strain distribution may be assumed to be a rectangle, trapezoid, parabola, or any other shape that results in prediction of strength in substantial agreement with the results of comprehensive tests.

- 8.16.2.7 A compressive stress/strain distribution, which assumes a concrete stress of $0.85 f^{\prime}{ }_{c}$ uniformly distributed over an equivalent compression zone bounded by the edges of the cross section and a line parallel to the neutral axis at a distance $a=\beta_{1} c$ from the fiber of maximum compressive strain, may be considered to satisfy the requirements of Article 8.16.2.6. The distance $c$ from the fiber of maximum strain to the neutral axis shall be measured in a direction perpendicular to that axis. The factor $\beta_{1}$ shall be taken as 0.85 for concrete strengths, $f^{\prime}{ }_{c}$, up to and including 4,000 psi. For strengths above $4,000 \mathrm{psi}, \beta_{1}$ shall be reduced continuously at a rate of 0.05 for each 1,000 psi of strength in excess of 4,000 psi but $\beta_{1}$ shall not be taken less than 0.65 . 


\subsubsection{Design for Flexure}

The AASHTO Standard Specifications first presents the maximum reinforcement for flexural members. Article 8.16.3.1.1 states that the ratio of reinforcement $\rho$ provided shall not exceed 0.75 of the ratio $\rho_{\mathrm{b}}$ that would produce balanced strain conditions for the section. The portion of $\rho_{\mathrm{b}}$ balanced by compression reinforcement need not be reduced by the 0.75 factor. Article 8.16.3.1.2 states that balanced strain conditions exist at a cross section when the tension reinforcement reaches the strain corresponding to its specified yield strength, $f_{y}$, just as the concrete in compression reaches its assumed ultimate strain of 0.003 .

The AASHTO Standard Specifications follow the traditional design approach for bending in reinforced concrete sections. Three cases are presented in the Specifications: rectangular sections with tension reinforcement only, flanged sections with tension reinforcement only, and rectangular sections with tension and compression reinforcement. The three cases for bending design are illustrated by Fig. 3.1, Fig. 3.2, and Fig. 3.3, respectively.

Article 8.16.3.2.1 gives the following equation for the design moment strength, $\phi M_{n}$, for rectangular sections with tension reinforcement only: 


$$
\begin{aligned}
\phi M_{n}=\phi\left[A_{s} f_{y} d\left(1-0.6 \frac{\rho f_{y}}{f_{c}^{\prime}}\right)\right] \\
=\phi\left[A_{s} f_{y}\left(d-\frac{a}{2}\right)\right]
\end{aligned}
$$

where,

$$
a=\frac{A_{s} f_{y}}{0.85 f_{c}^{\prime} b}
$$

The balanced reinforcement ratio, $\rho$, is then given by Article 8.16.3.2.2 as:

$$
\rho_{b}=\frac{0.85 \beta_{1} f_{c}^{\prime}}{f_{y}}\left(\frac{87,000}{87,000+f_{y}}\right)
$$

For instances when the compression flange thickness is less than $a$ (depth of the compression block), the design moment strength may be computed by:

$$
\phi M_{n}=\phi\left[\left(A_{s}-A_{s f}\right) f_{y}(d-a / 2)+A_{s f} f_{y}\left(d-0.5 h_{f}\right)\right]
$$

where,

$$
A_{s f}=\frac{0.85 f^{\prime}{ }_{c}\left(b-b_{w}\right) h_{f}}{f_{y}}
$$




$$
a=\frac{\left(A_{s}-A_{s f}\right) f_{y}}{0.85 f^{\prime}{ }_{c} b_{w}}
$$

and the balanced steel ratio is:

$$
\rho_{b}=\left(\frac{b_{w}}{b}\right)\left[\left(\frac{0.85 \beta_{1} f_{c}^{\prime}}{f_{y}}\right)\left(\frac{87,000}{87,000+f_{y}}\right)+\rho_{f}\right]
$$

where,

$$
\rho_{f}=\frac{A_{s f}}{b_{w} d}
$$

Article 8.16.3.4.1 gives the following equation for the design moment strength, $\phi M_{n}$, for Rectangular sections with tension and compression reinforcement as:

If

$$
\left(\frac{A_{s}-A_{s}^{\prime}}{b d}\right) \geq 0.85 \beta_{1}\left(\frac{f^{\prime}{ }_{c} d^{\prime}}{f_{y} d}\right)\left(\frac{87,000}{87,000-f_{y}}\right)
$$

then,

$$
\phi M_{n}=\phi\left[\left(A_{s}-A_{s}^{\prime}\right) f_{y}(d-a / 2)+A_{s}^{\prime} f_{y}\left(d-d^{\prime}\right)\right\rfloor
$$


where,

$$
a=\frac{\left(A_{s}-A_{s}^{\prime}\right) f_{y}}{0.85 f_{c}^{\prime} b}
$$

Article 8.16.3.4.2 states that when the value of $\left(A_{s}-A_{s}^{\prime}\right) / b d$ is less than the value required by Eqn. 3-10, such that the stress in the compression reinforcement is less than the yield strength, $f_{y}$, or when effects of compression reinforcement is less than the yield strength, $f_{y}$, or when effects of compression reinforcement are neglected, the design moment strength may be computed by the equations in Article 8.16.3.2 (Eqns. 3-1, 3-2, and 3-3).

Article 8.16.3.4.3 gives the balanced reinforcement ratio $\rho_{b}$ for rectangular sections with compression reinforcement as follows:

$$
\rho_{b}=\left[\frac{0.85 \beta_{1} f_{c}^{\prime}}{f_{y}}\left(\frac{87,000}{87,000+f_{y}}\right)\right]+\rho^{\prime}\left(\frac{f_{s}^{\prime}}{f_{y}}\right)
$$

where,

$$
f^{\prime}{ }_{s}=87,000\left[1-\left(\frac{d^{\prime}}{d}\right)\left(\frac{87,000+f_{y}}{87,000}\right)\right] \leq f_{y}
$$




\subsubsection{Design for Shear}

Shear design in the Standard Specifications is accomplished by computing the contribution to the shear capacity from both the concrete and steel. The Standard Specifications provides the following equation for the design of cross sections subjected to shear:

$$
V_{u} \leq \phi V_{n}
$$

where $V_{u}$ is the factored shear force at the section considered and $V_{n}$ is the nominal shear strength computed by:

$$
V_{n}=V_{c}+V_{s}
$$

where $V_{c}$ is the nominal shear strength provided by the concrete in accordance with Article 8.16.6.2, and $V_{s}$ is the nominal shear strength provided by the shear reinforcement in accordance with Article 8.16.6.3. Whenever applicable, effects of torsion shall be included.

The shear strength provided by the concrete, for members subject to shear and flexure only, $V_{c}$ shall be computed by: 


$$
V_{c}=\left(1.9 \sqrt{f^{\prime}{ }_{c}}+2,500 \rho_{w} \frac{V_{u} d}{M_{u}}\right) b_{w} d
$$

or,

$$
V_{c}=2 \sqrt{f^{\prime}{ }_{c}} b_{w} d
$$

where $b_{w}$ is the width of web and $\mathrm{d}$ is the distance from the extreme compression fiber to the centroid of the longitudinal tension reinforcement. For tapered webs, $b_{w}$ shall be the average width or 1.2 times the minimum width, whichever is smaller.

Additionally, the Standard Specifications provides the following two notes for the contribution of concrete shear resistance:

(a) $V_{c}$ shall not exceed $3.5 \sqrt{f^{\prime}{ }_{c}} b_{w} d$ when using more detailed calculations.

(b) The quantity $V_{u} d / M_{u}$ shall not be greater than 1.0 where $M_{u}$ is the factored moment occurring simultaneously with $V_{u}$ at the section being considered.

When the factored shear force, $V_{u}$ exceeds shear strength $\phi V_{c}$, shear reinforcement must be provided. The Standard Specifications provides for three cases of reinforcement. The first is when shear reinforcement is perpendicular to the axis of the member is used. The amount of reinforcement is then:

$$
V_{s}=\frac{A_{v} f_{y} d}{s}
$$

where $A_{v}$ is the area of shear reinforcement within a distance $s$.

When using inclined stirrups, the amount of required reinforcement is given by: 


$$
V_{s}=\frac{A_{v} f_{y}(\sin \alpha+\cos \alpha) d}{s}
$$

When a single vertical bar or a single group of vertical parallel bars located at the same distance from the support is used:

$$
V_{s}=A_{v} f_{y} \sin \alpha \leq 3 \sqrt{f^{\prime}{ }_{c}} b_{w} d
$$

The Standard Specifications also limit the amount of shear strength that the steel can provide. Article 8.16.6.3.9 states that shear strength $V_{s}$ shall not be taken greater than:

$$
V_{s} \leq 8 \sqrt{f^{\prime}} b_{w} d
$$

\subsection{AASHTO LRFD Code Specifications for the Design of Reinforced Concrete Members using Strut-and-Tie Modeling}

The AASHTO LRFD Specifications states that strut-and-tie models may be used to determine internal force effects near supports and the points of application of concentrated loads at strength and extreme event limit states. Additionally, the strut-andtie model should be considered for the design of deep footings and pile caps or other situations in which the distance between the centers of applied load and the supporting 
reactions is less than twice the member thickness. Strut-and-tie modeling is covered by Articles 5.6.3.2 through 5.6.3.6.

As previously mentioned, strut-and-tie modeling implicitly addresses the effects of both flexure and shear. Axial members in the truss model most explicitly satisfy force limitations as provided by the following generalized expression:

$$
P_{r}=\phi P_{n}
$$

where:

$P_{n}=$ nominal resistance of strut or tie

$\phi=$ resistance factor for tension or compression specified in Article 5.5.4.2, as appropriate

\subsubsection{Compression Struts}

AASHTO LRFD Specifications permit the use of either unreinforced or reinforced compression struts. AASHTO gives the following equation for the nominal resistance of an unreinforced compressive strut:

$$
P_{n}=f_{c u} A_{c s}
$$

where:

$P_{n}=$ nominal resistance of a compressive strut

$f_{c u}=$ limiting compressive stress as specified in Article 5.6.3.3.3 
$A_{c s}=$ effective cross-sectional area of strut as specified in Article 5.6.3.3.2

AASHTO provides the following equation for the condition where if the compressive strut contains reinforcement that is parallel to the strut and detailed to develop its yield stress in compression. For this reinforcing case, the nominal resistance of the strut shall be taken as:

$$
P_{n}=f_{c u} A_{c s}+f_{y} A_{s s}
$$

where:

$A_{s s}=$ area of reinforcement in the strut

$A_{c s}=$ effective cross-sectional area of strut as specified in Article 5.6.3.3.2

$f_{c u}=\quad$ limiting compressive stress as specified in Article 5.6.3.3.3

$f_{y}=\quad$ yield strength of steel

The cross sectional area of the compressive strut depends on the geometry of the reinforcing pattern. Figure 3.4 shows various reinforcing patterns, which affect the compressive strut's area. AASHTO states that the value of $\mathrm{A}_{\mathrm{cs}}$ shall be determined by considering both the available concrete area and the anchorage conditions at the ends of the strut, as shown in Fig. 3.4. When a strut is anchored by reinforcement, the effective 
concrete area may be considered to extend a distance of up to six bar diameters from the anchored bar, as shown in Fig. 3.4(a).

As stated previously, struts represent one dimensional stress fields, which should not exceed the compressive strength of the concrete (Yun and Rameriz, 1996). AASHTO provides the following for limiting compressive stress, $f_{c u}$ :

$$
f_{c u}=\frac{f^{\prime}{ }_{c}}{0.8+170 \varepsilon_{1}} \leq 0.85 f^{\prime}{ }_{c}
$$

where:

$$
\varepsilon_{1}=\varepsilon_{s}+\left(\varepsilon_{s}+0.002\right) \cot ^{2} \alpha_{s}
$$

and:

$\alpha_{s}=$ the smallest angle between the compressive strut and adjoining tension ties

$\varepsilon_{s}=$ the tensile strain in the concrete in the direction of the tension tie

$$
f_{c}^{\prime}=\text { specified compressive strength }(\mathrm{ksi})
$$

\subsubsection{Tension Ties}

AASHTO LRFD Specifications state that tension tie reinforcement shall be anchored to the nodal zones by specified embedment lengths, hooks, or mechanical anchorages. The tension force shall be developed at the inner face of the nodal zone. The nominal resistance of a tension tie shall be taken as: 


$$
P_{n}=f_{y} A_{s t}+A_{p s}\left[f_{p e}+f_{y}\right]
$$

where:

$A_{s t}=$ total area of longitudinal mild steel reinforcement in the tie

$A_{p s}=$ area of prestressing steel

$f_{y}=$ yield strength of mild steel longitudinal reinforcement

$f_{p e}=$ stress in prestressing steel due to prestress after losses

\subsubsection{Nodal Zones}

AASHTO LRFD Specifications state unless confining reinforcement is provided and its effect is supported by analysis or experimentation, the concrete compressive stress in the node regions of the strut shall not exceed:

- $\quad$ For node regions bounded by compressive struts and bearing areas: $0.85 \phi$

$$
f_{c}^{\prime}
$$

- For node regions anchoring a one-direction tension tie: $0.75 \phi f^{\prime}{ }_{c}$

- For node regions anchoring tension ties in more than one direction: $0.65 \phi f^{\prime}{ }_{c}$

where:

$\phi=$ the resistance factor for bearing on concrete as specified in Article 5.5.4.2.

In detailing the tension tie reinforcement, AASHTO LRFD Specifications states that the tension tie reinforcement shall be uniformly distributed over an effective area of concrete at least equal to the tension tie force divided by the stress limits specified herein. 
In addition to satisfying strength criteria for compression struts and tension ties, the nodal regions shall be designed to comply with the stress and anchorage limits specified in Articles 5.6.3.4.1 and 5.6.3.4.2. The bearing stress on the nodal region produced by concentrated loads or reaction forces shall satisfy the requirements specified in Article 5.7.5.

As with all reinforced concrete sections, crack control reinforcement should be provided. When employing the strut and tie model, structural members, not including slabs and footings, should contain a grid of reinforcing bars at each face of the member, typically referred to as skin steel. AASHTO LRFD Specifications state that the spacing of the bars in the orthogonal grid shall not exceed 12 inches. Additionally, the code allows crack control reinforcing that is located within the tension tie to be considered as part of the tension tie reinforcing. The ratio of reinforcement area to gross area shall not be less than 0.003 in each direction.

\subsection{Survey of State Transportation Departments}

A survey of all fifty State Transportation Departments was conducted to assess the implementation of the AASHTO LRFD strut-and-tie modeling procedure in their respective state. The survey was emailed to each Engineering Director, and was either answered directly by the Engineering Director or forwarded to the State Bridge Engineer who then completed the survey. The reply was then sent back to the author and, if required, further correspondence, in the form of a phone call, was conducted. A copy of 
the survey emailed to the Engineering Directors is located in Appendix A. Figure 3.2 shows a map of the United States with each of the participating states highlighted.

The first question in the survey sought to determine if their state was currently using the AASHTO LRFD Bridge Design Code. It is not only important to determine which states are or are not employing the LRFD Code but at the same time, it is equally important to determine the reasons for implementing or not implementing the LRFD Design Code.

Secondly, the respective state was asked if the LRFD code was being used what design method was being employed to design the pier caps. This question was meaningful due to the analysis and design options provided by the LRFD Bridge Design Code. Each state was also asked to provide sample calculations, whether they were using LFD or LRFD Bridge Design Codes, and the bridge plans related to the sample calculations they provided. With each reply, the representative of the state responding to the survey was asked to provide their contact information and position title for future correspondence. Additionally, for the states which have implemented the strut-and-tie model, it was asked (in further correspondence), in their opinion, if the strut-and-tie model was a feasible analysis and design method for bridge pier caps.

\subsection{Survey Results}

Table 3.1 summarizes the survey results (the author would like to point out the names of the states in the table and in this paper have been changed and listed in random order to insure the anonymity of each state). Table 3.1 lists the states participating in the 
survey, as well as whether the state was using the LRFD or LFD Bridge Design Code. The Bridge Code the state was currently using was divided into two categories: Superstructure and Substructure. The division was necessary due to the states using LRFD for the superstructure and LFD for the substructure. As can be seen in Fig. 3.5, 24 states or 48 percent of the states responded to the survey. Of the respondents 33 percent have switched in some fashion to the LRFD Bridge Design Code. However, most of the states using LRFD have not switched to designing the substructures by the strut-and-tie model. The group using the strut-and-tie model only makes up approximately 8 percent of the total responding. It should be noted, a number of states responding are beginning to implement the LRFD Code to substructures; however, they are in the very early stages with no trial designs as of the date of this survey.

The survey illustrated, among the respondents, that the state Departments of Highways are hesitant to employ the LRFD Bridge Design Code. For the most part, the states are attempting to ease into the LRFD Code by using it for superstructure design only. The author realizes the cost of acquiring the new computer software and the training for employees both for the new design method and the purchase of the corresponding software can be an expensive endeavor. However, a mixing of codes is occurring in the Bridge Design Industry. Case in point, State E uses LRFD as the code for the superstructure, while reverting back to LFD for the substructure. The mixing of design codes is a concern; however, is beyond the scope of this study. The prevalent reason for states not employing the Strut-and-Tie Model in their designs is the unfamiliarity with the procedure and the fact that the traditional design method has been a successfully proven method in designing pier caps. 
Two states responding to the survey use Strut-and-Tie Modeling to design the pier caps, State B and State V. These states also sent example calculations illustrating their steps in creating the model. In addition to the two states sample calculations, two other examples illustrating the strut-and-tie modeling procedure were obtained for comparison reasons. In each case, considerably different design procedures were employed. 

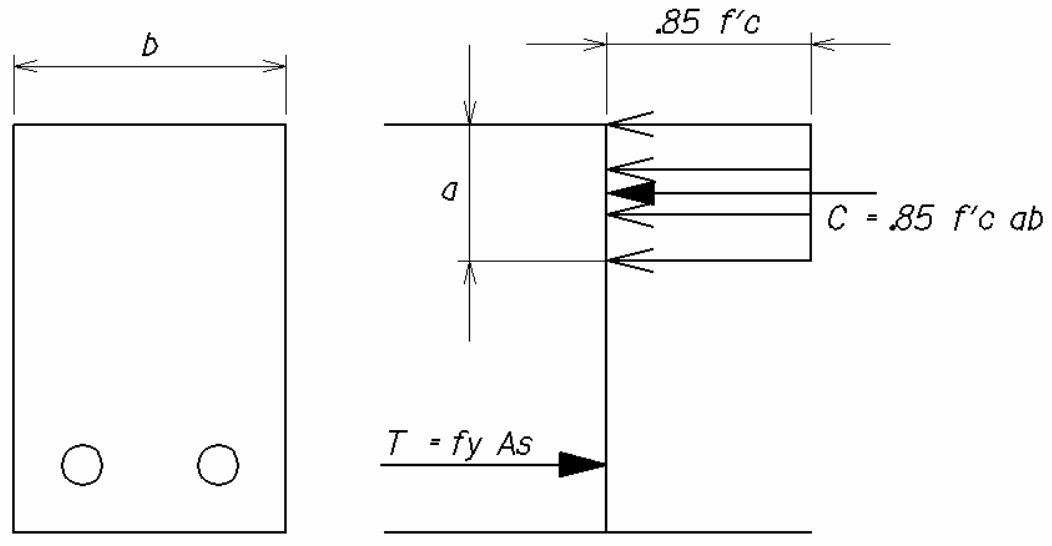

Figure 3.1. Rectangular Section with Tension Reinforcement Only 

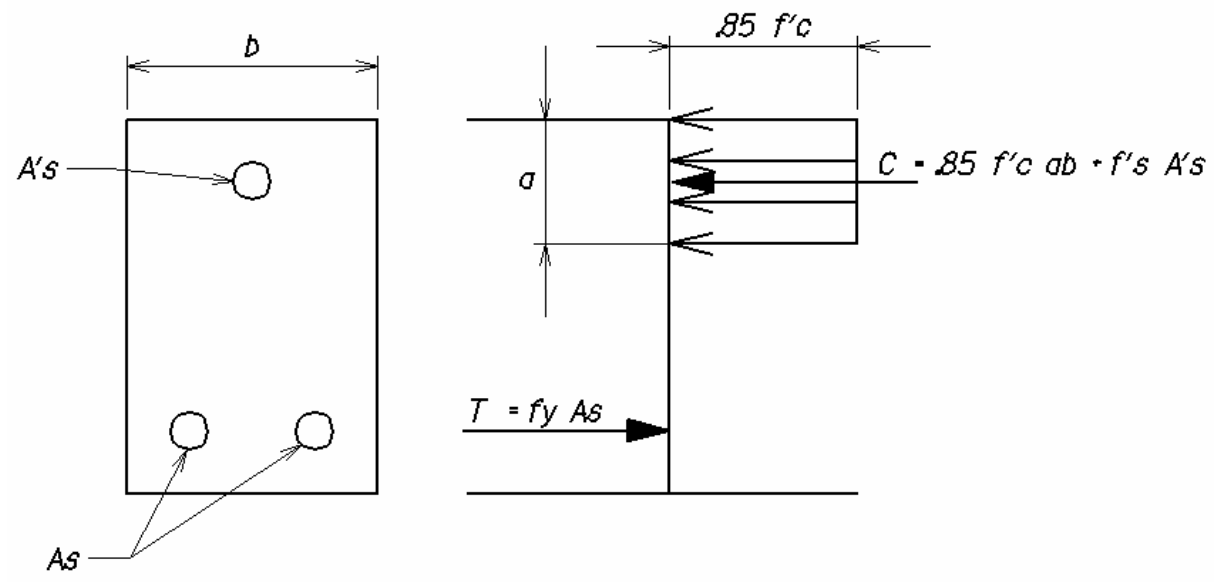

Figure 3.2. Rectangular Section with Compression and Tension Reinforcement 

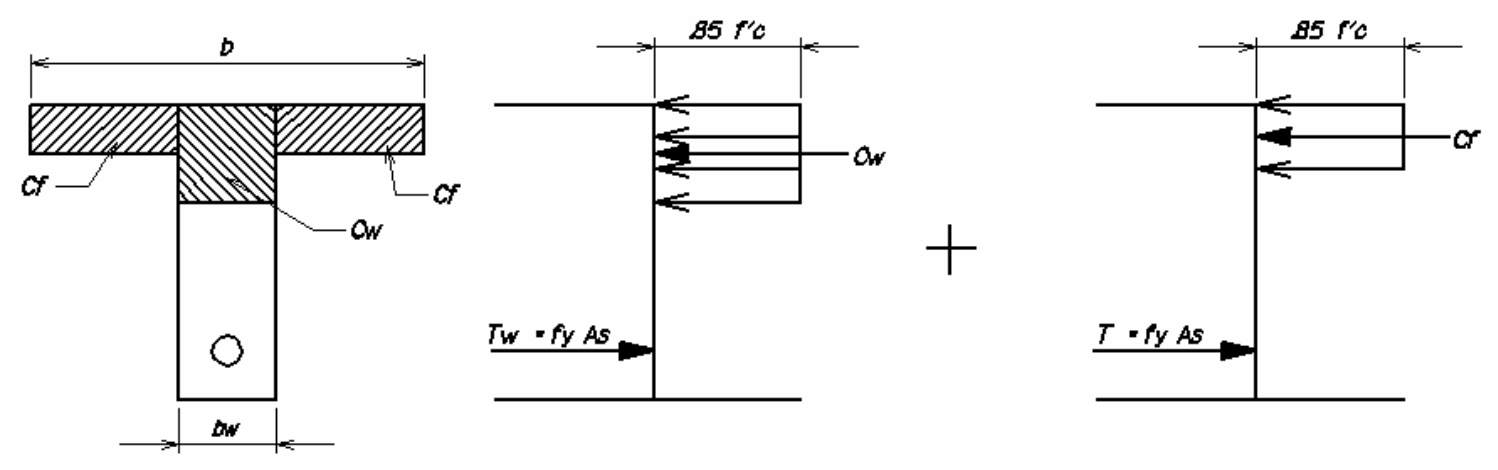

Figure 3.3. Flanged Section with Tension Reinforcement Only 

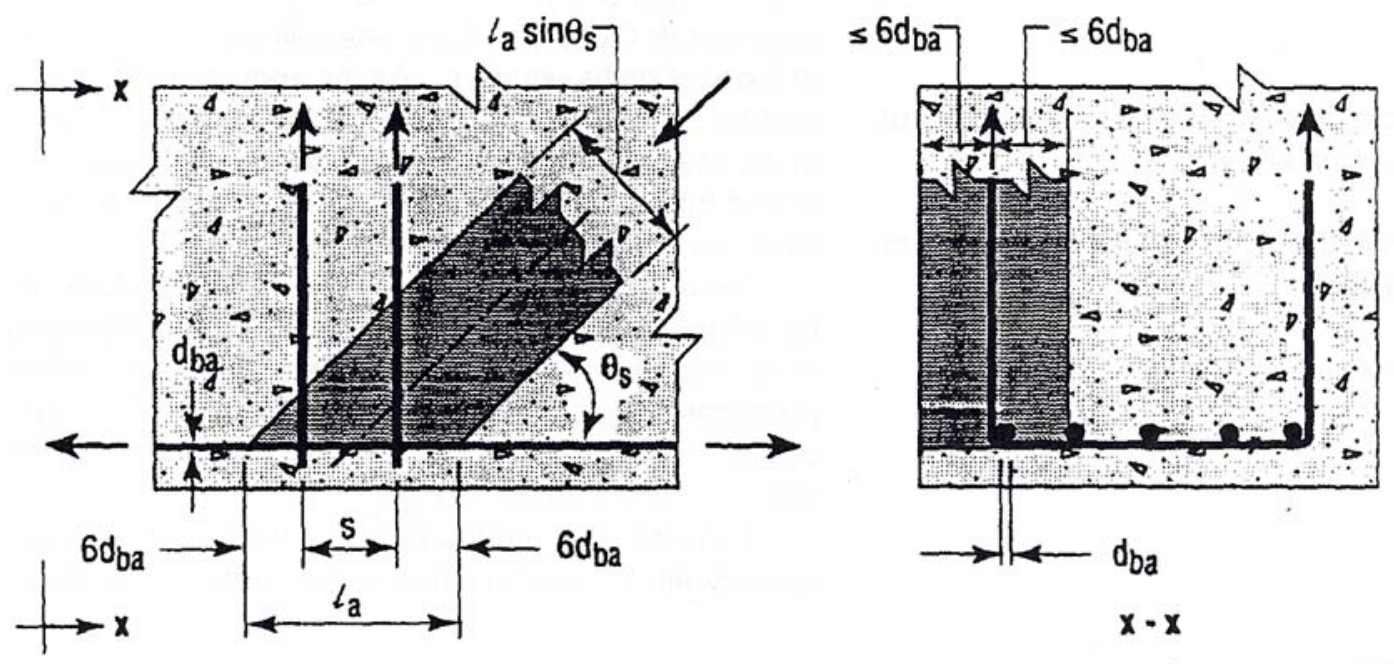

a) Strut anchored by reinforcement

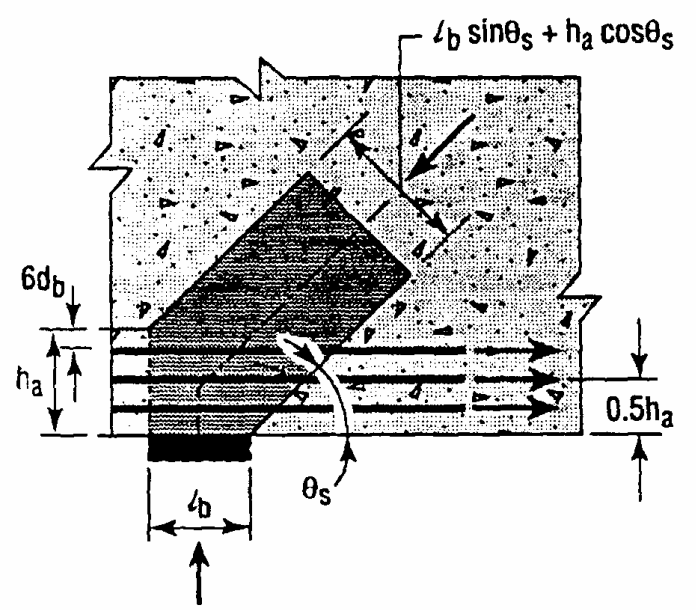

b) Strut anchored by bearing and reinforcement

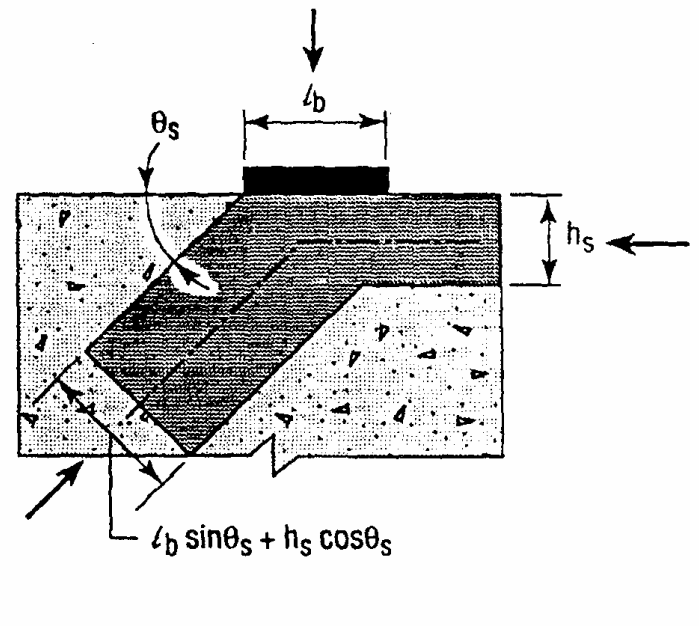

c) Strut anchored by bearing and strut

Figure 3.4. Compressive Strut anchorages (AASHTO, 1998) 


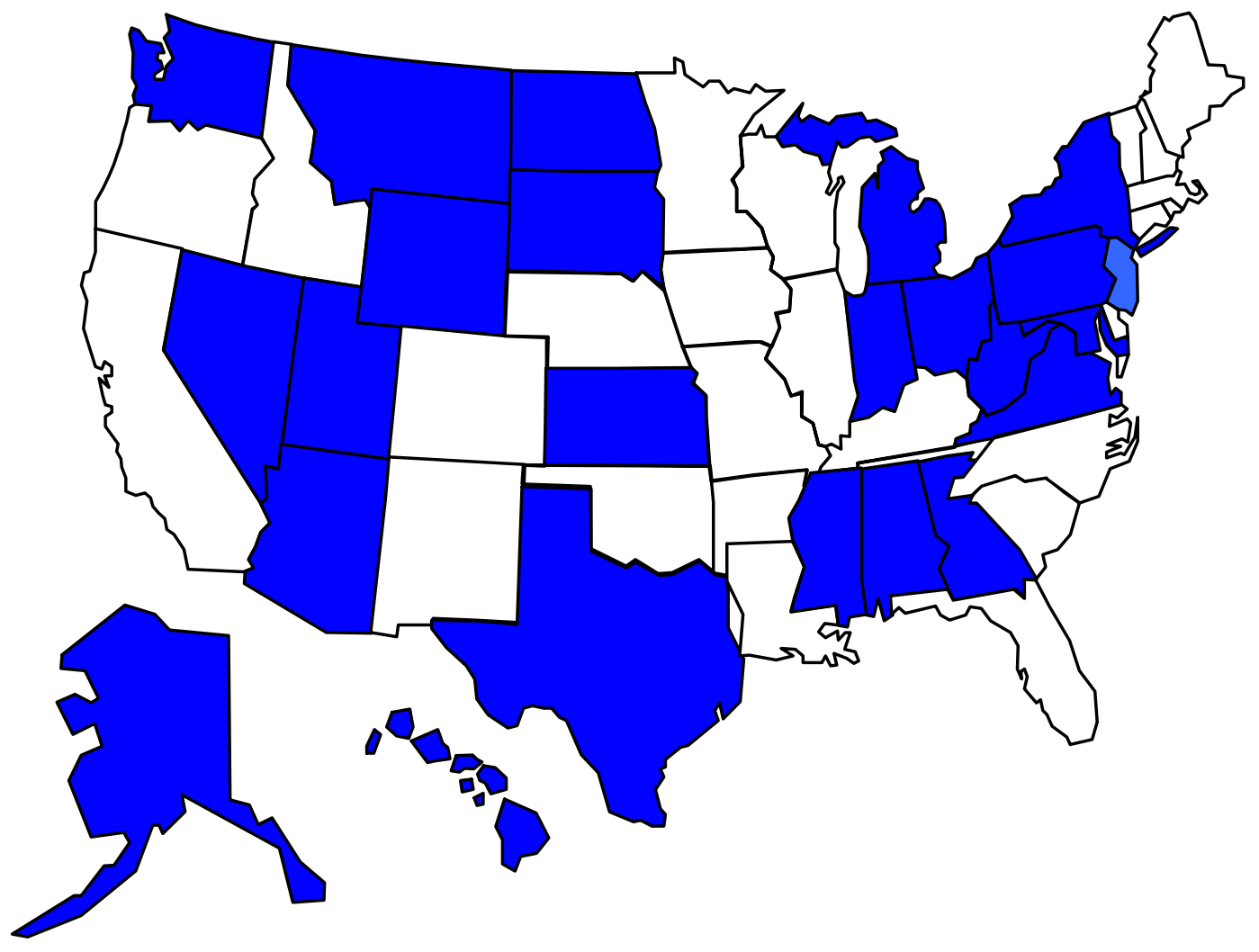

Figure 3.5. United States Map of Responding State Transportation Departments 


\section{Chapter 4}

\section{DESIGN COMPARISIONS}

\subsection{Introduction}

As previously stated, the strut-and-tie method is being promoted by the AASHTO LRFD Specifications for the design of deep reinforced concrete sections. The lack of familiarity with the procedure has caused most practicing engineers, from the states responding to the survey, to avoid implementation of LRFD substructure design. This chapter presents a series of four design comparisons performed to illustrate the use of strut-and-tie modeling and to compare these designs with traditional sectional approaches.

The description of the proposed design procedure presents the process of defining loads and location of loads to produce the maximum moments on the cantilever of the hammerhead pier. The section for the creation of the truss model provides background information in truss modeling as well as the procedure used in the design studies for modeling the hammerhead pier's internal truss. The final section in the design procedure is the dimensioning of the compressive struts, tension ties, and nodal zones. This section also discusses the placement of reinforcement for the shear and temperature effects. 
The design studies provide examples of the strut-and-tie model applied to previously designed hammerhead piers, which used the AASHTO Standard Specifications. This will allow for a comparison of the two designs and their accompanying reinforcing requirements. Finally, the results of the design studies will be discussed as well as the trends of industry to embrace the strut-and-tie model as a viable design option for deep sections.

\subsection{Description of Design Procedures}

\subsubsection{Load Generation Procedure}

The first load to be considered in the pier design is the dead load reactions generated by the superstructure. Members contributing to the dead load reactions are the beam, intermediate diaphragms, deck, pier diaphragm, parapet, and future wearing surface. The dead load reactions should be calculated for the interior and exterior beams.

Live loading consisted of using the HL-93 loading from the AASHTO LRFD Specifications (AASHTO, 1998). For the design studies presented in this chapter, the

software program CONSYS $2000^{\circledR}$ was used to generate the live load reactions. When placing the truck component of the HL-93 live load, the designer should place the second wheel directly over the pier insuring the maximum reaction. The load placement is illustrated in Fig. 4.1. When considering the load distribution to the beams, the HL-93 reaction should be placed so that to induce the maximum moment on the cantilever of the 
hammerhead pier. For the design study, the maximum moment is produced by placing the HL-93 reaction two feet from the face of the curb or parapet as shown in Fig. 4.2.

The lane load component of the HL-93 loading reaction was also found using the CONSYS $2000^{\circledR}$ program. The lane load must also be placed to induce the maximum moment, which for the design study was at the face of the curb and is illustrated by Fig. 4.3.

Upon completion of determining the exterior and interior beam reactions, the loads must be factored in accordance with AASHTO LRFD Specifications (e.g. see Table 3.4.1-1 (AASHTO, 1998)). The load combination, which governed the design studies, was Strength I from the AASHTO LRFD Specifications. Strength I is defined as the following:

$$
\text { Factored Load }=\text { Truck }(1.75+I M)+\text { Lane }(1.75)+\text { Dead load }(1.25)
$$

Additionally, the load effects from water, wind, self-weight, and wind on the live load were not considered as part of the load combinations for the design studies.

\subsubsection{Strut-and-Tie Model Truss Background and Development for Hammerhead Piers}

\subsubsection{Strut-and-Tie Model Background}

As previously stated, the major concern in employing the strut-and-tie modeling procedure is the development of the truss model. It should be noted that the creation of 
the model is an iterative process involving refinement of the model after each solution. Significant experience and engineering judgment are required to develop a final model. While it is true that the model is subjective, some clear guidelines have been presented in order to more consistently model structural elements when employing the truss model.

The strut-and-tie model is based on the flow of forces in the entire structural member instead of sections along the member. The flow of forces is resisted by tension ties and compressive struts, which along with nodal zones form an internal truss. In general, the model is developed by defining the flow of forces in the structural member; locating and sizing the nodal zones; determining the truss geometry; and solving for the forces in the struts and ties. The steps for defining the strut-and-tie model are illustrated by Fig. 4.4 (Collins and Mitchell, 1991).

The internal truss is based on the lower bound theory of plasticity. Therefore, the actual capacity of the structure is always equal to or greater than that of the idealized truss. The hypothesis based on lower bound plasticity is correct only if proper measures are performed to assure that "splitting" does not occur. That is, the forces may spread out along the length of the strut resulting in the strut failing by splitting at a lower load than it would have failed by crushing at had the stress trajectories been parallel. Such effects can, however, be easily accounted for in provisions by reducing ultimate stress limit values (Kuchman and Tjhin, 2002).

The first step in deciding the location of the ties, struts, and nodes is to define the flow of forces in the uncracked D-region of the structural member. Locating D-Regions can be accomplished using an elastic analysis, such as a finite element analysis. It should be noted, while this is a useful means of starting a model, it is not essential (MacGregor, 
1997). Furthermore, Huang, et. al. (1998), suggests that a hammerhead bridge pier cap should be considered entirely as a D-Region. However, Schlaich et. al. (1987), points out that in normally or lightly stressed regions the direction of the struts and ties in the model may deviate considerably from the elastic pattern without exceeding the structure's ductility. The ties and hence the reinforcement may be arranged according to practical considerations. That is, the structure will adapt itself to the assumed internal structural system. Of course, in every case an analysis and safety check must be made using the final model. The method of orienting the strut-and-tie-model along the force paths indicated by the theory of elasticity obviously neglects some ultimate load capacity, which could be utilized by a pure application of the theory of plasticity. On the other hand, it has the major advantage that the same model can be used for both the ultimate load and the serviceability check.

Orienting the geometry of the model to the elastic stress distribution is also a safety requirement because the tensile strength of concrete is only a small fraction of the compressive strength. In certain cases, it would be unsafe even if both requirements of the lower bound theorem of the theory of plasticity are fulfilled, namely, equilibrium and actual stress is less than the allowable stress. Compatibility evokes tensile forces, usually transverse to the direction of the loads that may cause premature cracking and failure (Schlaich, et.al., 1987).

As a rule of thumb, Schlaich, et. al. (1987) proposes that in heavier members the struts should reside eight to twelve inches inside of the member. Due to the fact that the truss models the centroid of the elements, the rule of thumb should provide adequate space for the reinforcing pattern to reside. 
In addition to using elastic analysis, crack patterns of test specimens can be used to define the "best" strut-and-tie model (MacGregor, 1997). This would suggest an agreement between the crack pattern and the truss model. However, this is not a practical approach for most practicing engineers as cracking patterns are not readily available.

\subsubsection{Truss Definition Procedure for Hammerhead Pier Caps}

In beginning the modeling procedure it is first helpful to locate the nodal zones in the pier cap. The nodal zones are first defined where external loads, e.g. beam reactions, act on the pier cap. Referring to Fig. 4.5, the top three nodes in the truss model are located directly under the reactions. For the nodes located on the bottom of the truss, the stress path from the cap to the column is first defined. The stress path can be considered to follow the reinforcing pattern that transfers stress from the cap to the column. The depth where the nodes are located is dictated by the location of where the tensile ties and compression struts are defined. The final node locations are shown in Fig. 4.5 for a three-girder bridge.

It should be noted that the compression struts and tension ties should intersect at the nodal zones and represent the location of the reinforcing pattern. While Schalich et. al. does suggest compression struts to reside eight to twelve inches inside of the member, they also suggest that the truss models the centroid of the structural elements, namely the reinforcement. Using the predicted flow of forces and the location of reinforcing steel in the structural member, a beginning truss model can be developed. In most instances, larger diameter bars are used in the pier cap for tensile reinforcing. As a result, the 
reinforcing mat resides at three to six inches inside of the pier cap. An example of tensile tie and compression strut location for a three-beam configuration is given in Fig. 4.5.

\subsubsection{Pier Design Procedure}

The solution for the truss forces can be accomplished by using a software program or by performing manual calculations. The truss solution will also aid in defining the members that are in tension and compression for complex truss systems. The dimensioning of the compression strut, tension tie, and nodal zones are governed by Articles 5.6.3.2 through 5.6.3.6 of the AASHTO LRFD Specifications and were previously discussed in Section 3.3.

The theory for the required and available compressive strut areas were discussed in Section 3.3 of this paper; however, the procedure for calculating the compressive struts is as follows. Based on the calculated $A_{c s}$ required, a required effective depth of the compressive strut is calculated as:

$$
D_{R}=\frac{A_{c s}}{\text { Width Compressive Strut }}
$$

where:

$$
\begin{aligned}
& \mathrm{DR}=\text { required effective depth } \\
& A_{c s}=\text { required area of concrete in compression }
\end{aligned}
$$

Width of Compressive Strut $=$ taken as the width of the pier cap (Oliva, 1997) 
In order to calculate the capacity of the available compressive area, the nodal zone dimensions must be defined. The width and the depth of the nodal zone can be taken as the width of the required bearing area (previously calculated in the superstructure design) (Oliva, 1997). Using the smallest angle between the compressive strut and adjoining tension ties $\alpha_{s}$, the available effective depth can be calculated as follows:

$$
D_{A}=\left(W^{*} \sin \alpha_{s}\right)+\left(D * \cos \alpha_{s}\right)
$$

where:

$$
\begin{aligned}
& \mathrm{D}_{\mathrm{A}}=\text { available effective depth } \\
& W=\text { width of the nodal zone } \\
& D=\text { depth of the nodal zone } \\
& \alpha_{s}=\text { the smallest angle between the compressive strut and adjoining } \\
& \quad \text { tension ties }
\end{aligned}
$$

While the dimensioning of the compressive strut entails the limiting of the concrete stress in the nodal zone, AASHTO LRFD Specifications require the concrete compressive stress in the node regions of the strut shall not exceed the following:

- For node regions bounded by compressive struts and bearing areas: $0.85 \phi$

$$
f^{\prime}{ }_{c}
$$

- For node regions anchoring a one-direction tension tie: $0.75 \phi f^{\prime}{ }_{c}$

- For node regions anchoring tension ties in more than one direction:

$$
0.65 \phi f^{\prime}{ }_{c}
$$


where:

$\phi=$ the resistance factor for bearing on concrete as specified in Article 5.5.4.2.

\subsection{Design Studies}

Four bridge designs were chosen for the comparison study between the strength design method and the strut-and-tie design method (see AASHTO Section 5.6.3.1). The primary basis of selection for the designs was that the piers had to be hammerhead piers that met the definition of a deep structural member defined by AASHTO LRFD Specifications. Additionally, the designs were selected to provide a varying ratio of the overhang length with respect to the column width. The significance of the overhang to column width ratio is that the differing geometries provided differing truss geometries. The final designs chosen were as follows: Barboursville Bridge (West Virginia), South Madison Bridge (West Virginia), Clear Fork Bridge (Tennessee), and Shepherd Bridge (West Virginia).

\subsubsection{Barboursville Bridge Hammerhead Pier Design Example}

\subsubsection{Project Description}

The Barboursville Bridge is located in Barboursville, West Virginia and spans the Gyandotte River. The bridge provides access to a newly constructed community park. The structure is comprised of three spans totaling 329 feet: span 1 is 109.25 feet, span 2 is 110.50 feet, and span 3 is 109.25 feet. The superstructure consists of three Type IV 
prestressed concrete beams that support a nine-inch deck and is illustrated by Fig. 4.6 (bridge elevation) and Fig. 4.7 (typical section). The beams are supported at the beginning of bridge bearing and end of bridge bearing by abutments that are integral with the deck. The integral abutments are supported by pilings that are embedded into bedrock. Additionally, the bridge utilizes two hammerhead piers as intermediate supports. The piers are located in the Gyandotte River and have an overall height of $62.67 \mathrm{ft}$ are positioned on spread footings that are keyed into bedrock. The ratio of the cantilever to width of column is for the pier 1.724. Figure 4.8 shows the dimensions of the pier and the reinforcing pattern provided by the original design.

\subsubsection{Original Analysis/Design}

The original design was conducted using the AASHTO Standard Specifications and the live loading consisted of the HS-25 truck and lane load (the live load was controlled by the lane load). Multiple live load cases were generated by placing lane loads in different locations on the superstructure. Five live load cases were entered into the program, which included one and two lanes loaded. Other loads considered to be acting on the pier cap were dead loads, buoyancy, wind loads, temperature, and water pressure.

The original analysis of the hammerhead pier was performed using the Georgia Pier Program (1984). The Georgia Pier program is a based program that employs the AASHTO Standard Specifications and is widely used by the West Virginia Department of Highways for the design of piers. An input file containing the loads and pier geometry 
is created in a text file and loaded into the DOS program for calculation. The output file generated by Georgia Pier is also in a text file and contains the governing load case as well as the reinforcing requirements.

The original analysis yielded eight number-ten bars for the tension reinforcing in the pier cap. Furthermore, the original design also specified double number-five shear stirrups spaced at seven inches. The final design of the pier is shown in Fig. 4.8.

\subsubsection{Strut-and-Tie Analysis/Design}

The strut-and-tie analysis and the pier design were completed using the procedure previously defined in this chapter. After performing several iterations a truss model, illustrated by Fig. 4.9, was considered optimum and was used for the pier cap analysis. Figure 4.9 also shows the resulting forces obtained from the truss analysis. The truss analysis was performed using the software program RISA2 $\mathrm{D}^{\circledR}$ and checked by manual calculations. An $\operatorname{Excel}^{\circledR}$ spreadsheet was used for the sizing the reinforcement for the tension ties and calculation of the required compression area. The spreadsheet is presented in Table 4.1.

As can be seen in Table 4.1, the required area of the tensile steel is $11.7 \mathrm{in}^{2}$. Number 10 reinforcing bars were selected for the tensile steel requiring 10 bars or 12.27 $i^{2}$ of tensile reinforcing. Furthermore, the required area of compression concrete in compressive strut $\# 2$ is 464.53 in $^{2}$. Referring to Fig. 4.10, the calculation of the required effective depth and the available effective depth for compressive strut \#2 for illustration purposes is as follows. 
- Assuming a 45 " width of the compressive strut (width of pier cap) the required effective depth is:

$$
D_{R}=\frac{464.53 \mathrm{in}^{2}}{45^{\prime \prime}}=10.323^{\prime \prime}
$$

- The available effective depth is given by:

$$
D_{A}=(26 * \sin 52.306)+(26 * \cos 52.306)=36.47 "
$$

- $\quad$ Comparing $D_{R}$ and $D_{A}$ :

$$
36.47 ">10.323 " \therefore \text { no reinforcing is required. }
$$

The final steps in completing the pier cap design is completing the shear design and providing evenly distributed temperature steel. The amount of shear stirrups required was double number-six shear stirrups spaced at eight inches. Figure 4.11 shows the final reinforcing details for the pier cap in the elevation view.

\subsubsection{South Madison Bridge Hammerhead Pier Design Example}

\subsubsection{Project Description}

The South Madison Bridge is located in Madison, West Virginia and spans the Pond Fork of the Coal River. The bridge is comprised of two spans totaling 148.12 feet: span 1 is 74.06 feet and span 2 is 74.06 feet. The superstructure utilizes three spread 
prestressed box beams to support an eight-inch deck and is illustrated by Fig. 4.12 (bridge elevation) and Fig. 4.13 (typical section). The beams are supported at the beginning of bridge bearing and end of bridge bearing by abutments that are integral with the deck. The integral abutments are supported by pilings that are embedded into bedrock. Additionally, the bridge utilizes one hammerhead pier as an intermediate support. The pier is located in the middle of Pond Fork and has an overall height of $26.25 \mathrm{ft}$. The pier is positioned on a spread footing that is keyed into bedrock. The ratio of the cantilever to width of column is for the pier 1.52. Figure 4.14 shows the dimensions of the pier in the elevation view and the reinforcing pattern provided by the original design.

\subsubsection{Original Analysis/Design}

The loading for the original design was completed using an HS-25 truck and lane loading; land loading was found to control. Multiple live load cases were generated by placing lane loads in different locations on the superstructure. A total of five live load cases were entered into the design program, which included one and two lanes loaded. Other loads considered to act on the pier cap were dead loads, buoyancy, wind loads, temperature, and water pressure.

As with the Barboursville Bridge, the original analysis of the hammerhead pier was performed using the Georgia Pier Program (1984) previously discussed. The original analysis yielded seven number- eight bars for the tension reinforcing in the pier cap. Furthermore, the original design also specified double number-five shear stirrups 
spaced at nine and three-quarters inches. The final design of the pier is shown in Fig. 4.14 .

\subsubsection{Strut-and-Tie Analysis/Design}

The strut-and-tie analysis and the pier design were completed using the procedure previously defined in this chapter. After performing several iterations, a truss model illustrated by Fig. 4.15 was considered optimum and was used for the pier cap analysis. Figure 4.15 also shows the resulting forces obtained from the truss analysis. The truss analysis was performed using the software program RISA2D ${ }^{\circledR}$ and checked by manual calculations. An Excel ${ }^{\circledR}$ spreadsheet was used for the sizing the reinforcement for the tension ties and calculation of the required compression area. The spreadsheet is presented in Table 4.2 .

As can be seen in Table 4.2, the required area of the tensile steel is $7.57 \mathrm{in}^{2}$. Using the area of a number-eight bar, the final design requires ten number-eight bars providing $7.85 \mathrm{in}^{2}$ of tensile reinforcing. Furthermore, the required area of compression concrete in compressive strut \#2 is $296.70 \mathrm{in}^{2}$. Referring to Fig. 4.16, the calculation of the required effective depth and the available effective depth for compressive strut \#2 for illustration purposes is as follows.

- Assuming 42" width of the compressive strut (width of pier cap) the required effective depth is:

$$
D_{R}=\frac{296.70 \mathrm{in}^{2}}{42^{\prime \prime}}=7.1^{\prime \prime}
$$


- The available effective depth is given by:

$$
D_{A}=(34 * \sin 58.1092)+(34 * \cos 58.1092)=46.83 "
$$

- Comparing $D_{R}$ and $D_{A}$ :

$$
46.83 ">7.1 " \therefore \text { no reinforcing is required. }
$$

The final steps in completing the pier cap design is completing the shear design and providing evenly distributed temperature steel. The amount of shear stirrups required was double number-six shear stirrups spaced at nine inches. Figure 4.17 shows the final reinforcing details for the pier cap in the elevation view.

\subsubsection{Clear Fork Bridge Hammerhead Pier Design Example}

\subsubsection{Project Description}

The Clear Fork Bridge is located on State Route 52 in Tennessee and spans the Clear Fork River. The bridge is a replacement structure. The structure is comprised of four spans totaling 995 feet: span 1 is 145 feet, span 2 is 220 feet, span 3 is 350 feet, and span 4 is 280 feet. The superstructure consists of four - $98 \frac{1 / 4}{4}$ inch deep hybrid steel girders that support a $9 \frac{1}{4}$ inch deck and is illustrated by Fig. 4.18 (bridge elevation) and

Fig. 4.19 (typical section). The beams are supported at the beginning of bridge bearing 
and end of bridge bearing by concrete pedestal abutments. The pedestal abutments are supported by pilings that are embedded into bedrock. Additionally, the bridge utilizes three hammerhead piers as intermediate supports. The first and third pier is located to the left and right of the Clear Fork River; while, pier two is located in the Clear Fork River. Pier 1, which was used for the design study, has an overall height of $54.37 \mathrm{ft}$ and is positioned on spread footings that are keyed into bedrock, was used for the design study. The ratio of the cantilever to width of column is for the pier 1.11. Figure 4.20 shows the dimensions of the pier and the reinforcing pattern provided by the original design.

\subsubsection{Original Analysis/Design}

The original design was conducted using the AASHTO Standard Specifications and the live loading consisted of the HS-25 truck and lane load (the live load was controlled by the lane load). Multiple live load cases were generated by placing lane loads in different locations on the superstructure. Two live load cases were entered into the program, which included one and two lanes loaded. Other loads considered to act on the pier cap were dead loads, buoyancy, wind loads, temperature, and water pressure.

As with the Barboursville Bridge, the original analysis of the hammerhead pier was performed using the Georgia Pier Program (1984). The original analysis yielded twenty-one number-eleven bars for the tension reinforcing in the pier cap. Furthermore, the original design also specified double number-six shear stirrups spaced at four inches. The final design of the pier is shown in Figure 4.20. 


\subsubsection{Strut-and-Tie Analysis/Design}

The strut-and-tie analysis and the pier design were completed using the procedure previously defined in this chapter. After performing several iterations, a truss model illustrated by Fig. 4.21 was considered optimum and was used for the pier cap analysis. Figure 4.21 also shows the resulting forces obtained from the truss analysis. The truss analysis was performed using the software program RISA2D ${ }^{\circledR}$ and checked by manual calculations. An Excel ${ }^{\circledR}$ spreadsheet was used for the sizing the reinforcement for the tension ties and calculation of the required compression area. The spreadsheet is represented by Table 4.3 .

As can be seen in Table 4.3, the required area of the tensile steel is $43.177 \mathrm{in}^{2}$. Using the area of a number-eleven bar, the final design requires twenty-nine numbereleven bars providing 43.5 in $^{2}$ of tensile reinforcing. Furthermore, the required area of compression concrete in compressive strut \#1 is $1896.63 \mathrm{in}^{2}$. Referring to Fig. 4.22, the calculation of the required effective depth and the available effective depth for compressive strut \#1 for illustration purposes is as follows.

- Assuming 90" width of the compressive strut (width of pier cap) the required effective depth is:

$$
D_{R}=\frac{1896.63 \mathrm{in}^{2}}{90^{\prime \prime}}=21.07^{\prime \prime}
$$

- The available effective depth is given by:

$$
D_{A}=(24 * \sin 38.3675)+(24 * \cos 38.3675)=33.72 "
$$


- Comparing $D_{R}$ and $D_{A}$ :

$33.72 ">21.07 " \therefore$ no reinforcing is required.

The final steps in completing the pier cap design is completing the shear design and providing evenly distributed temperature steel. The amount of shear stirrups required was double number-six shear stirrups spaced at five inches. Figure 4.23 shows the final reinforcing details for the pier cap in the elevation view.

\subsubsection{Shepherd Bridge Hammerhead Pier Design Example}

\subsubsection{Project Description}

The Shepherd Bridge is located in Wheeling, West Virginia and spans the Big Wheeling Creek River. The bridge is a replacement structure for a Whipple Truss constructed in 1882 that is to remain in place due to historical considerations. The bridge along with the new roadway alignment is to provide improved access to the neighboring community. The structure is comprised of three spans totaling 202 feet: span 1 is 66.25 feet, span 2 is 67.5 feet, and span 3 is 66.25 feet. The superstructure consists of three spread-box prestressed concrete beams that support an eight-inch deck and is illustrated by Fig. 4.24 (bridge elevation) and Fig. 4.25 (typical section). The beams are supported at the beginning of bridge bearing and end of bridge bearing by abutments that are integral with the deck. The integral abutments are supported by pilings that are embedded into bedrock. Additionally, the bridge utilizes two hammerhead piers as intermediate 
supports. The piers are located in the Big Wheeling Creek River and have an overall height of 38.092 feet are positioned on spread footings that are keyed into bedrock. The ratio of the cantilever to width of column is for the pier is 0.5 . Figure 4.26 shows the dimensions of the pier and the reinforcing pattern provided by the original design.

\subsubsection{Original Analysis/Design}

The original design was conducted using the AASHTO Standard Specifications and the live loading consisted of the HS-25 truck and lane load (the live load was controlled by the lane load). Placing lane loads in different locations on the superstructure generated multiple live load cases. A total of seven live load cases were entered into the program, which included one and two lanes loaded. Other loads considered to act on the pier cap were dead loads, buoyancy, wind loads, temperature, and water pressure.

As with both the Barboursville Bridge and Shepherd Bridge, the original analysis

of the hammerhead pier was performed using the Georgia Pier Program (1984). The original analysis yielded seven number-ten bars for the tension reinforcing in the pier cap. Furthermore, the original design also specified number-five shear stirrups spaced at 6.75 inches. The final design of the pier is shown in Fig. 4.26. 


\subsubsection{Strut-and-Tie Analysis/Design}

The strut-and-tie analysis and the pier design were completed using the procedure previously defined in this chapter. After performing several iterations, a truss model illustrated by Fig. 4.27 was considered optimum and was used for the pier cap analysis. Figure 4.27 also shows the resulting forces obtained from the truss analysis. The truss analysis was performed using the software program RISA2D ${ }^{\circledR}$ and checked by manual calculations. An Excel ${ }^{\circledR}$ spreadsheet was used for the sizing the reinforcement for the tension ties and calculation of the required compression area. The spreadsheet is presented in Table 4.4 .

As can be seen in Table 4.4, the required area of the tensile steel is $10.865 \mathrm{in}^{2}$. Using the area of a number-ten bar, the final design requires nine number-ten bars providing $11.10 \mathrm{in}^{2}$ of tensile reinforcing. Furthermore, the required area of compression concrete in compressive strut \#1 is $444.31 \mathrm{in}^{2}$. Referring to Fig. 4.28, the calculation of the required effective depth and the available effective depth for compressive strut \#1 for illustration purposes is as follows.

- Assuming 48" width of the compressive strut (width of pier cap) the required effective depth is:

$$
D_{R}=\frac{444.31 \mathrm{in}^{2}}{48^{\prime \prime}}=9.25^{\prime \prime}
$$

- The available effective depth is given by:

$$
D_{A}=(36 * \sin 42.879)+(36 * \cos 42.879)=50.88^{\prime \prime}
$$


- Comparing $D_{R}$ and $D_{A}$ :

$50.88 ">9.25 " \therefore$ no reinforcing is required.

The final steps in completing the pier cap design is completing the shear design and providing evenly distributed temperature steel. The amount of shear stirrups required was number-five shear stirrups spaced at 8.75 inches. Figure 4.29 shows the final reinforcing details for the pier cap in the elevation view.

\subsection{Discussion of Results}

Consistently, for the case studies of this paper, the strut-and-tie model requires more flexural steel than the traditional design procedures. As can be seen in Table 4.5, the increase of the required flexural steel ranges from approximately 25 percent to approximately 38 percent. A major contribution to the increase of required steel is due to the concurrent application of the truck load and the lane load associated with the AASHTO LRFD HL-93 loading. The Standard Specifications do not approach live load generation in this manner, only allowing for one of the loads to be applied. The increase in load will ultimately cause an increase in the required flexural steel.

The required amount of shear steel is not consistent as it pertains to the two design methods. Table 4.5 illustrates the variance in the required amount of steel ranging from approximately 53.0 percent to -23.0 percent. The negative value indicates that the strut-and-tie model required less shear stirrups than the strength design method. 
Table 4.1. Tensile Reinforcement Calculations and Concrete Compression Requirements - Barboursville Bridge

\begin{tabular}{|c|c|c|c|c|c|c|c|}
\hline \multicolumn{8}{|c|}{ Required Tension Capacities } \\
\hline Strut & $\mathrm{Pu}$ & $\phi$ & Pn & $A_{s}$ Req'd & Bars & $A_{s}$ Prov'd & $\varepsilon_{\mathbf{s}}$ \\
\hline 1 & 442.43 & 0.70 & 632.0429 & 11.704 & $10-\# 10$ & 12.27 & 0.001271 \\
\hline 2 & 442.43 & 0.70 & 632.0429 & 11.704 & $10-\# 10$ & 12.27 & 0.001271 \\
\hline \multicolumn{8}{|c|}{$(\operatorname{Pn}$ Req'd = Pu/.7) } \\
\hline \multicolumn{8}{|c|}{$\begin{array}{l}\text { Required Compression } \\
\text { Capacities }\end{array}$} \\
\hline Strut & $\alpha_{s}$ & $\varepsilon_{\mathbf{s}}$ & $\varepsilon_{1}$ & $\mathbf{f}_{\mathrm{cu}}$ & $\mathrm{Pu}$ & Pn Req'd & Acu Req'd \\
\hline 1 & 41.35 & 0.00127 & 0.0055 & 1.730 & 342.14 & 488.8 & 282.54 \\
\hline 2 & 52.306 & 0.00127 & 0.0032 & 2.225 & 723.57 & 1033.7 & 464.53 \\
\hline \multicolumn{8}{|c|}{$(\mathrm{Pn}$ Req'd = Pu/.7) } \\
\hline
\end{tabular}


Table 4.2. Tensile Reinforcement Calculations and Concrete Compression Requirements - South Madison Bridge

\begin{tabular}{|c|c|c|c|c|c|c|c|}
\hline \multicolumn{8}{|c|}{ Required Tension Capacities } \\
\hline Strut & $\mathrm{Pu}$ & $\phi$ & Pn & $A_{s}$ Req'd & Bars & $A_{s}$ Prov'd & $\varepsilon_{\mathbf{s}}$ \\
\hline 1 & 286 & 0.70 & 408.5714 & 7.566 & 6-\#11 & 10.5 & 0.000939 \\
\hline 2 & 286 & 0.70 & 408.5714 & 7.566 & $6-\# 11$ & 10.5 & 0.000939 \\
\hline \multicolumn{8}{|c|}{$(\operatorname{Pn}$ Req'd = Pu/.7) } \\
\hline \multicolumn{8}{|c|}{$\begin{array}{l}\text { Required Compression } \\
\text { Capacities }\end{array}$} \\
\hline Strut & $\alpha_{s}$ & $\varepsilon_{\mathbf{s}}$ & $\varepsilon_{1}$ & $\mathbf{f}_{\mathrm{cu}}$ & $\mathrm{Pu}$ & Pn Req'd & Acu Req'd \\
\hline 1 & 42.0824 & 0.00094 & 0.0045 & 1.908 & 350.023 & 500.0 & 262.09 \\
\hline 2 & 58.1092 & 0.00094 & 0.0021 & 2.602 & 540.329 & 771.9 & 296.70 \\
\hline \multicolumn{8}{|c|}{$(\operatorname{Pn}$ Req'd = Pu/.7) } \\
\hline
\end{tabular}


Table 4.3. Tensile Reinforcement Calculations and Concrete Compression Requirements - Clear Fork Bridge

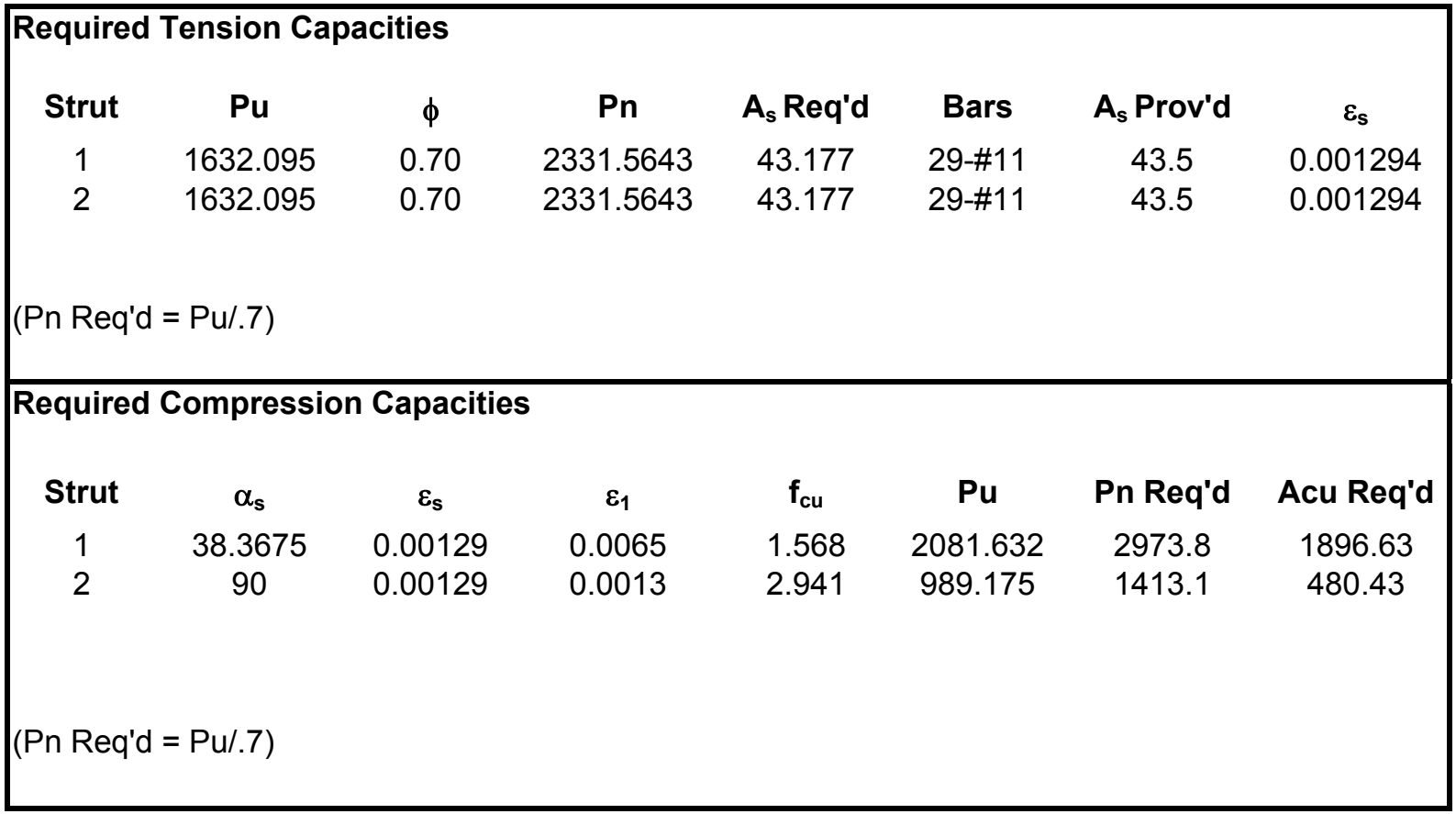


Table 4.4. Tensile Reinforcement Calculations and Concrete Compression Requirements - Shepherd Bridge

\begin{tabular}{|c|c|c|c|c|c|c|c|}
\hline \multicolumn{8}{|c|}{ Required Tension Capacities } \\
\hline Strut & $\mathrm{Pu}$ & $\phi$ & Pn & $A_{s}$ Req'd & Bars & $A_{s}$ Prov'd & $\varepsilon_{\mathbf{s}}$ \\
\hline 1 & 410.685 & 0.70 & 586.6929 & 10.865 & $9-\# 10$ & 11.1 & 0.001282 \\
\hline 2 & 410.685 & 0.70 & 586.6929 & 10.865 & $9-\# 10$ & 11.1 & 0.001282 \\
\hline \multicolumn{8}{|c|}{$(P n$ Req'd = Pu/.7) } \\
\hline
\end{tabular}

\begin{tabular}{|c|c|c|c|c|c|c|c|}
\hline \multicolumn{8}{|c|}{$\begin{array}{l}\text { Required Compression } \\
\text { Capacities }\end{array}$} \\
\hline Strut & $\alpha_{s}$ & $\varepsilon_{\mathbf{s}}$ & $\varepsilon_{1}$ & $\mathbf{f}_{\mathrm{cu}}$ & $\mathrm{Pu}$ & Pn Req'd & Acu Req'd \\
\hline 1 & 42.879 & 0.00128 & 0.0051 & 1.802 & 560.437 & 800.6 & 444.31 \\
\hline 2 & 68.962 & 0.00128 & 0.0018 & 2.726 & 129.154 & 184.5 & 67.68 \\
\hline \multicolumn{8}{|c|}{$(\operatorname{Pn}$ Req'd $=$ Pu/.7) } \\
\hline
\end{tabular}




\begin{tabular}{|c|c|c|c|c|c|}
\hline \multirow[b]{3}{*}{ Parameters } & \multicolumn{5}{|c|}{ LFD DESIGN vs. Strut and Tie Design - South Madison Bridge } \\
\hline & \multicolumn{2}{|c|}{$\begin{array}{l}\text { Area of Steel Required } \\
\quad\left(\mathrm{in}^{2} / \mathrm{ft} \text { for shear) }\right.\end{array}$} & \multicolumn{2}{|c|}{ Specified Reinforcing Bars } & \multirow[t]{2}{*}{ Percent Increase } \\
\hline & LFD & STM & LFD & STM & \\
\hline Tension Steel-cap & 6.28 & 7.85 & 7 - \#8 & $10-\# 8$ & $25.00 \%$ \\
\hline Shear Steel-cap & 0.755 & 1.178 & D\#5@9.75" & D\#6@9" & $56.03 \%$ \\
\hline \multicolumn{6}{|c|}{ LFD DESIGN vs. Strut and Tie Design - Barboursville Bridge } \\
\hline & \multicolumn{2}{|c|}{$\begin{array}{l}\text { Area of Steel Required } \\
\quad\left(\mathrm{in}^{2} / \mathrm{ft} \text { for shear) }\right.\end{array}$} & \multicolumn{2}{|c|}{ Specified Reinforcing Bars } & Percent Increase \\
\hline Parameters & LFD & STM & LFD & STM & \\
\hline Tension Steel-cap & 9.8175 & 12.27 & $8-\# 10$ & $10-\# 10$ & $24.98 \%$ \\
\hline Shear Steel-cap & 1.052 & 1.325 & D\#5@7.0" & D\#6@8.0" & $25.95 \%$ \\
\hline \multicolumn{6}{|c|}{ LFD DESIGN vs. Strut and Tie Design - Clear Fork Bridge } \\
\hline & \multicolumn{2}{|c|}{$\begin{array}{l}\text { Area of Steel Required } \\
\quad\left(\mathrm{in}^{2} / \mathrm{ft} \text { for shear) }\right.\end{array}$} & \multicolumn{2}{|c|}{ Specified Reinforcing Bars } & Percent Increase \\
\hline Parameters & LFD & STM & LFD & STM & \\
\hline Tension Steel-cap & 31.18 & 43.06 & $21-\# 11$ & $29-\# 11$ & $38.10 \%$ \\
\hline Shear Steel-cap & 2.65 & 2.12 & D\#6@4" & D\#6@5" & $-20.00 \%$ \\
\hline \multicolumn{6}{|c|}{ LFD DESIGN vs. Strut and Tie Design - Shepherd Bridge } \\
\hline & \multicolumn{2}{|c|}{$\begin{array}{l}\text { Area of Steel Required } \\
\left(\mathrm{in}^{2} / \mathrm{ft} \text { for shear) }\right.\end{array}$} & \multicolumn{2}{|c|}{ Specified Reinforcing Bars } & Percent Increase \\
\hline Parameters & LFD & STM & LFD & STM & \\
\hline Tension Steel-cap & 8.54 & 11.05 & 7 - \#10 & $9-\# 10$ & $29.4 \%$ \\
\hline Shear Steel-cap & .552 & .4485 & D\#5@6.5 & D\#5@8.25" & $-23.00 \%$ \\
\hline
\end{tabular}

Table 4.5. Comparison between LFD and Strut-and-Tie Modeling Results 


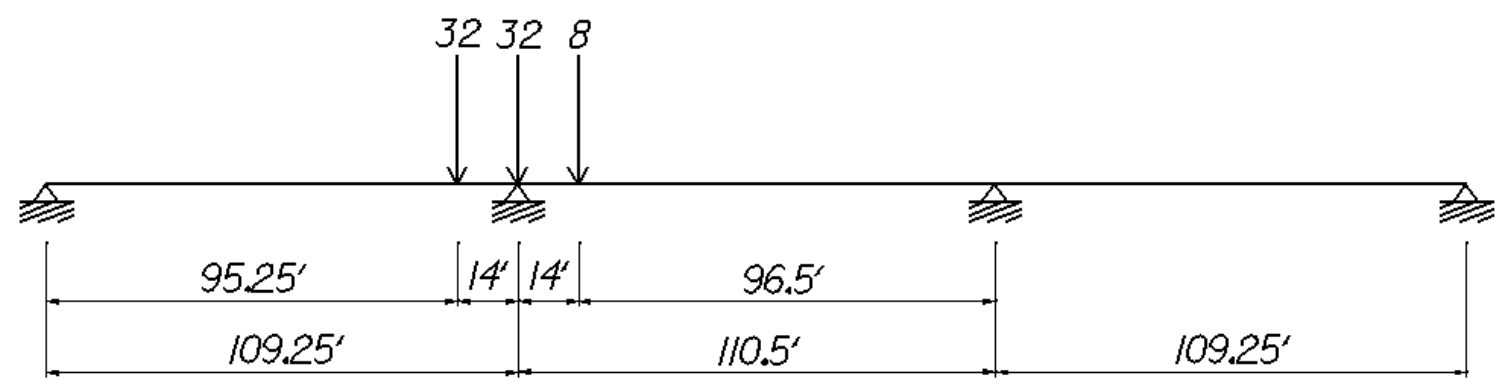

Figure 4.1. HL-93 Reaction calculation configuration 


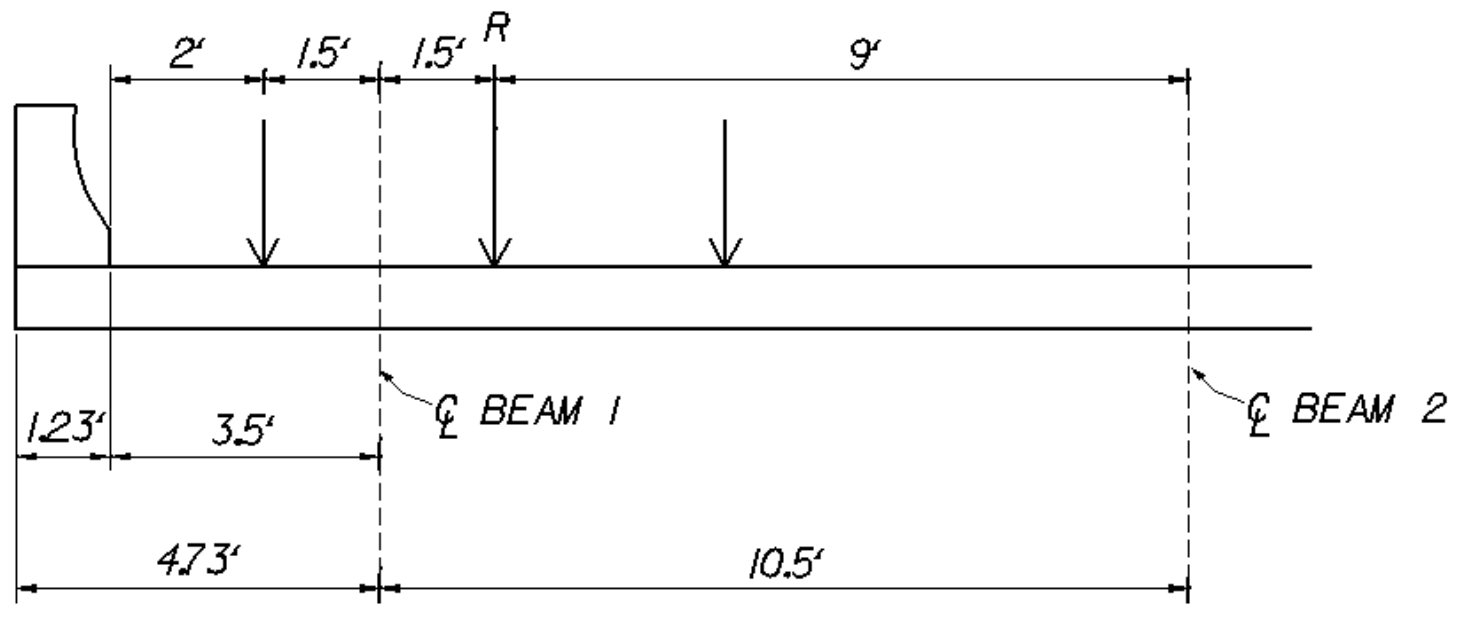

Figure 4.2. Illustration of Wheel Placement 


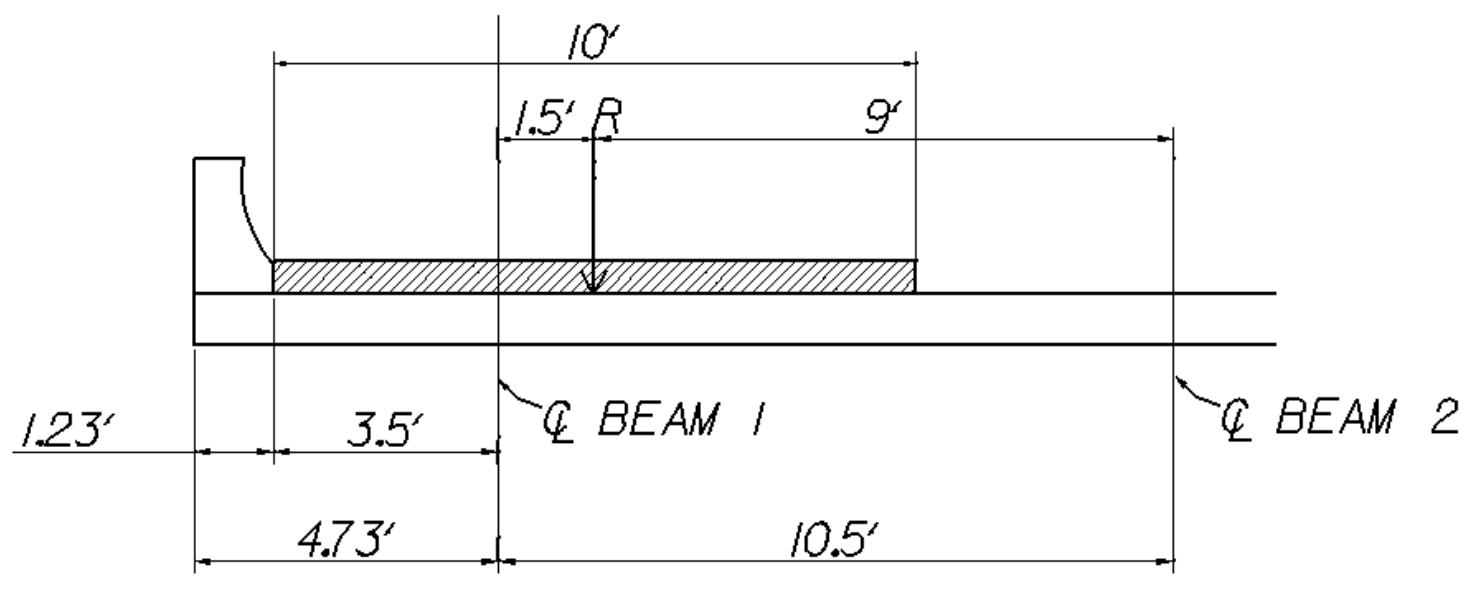

Figure 4.3. Illustration of Lane Loading Placement 


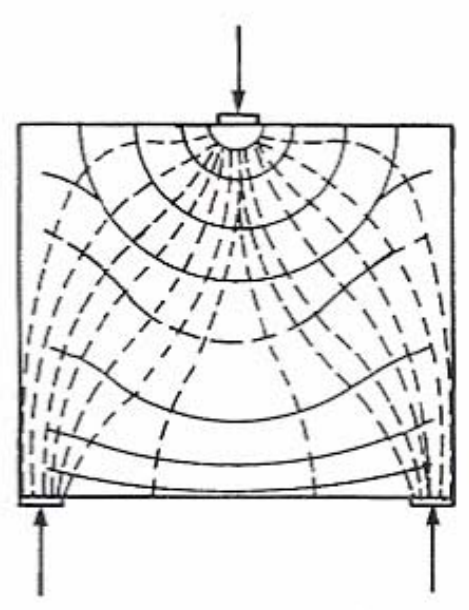

(a) Stress trajectories.

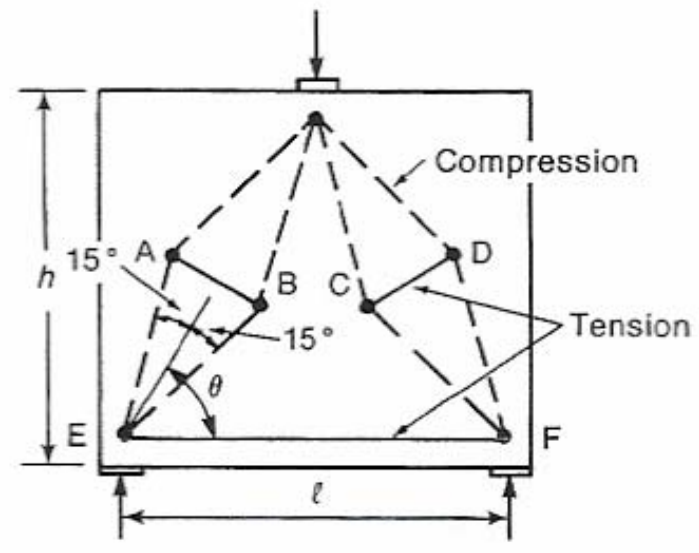

(c) Truss model.

$\theta=68^{\circ}$ if $\mathrm{e} / \mathrm{h}<0.8$

$=37^{\circ}$ if $\ell / h=2.0$

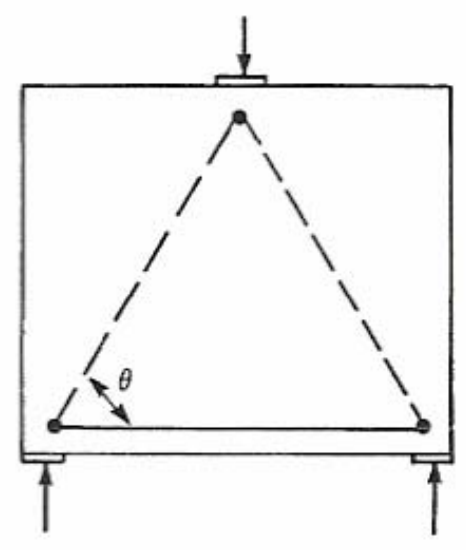

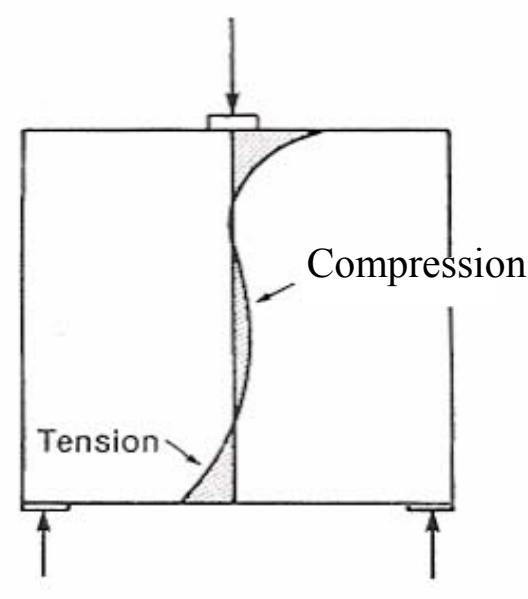

(b) Distribution of theoretical horizontal elastic stresses at mic

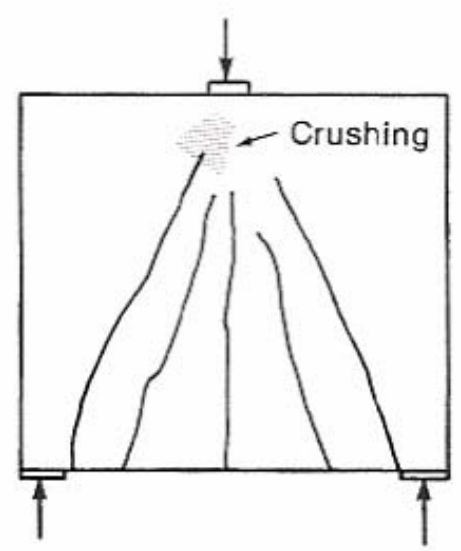

(d) Crack pattern in test.

(e) Simplified truss.

Figure 4.4 Steps for defining a truss model. (Collins and Mitchell, 1991) 


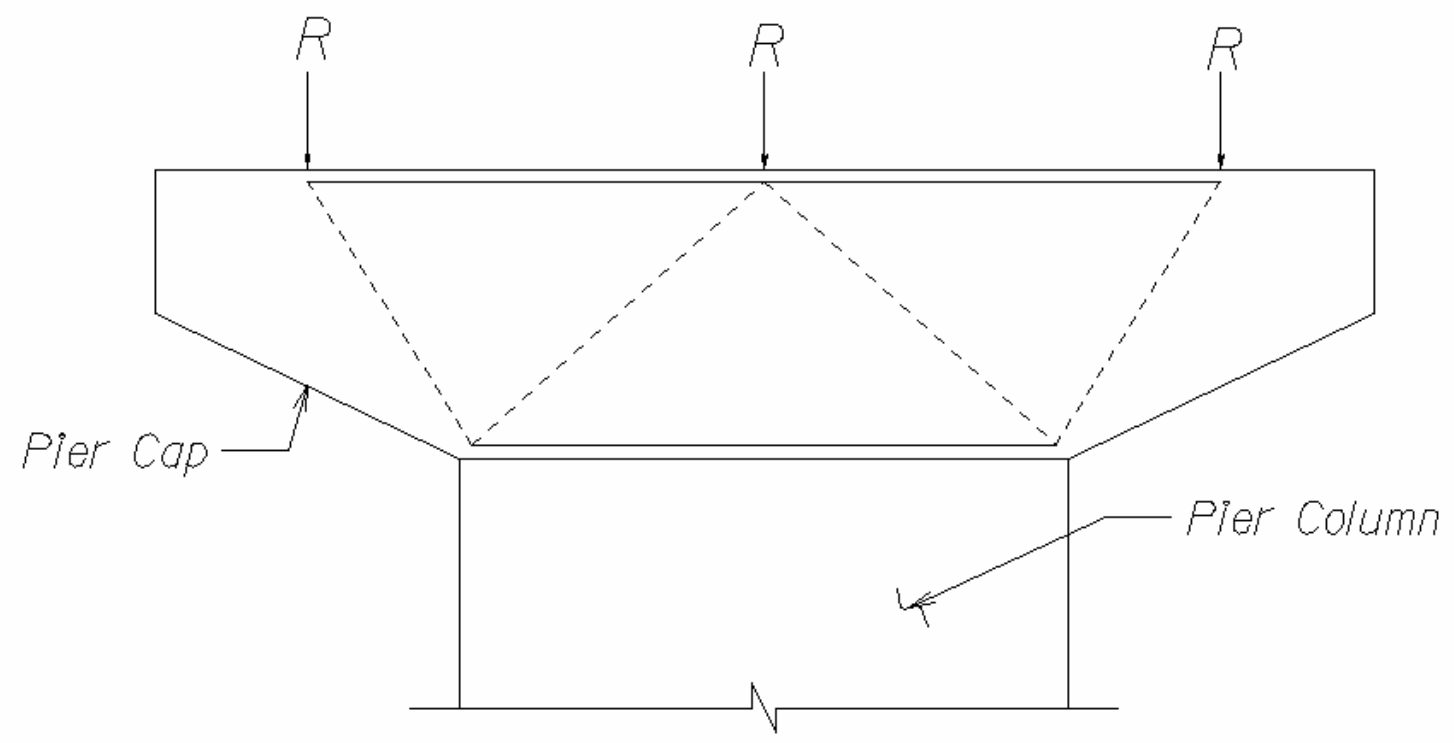

Figure 4.5. Hammerhead Pier Cap with Truss Model 


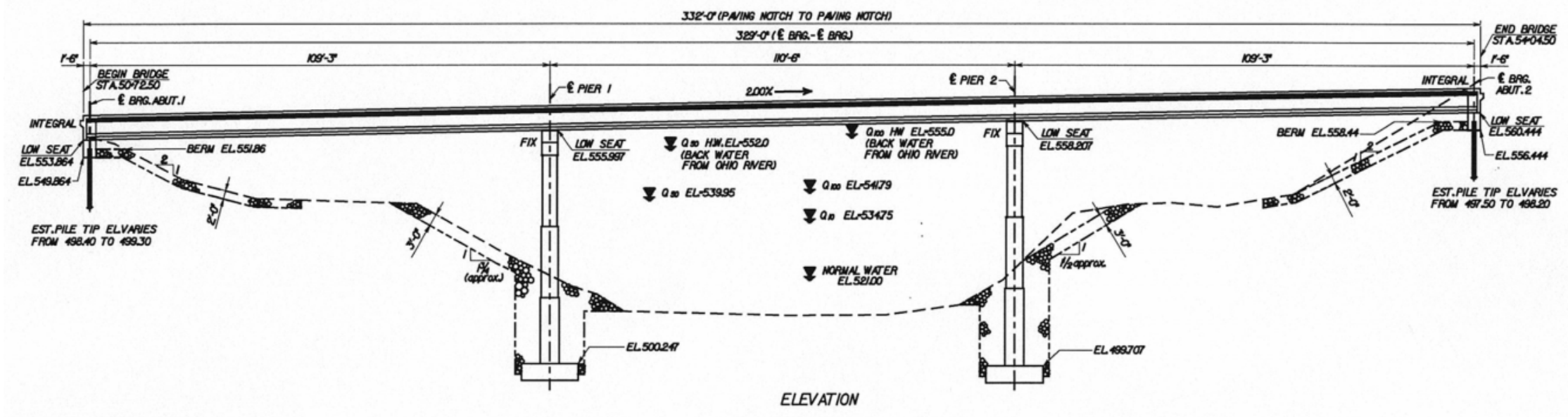

Figure 4.6 Bridge Elevation - Barboursville Bridge 


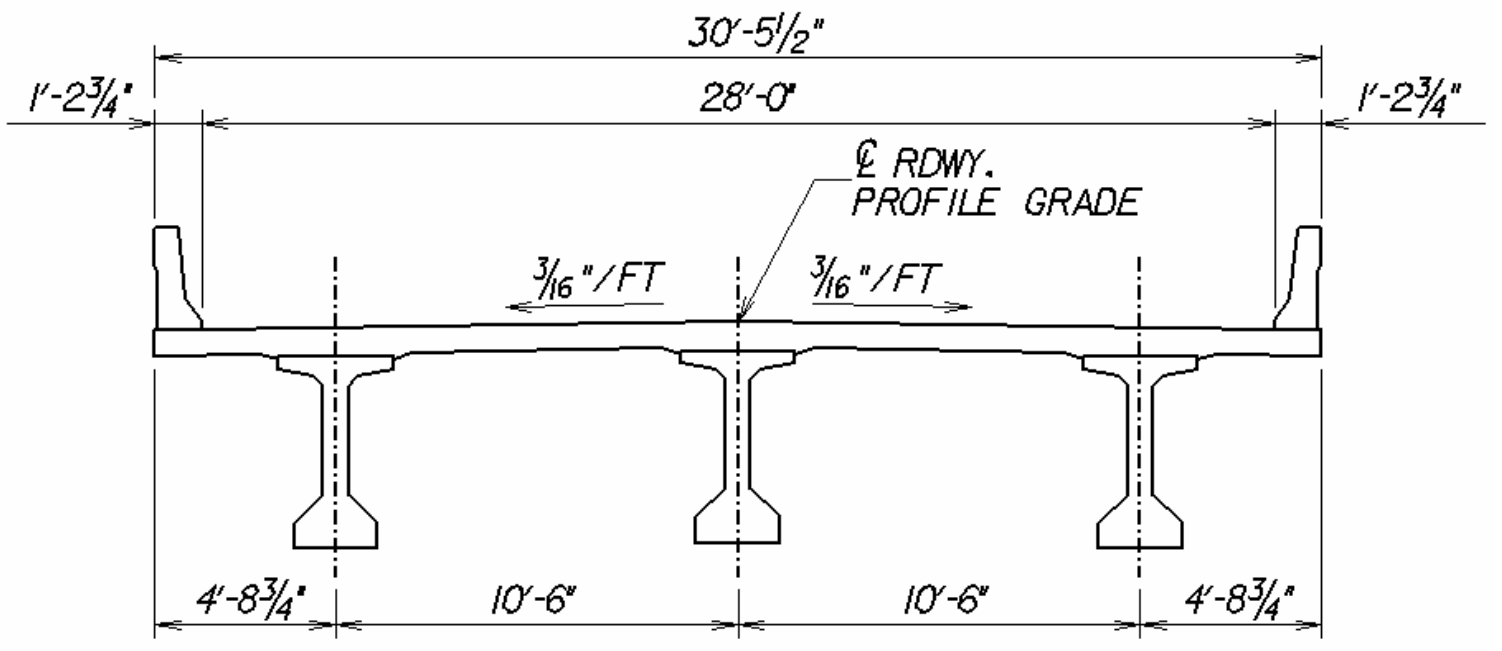

Figure 4.7 Typical Section - Barboursville Bridge 


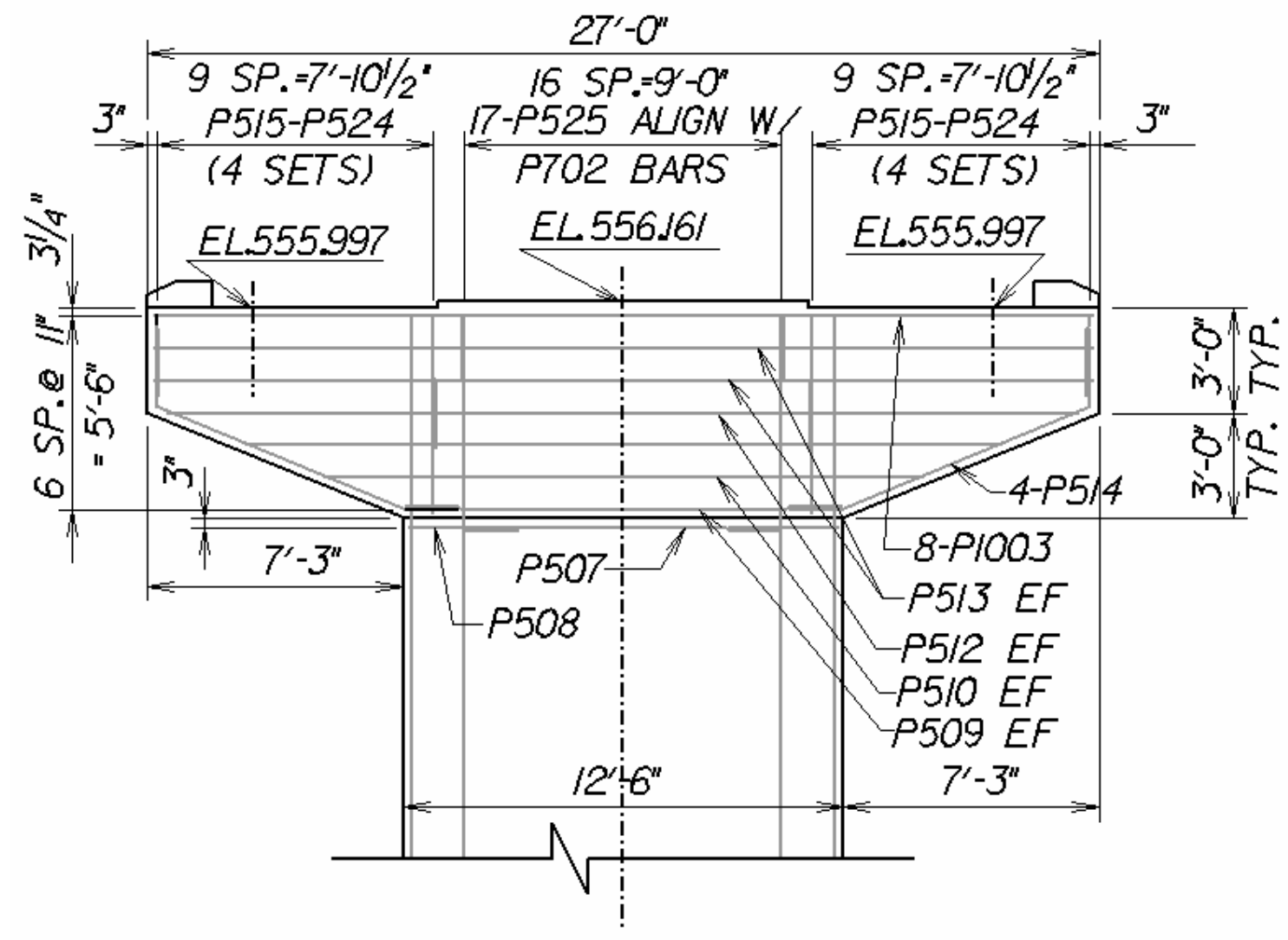

Figure 4.8. Barboursville Pier Cap LFD Design 


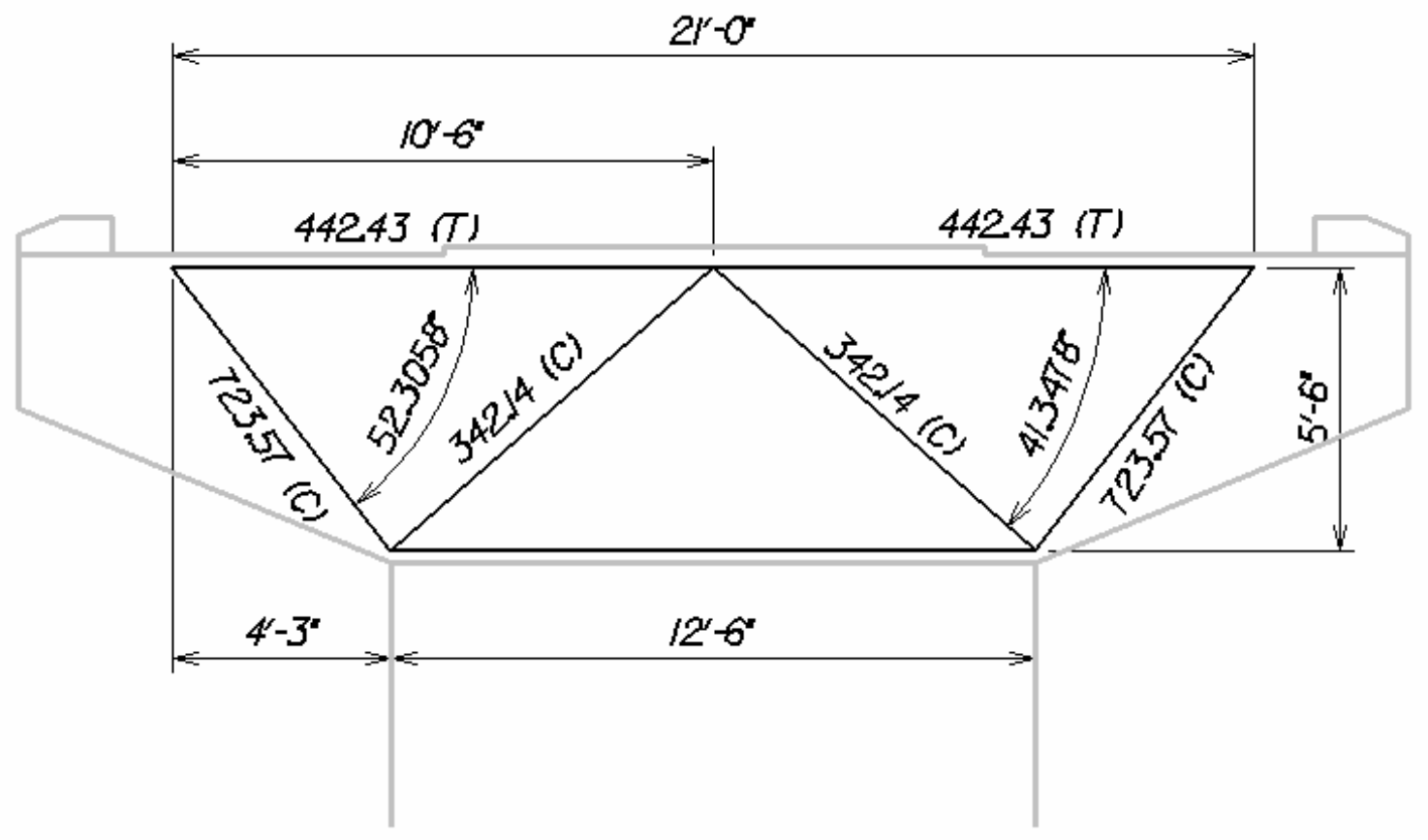

Figure 4.9. Barboursville Truss Model Dimensions and Solutions 


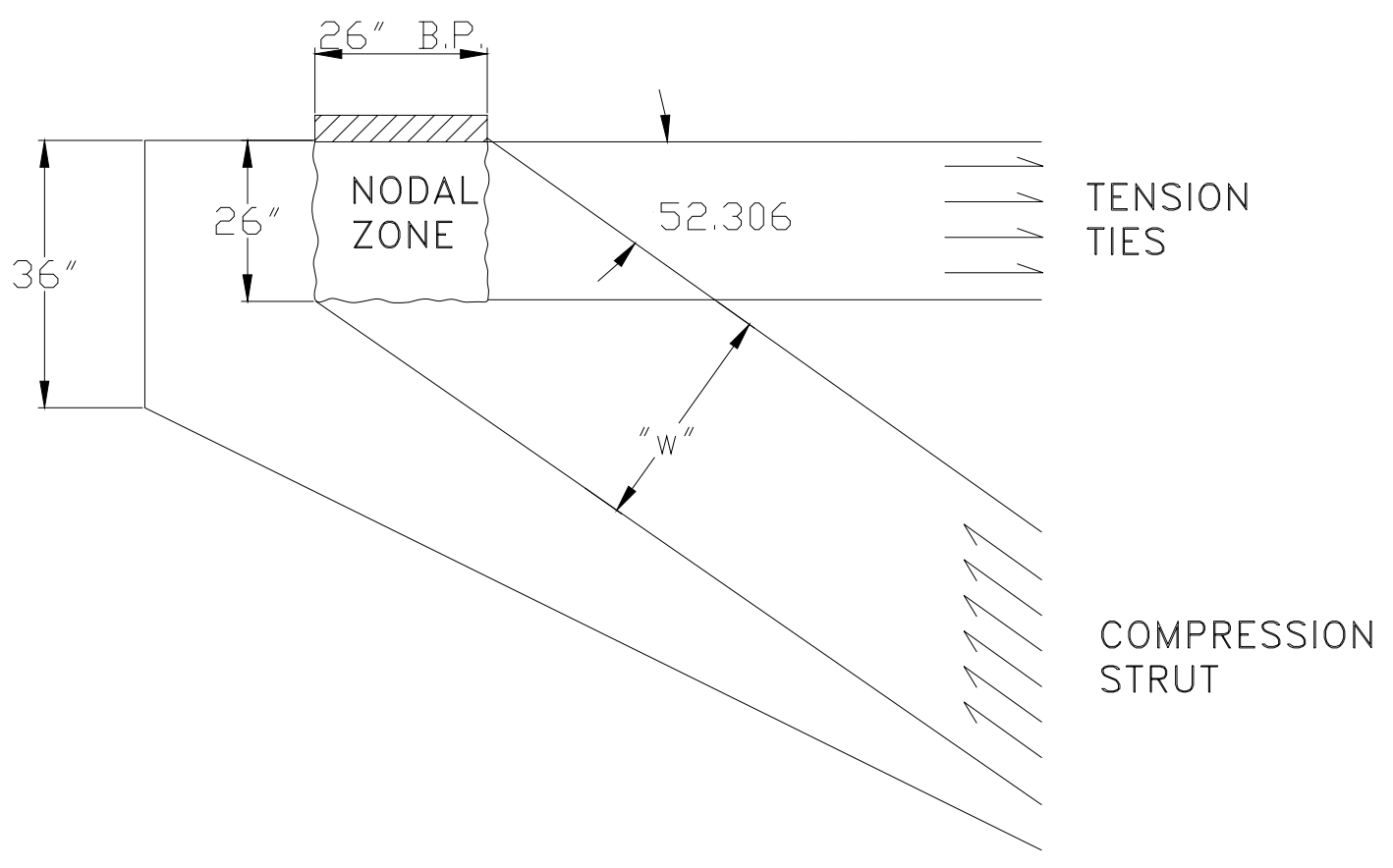

Figure 4.10. Effective Depth Calculation for Barboursville Bridge Pier Cap 


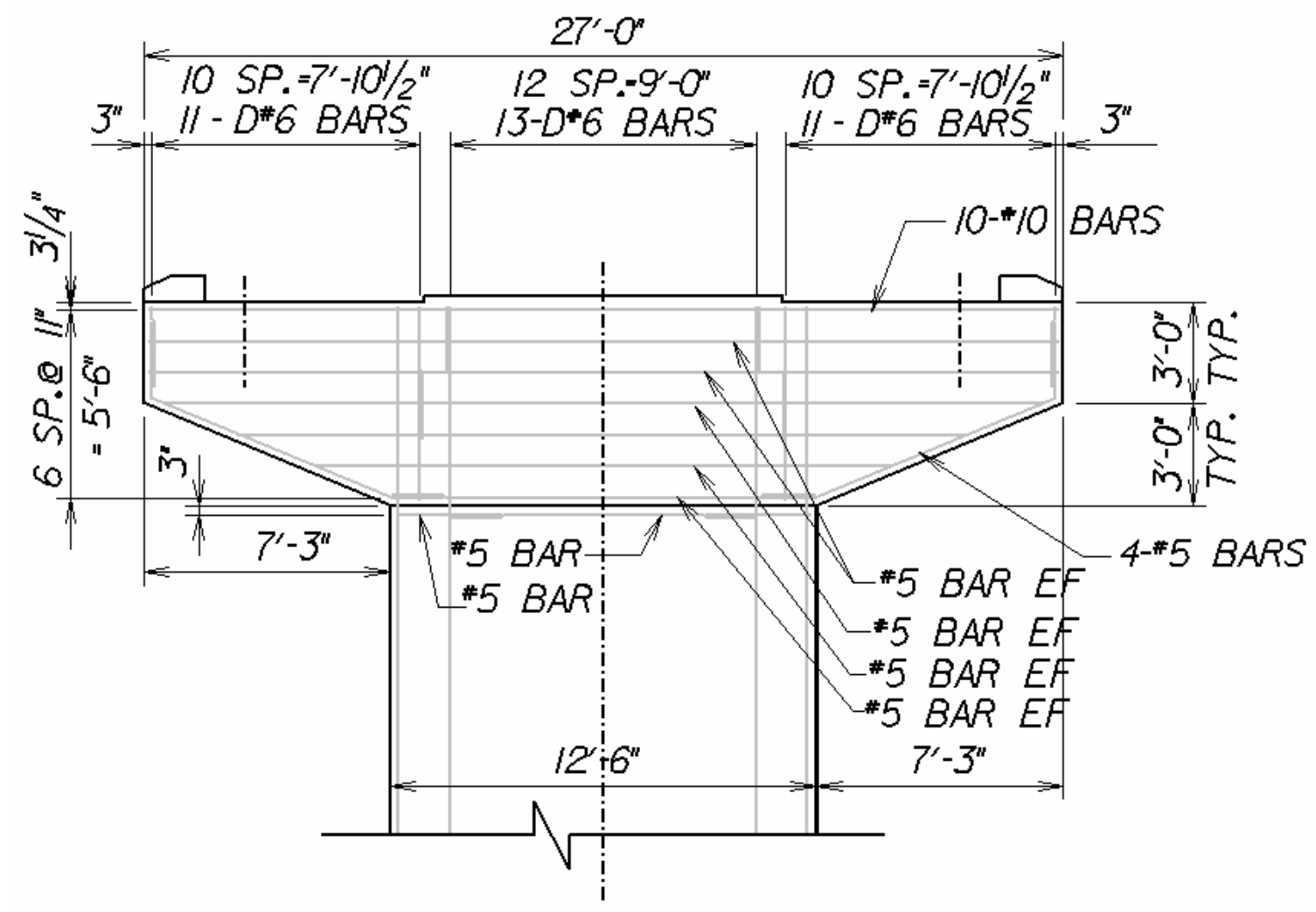

Figure 4.11. Barboursville Bridge Strut-and-Tie Modeling Reinforcing Details 


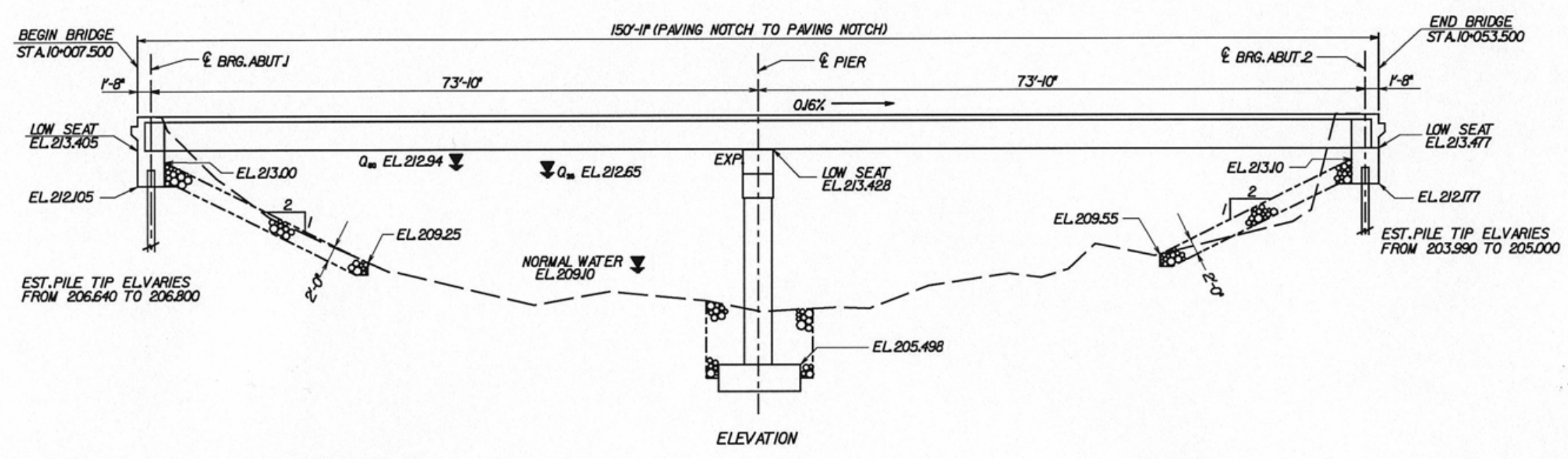

Figure 4.12 Bridge Elevation - South Madison Bridge 


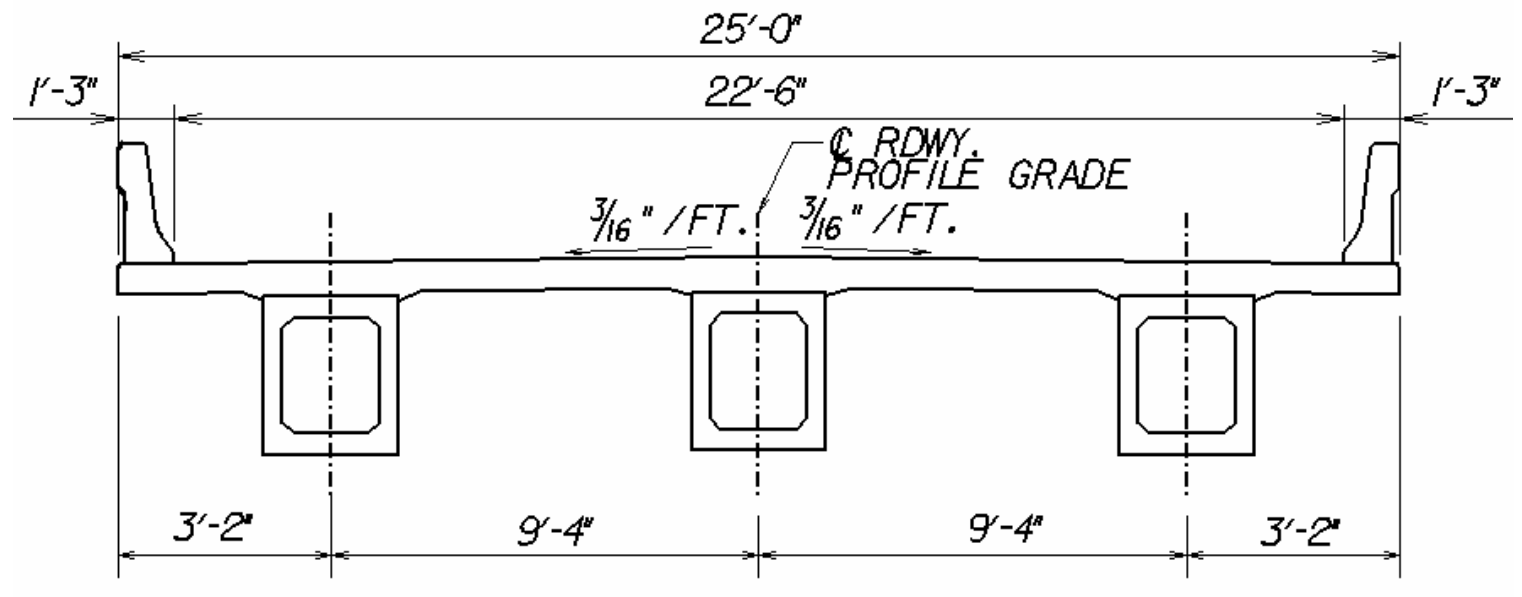

Figure 4.13 Typical Section - South Madison Bridge 


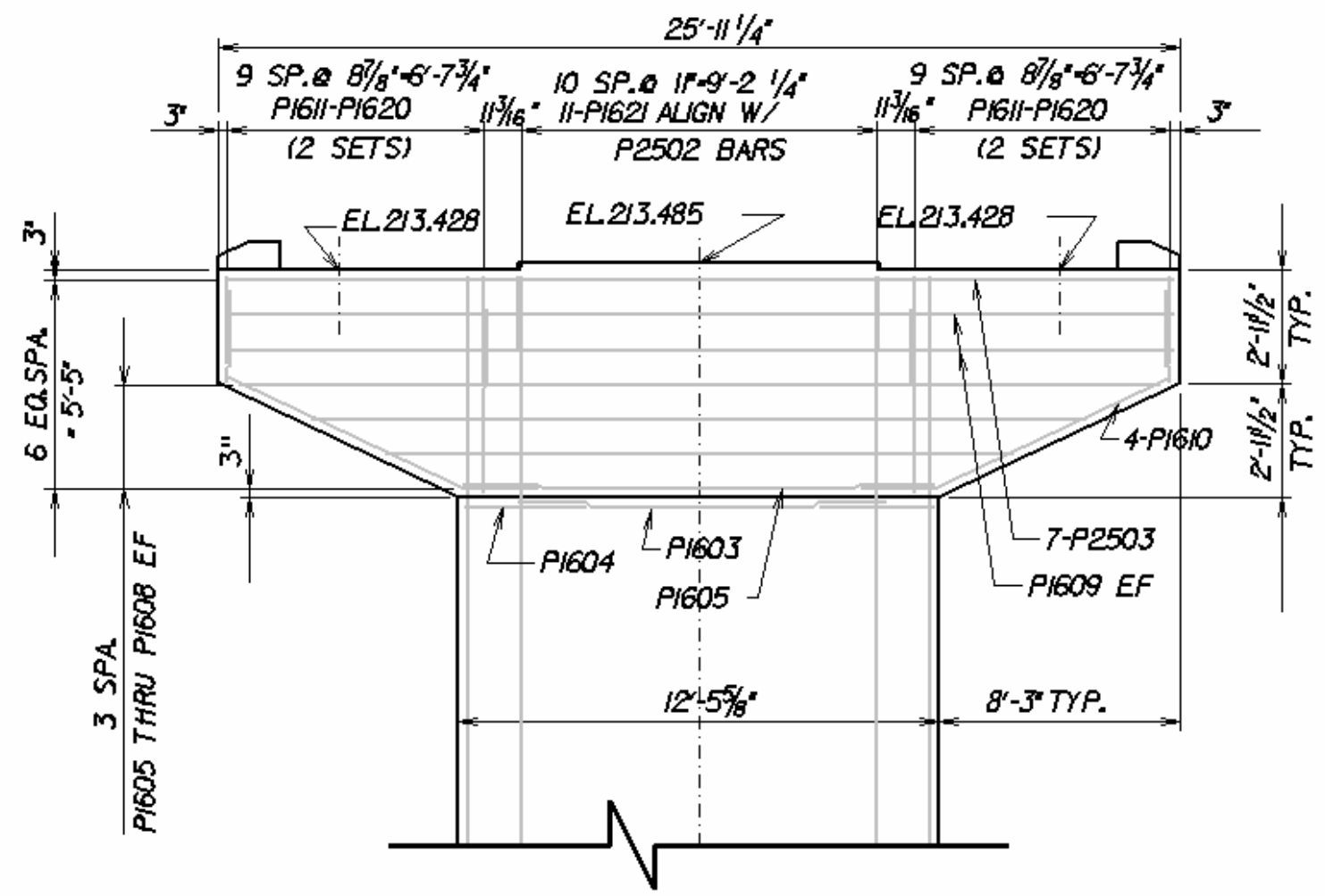

Figure 4.14. South Madison Bridge Pier Cap LFD Design 


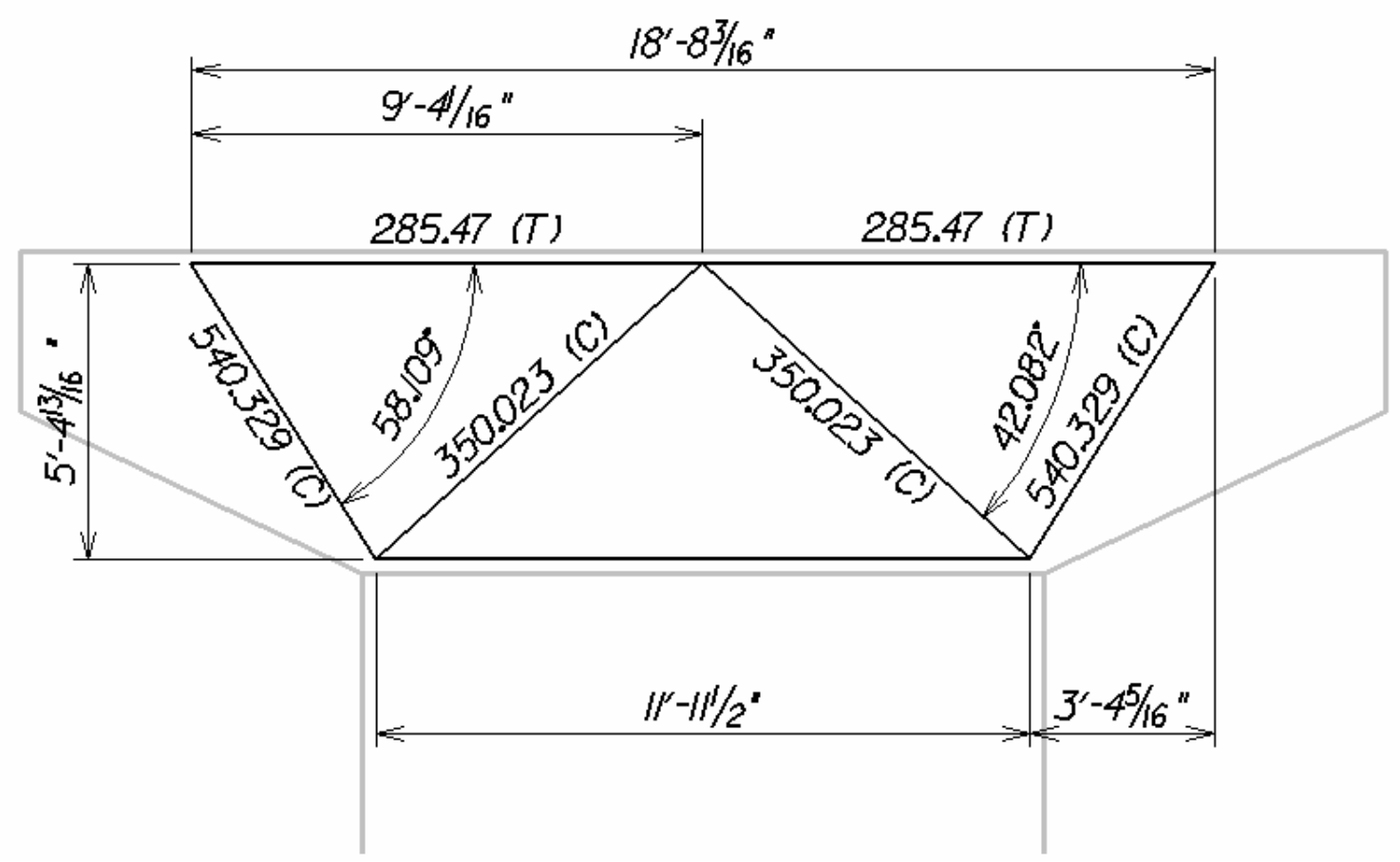

Figure 4.15. South Madison Truss Model Dimensions and Solutions 


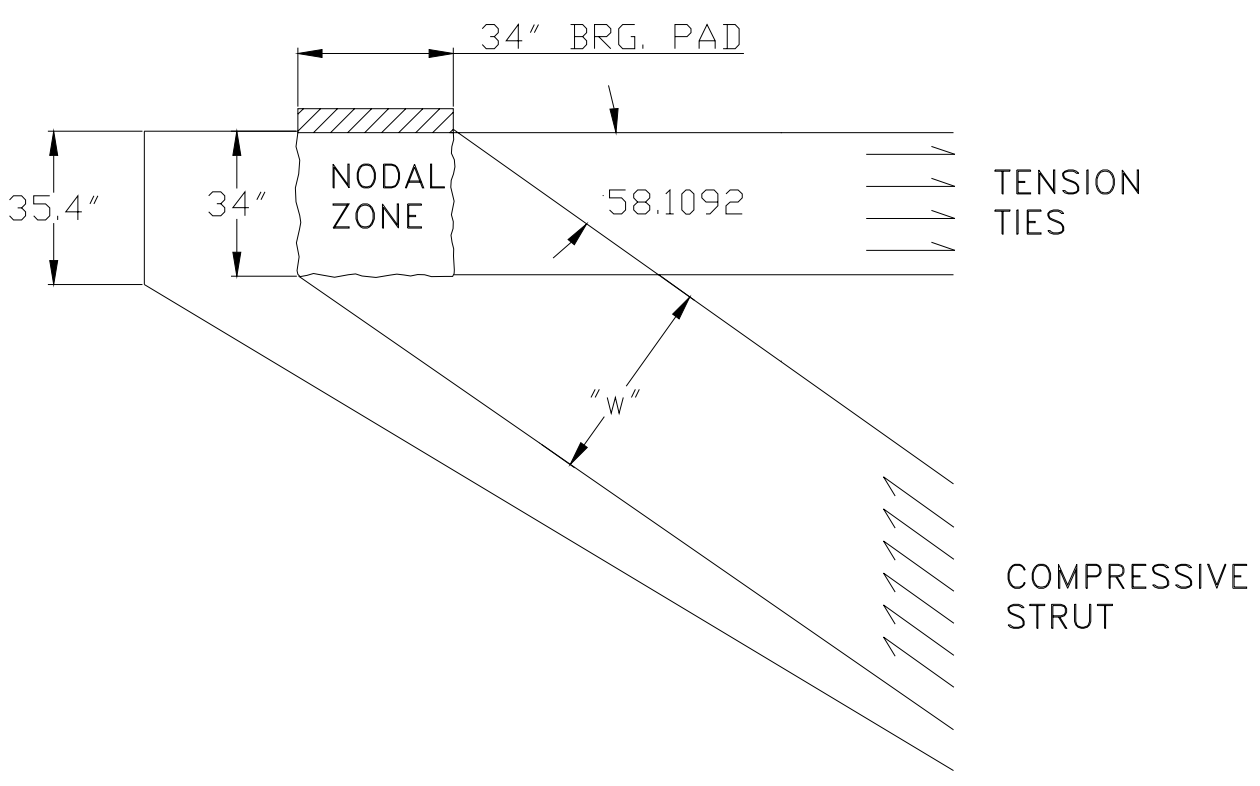

Figure 4.16 Effective Depth Calculation for South Madison Bridge Pier Cap 


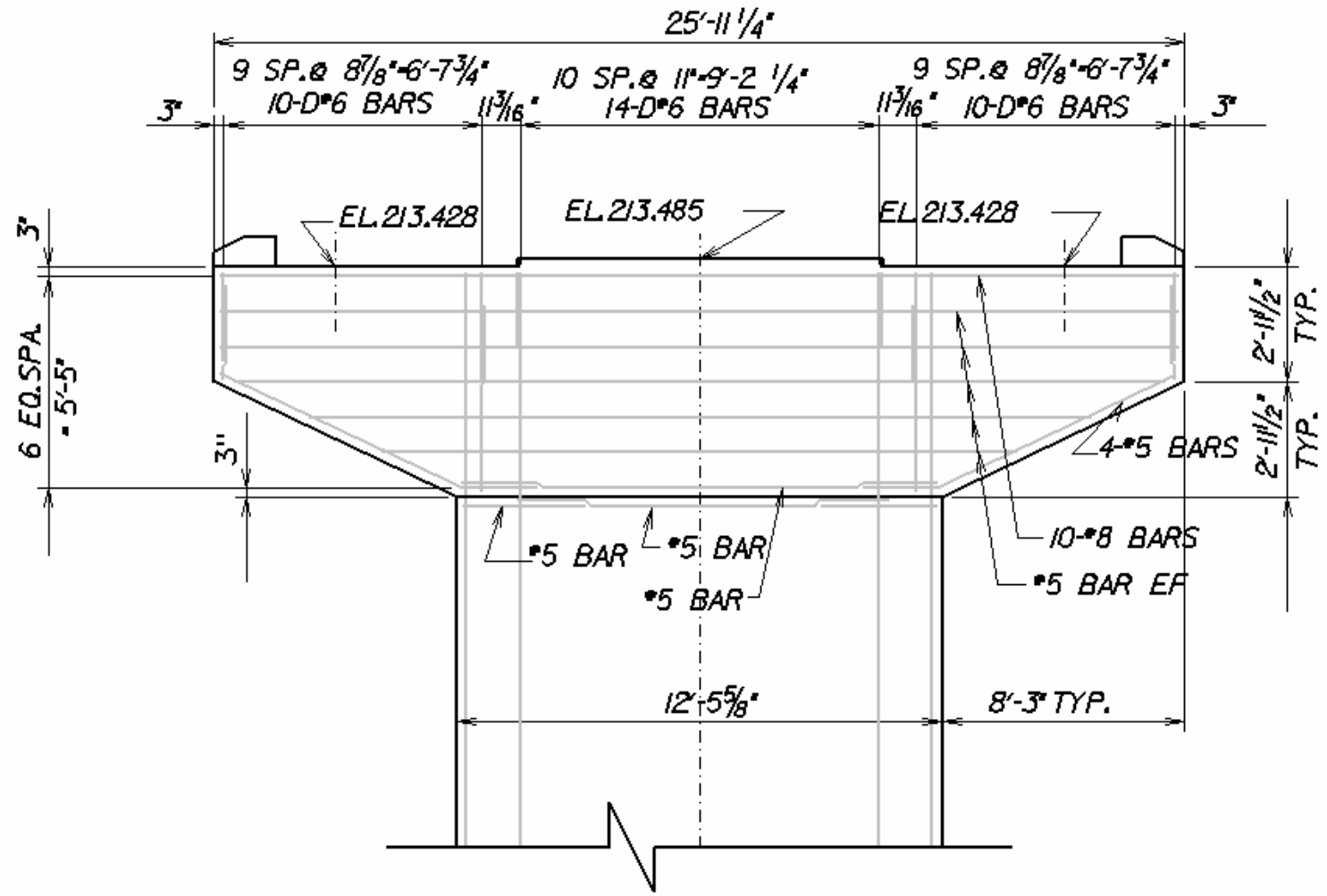

Figure 4.17. South Madison Bridge Strut-and-Tie Modeling Reinforcing Details 
TOTAL IENGTH OF BRDEE - 995. O

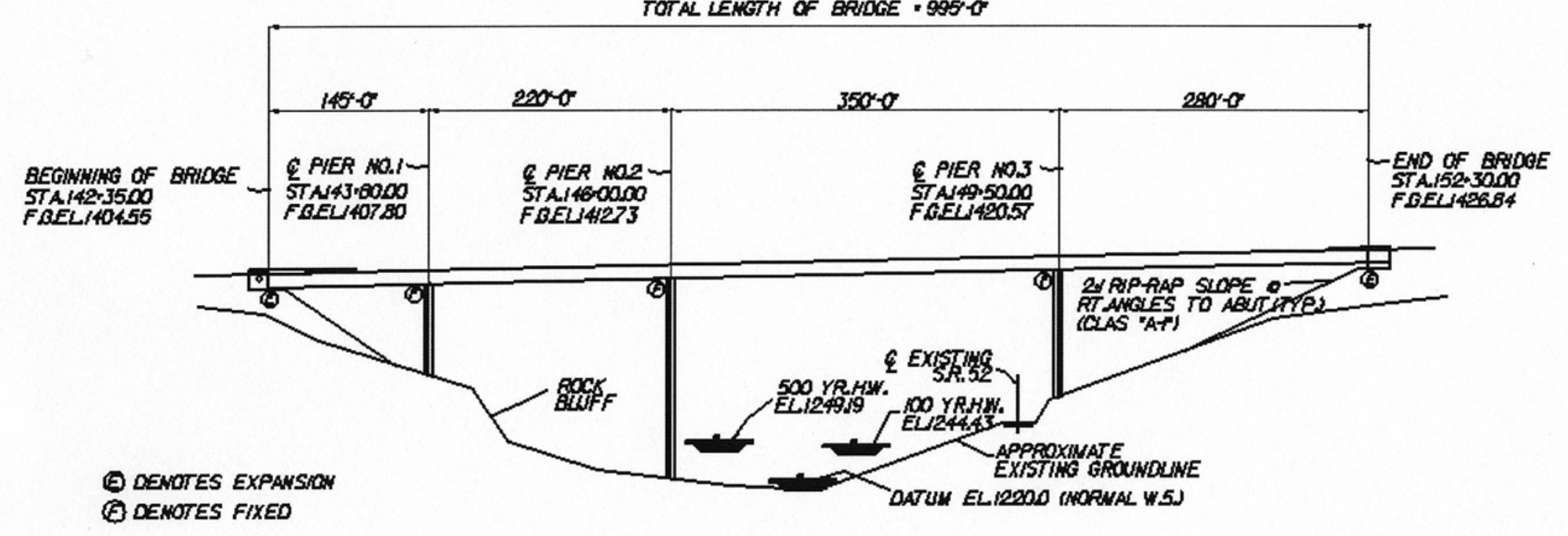

Figure 4.18 Bridge Elevation - Clear Fork Bridge 


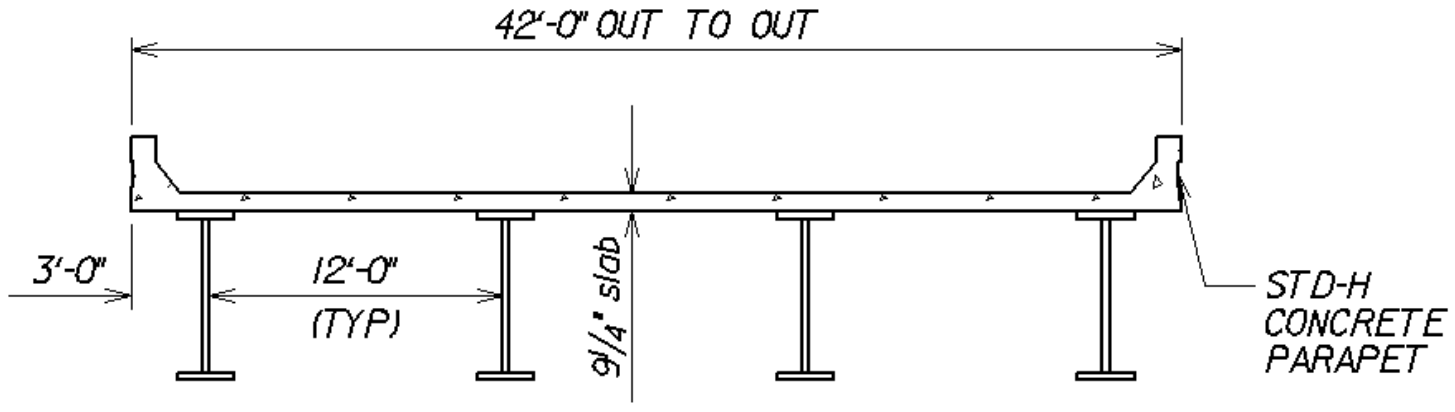

Figure 4.19 Typical Section - Clear Fork Bridge 


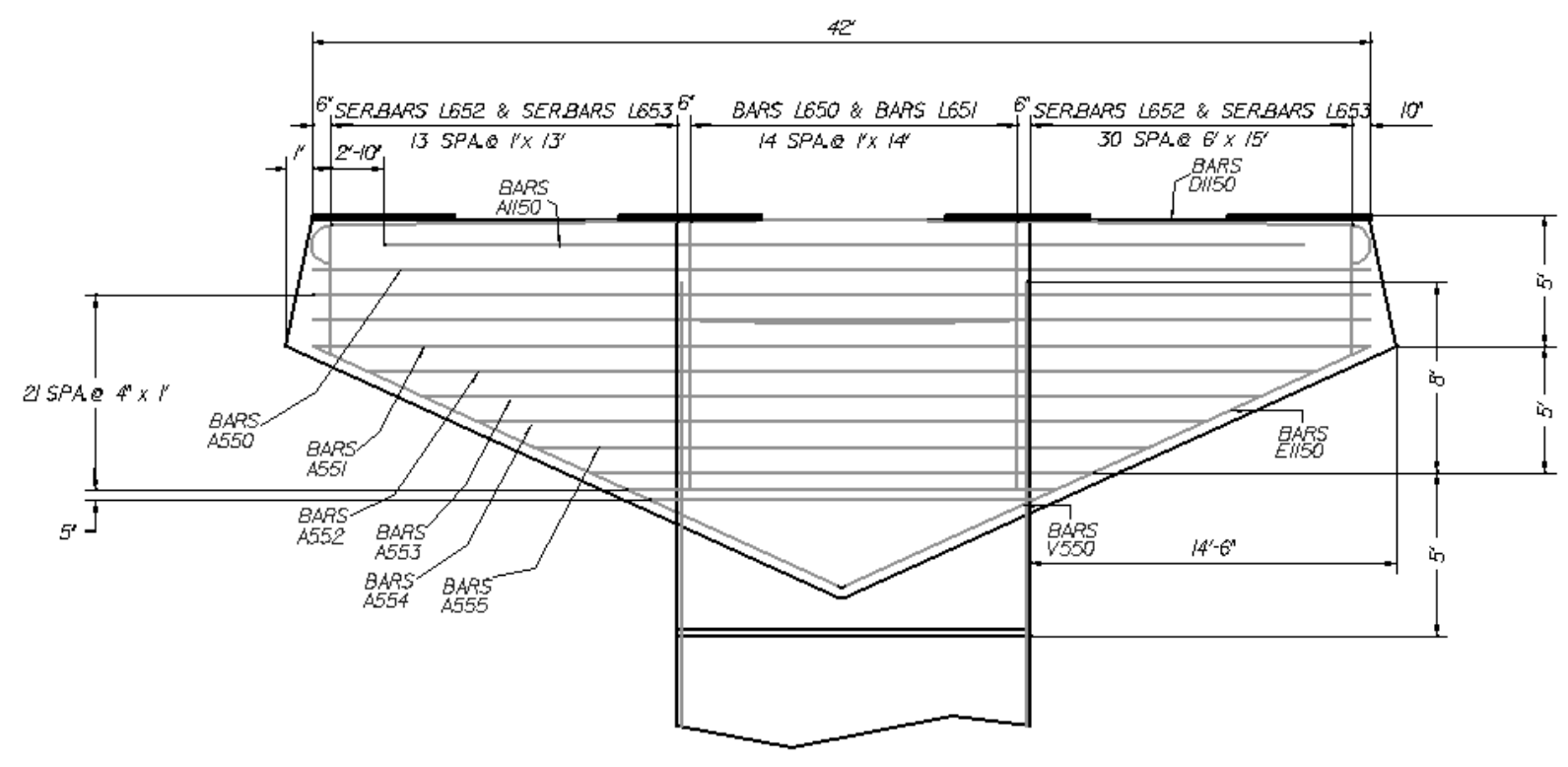

Figure 4.20 Clear Fork Bridge Pier Cap LFD Design 


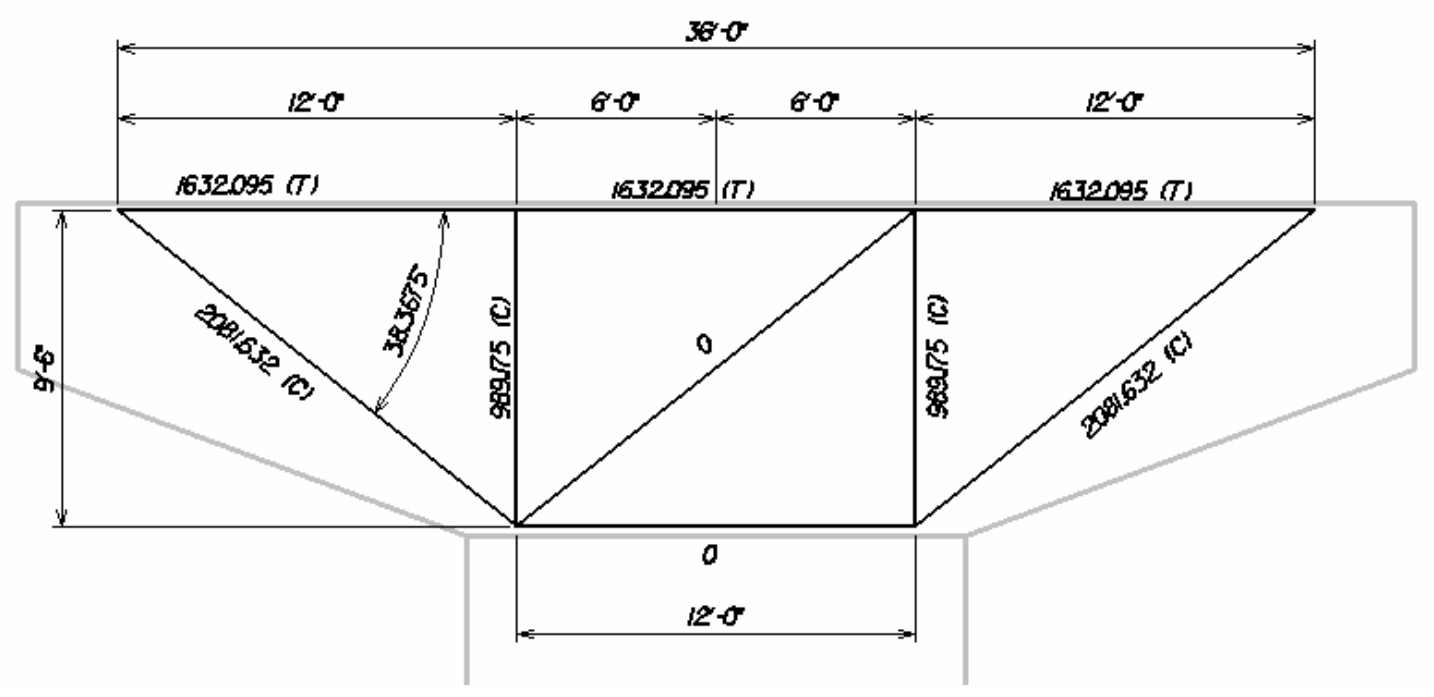

Figure 4.21 Clear Fork Truss Model Dimensions and Solutions 


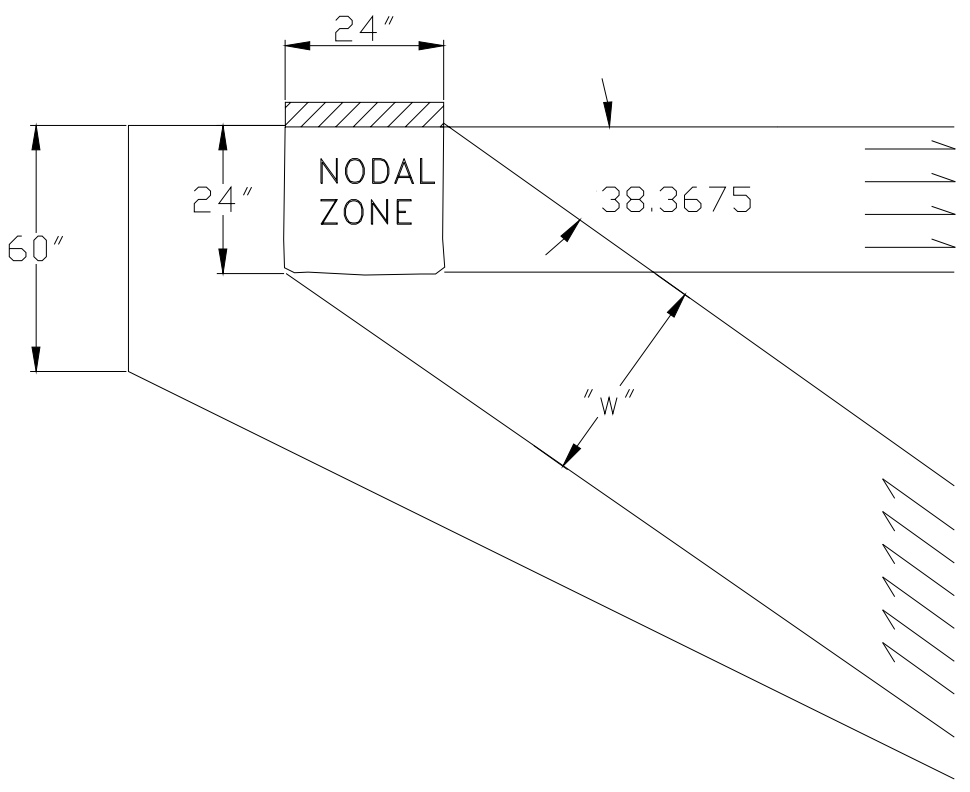

Figure 4.22. Effective Depth Calculation for Clear Fork Bridge Pier Cap 


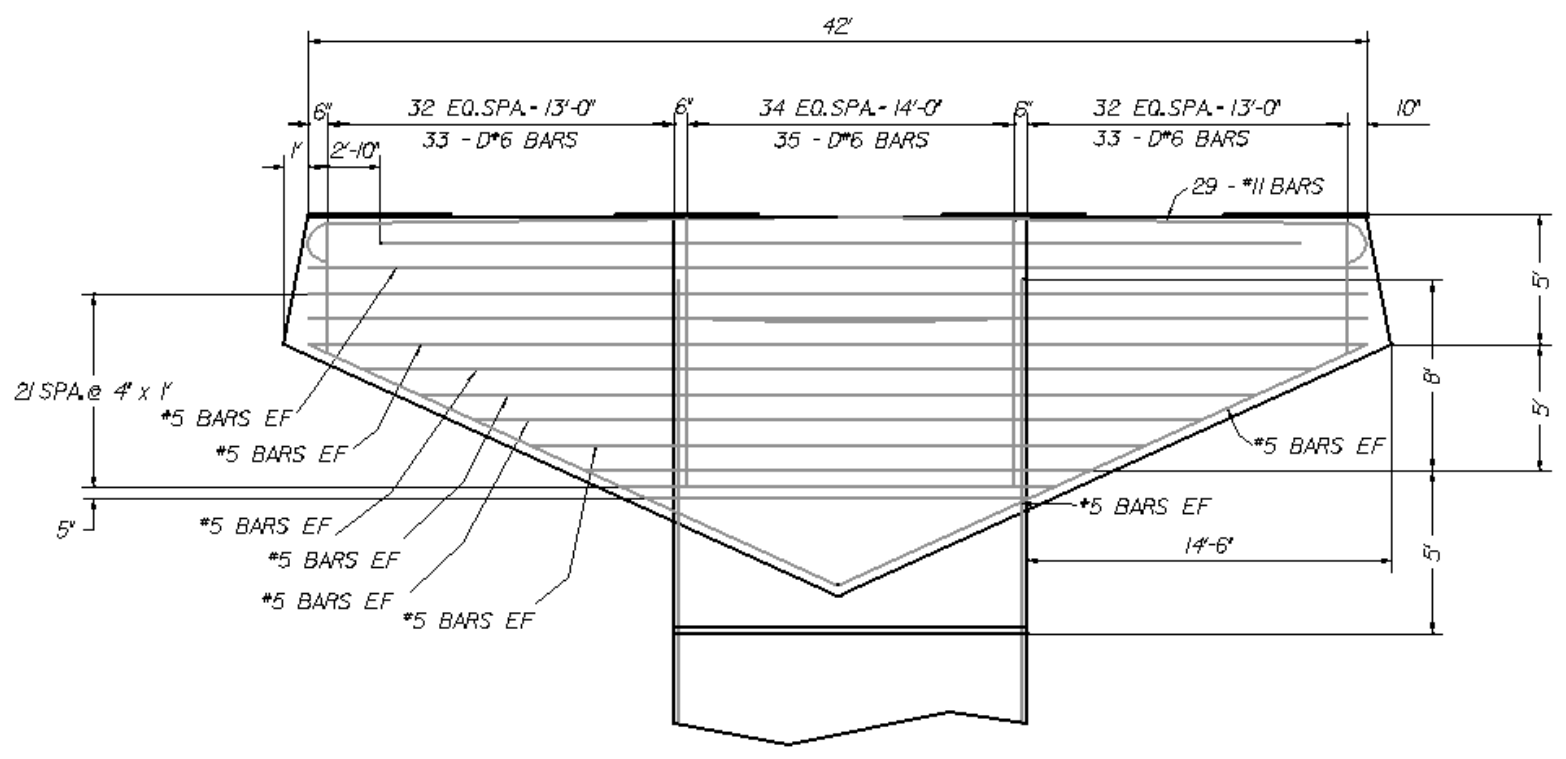

Figure 4.23 Clear Fork Bridge Strut-and-Tie Modeling Reinforcing Details 


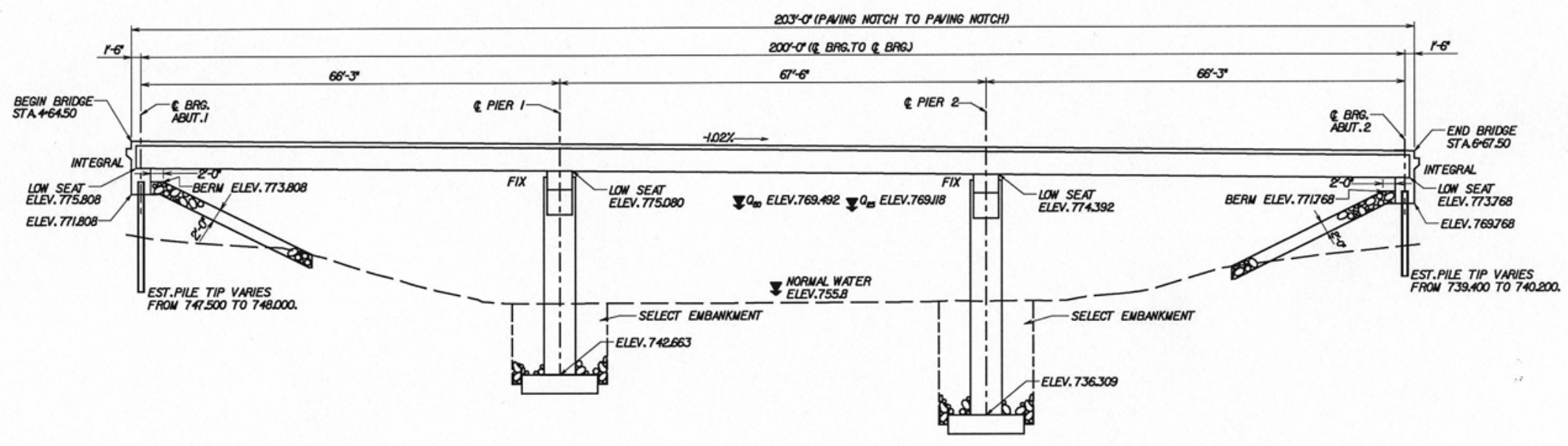

Figure 4.24 Bridge Elevation - Shepherd Bridge 


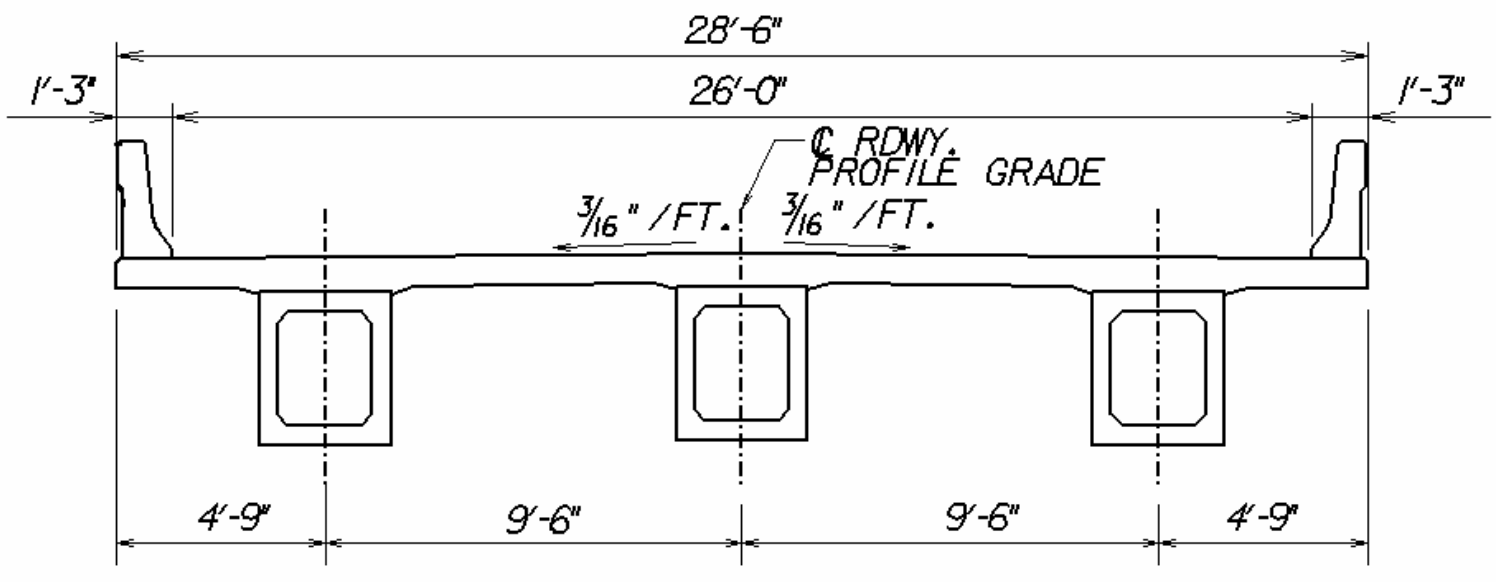

Figure 4.25 Typical Section - Shepherd Bridge 


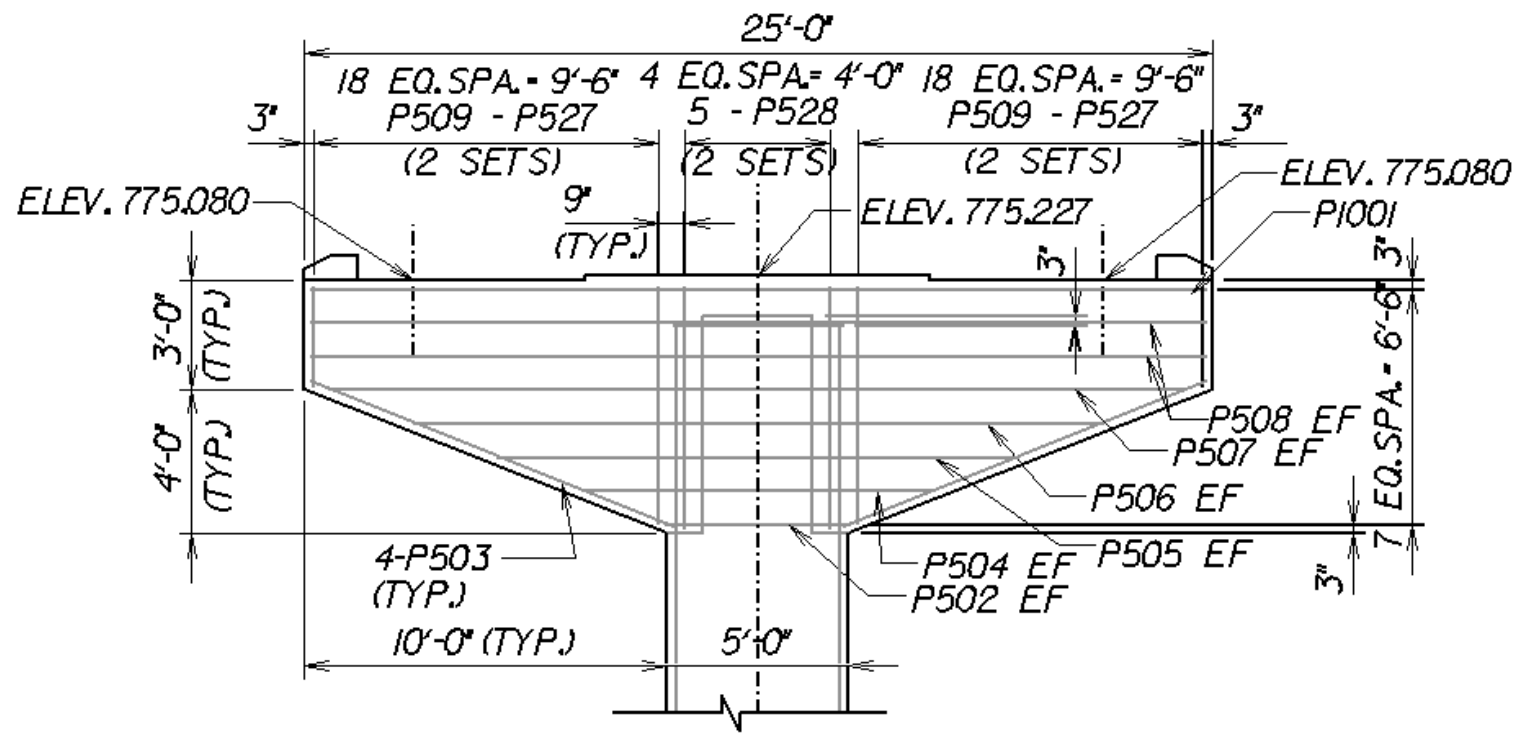

Figure 4.26. Shepherd Bridge Pier Cap LFD Design 


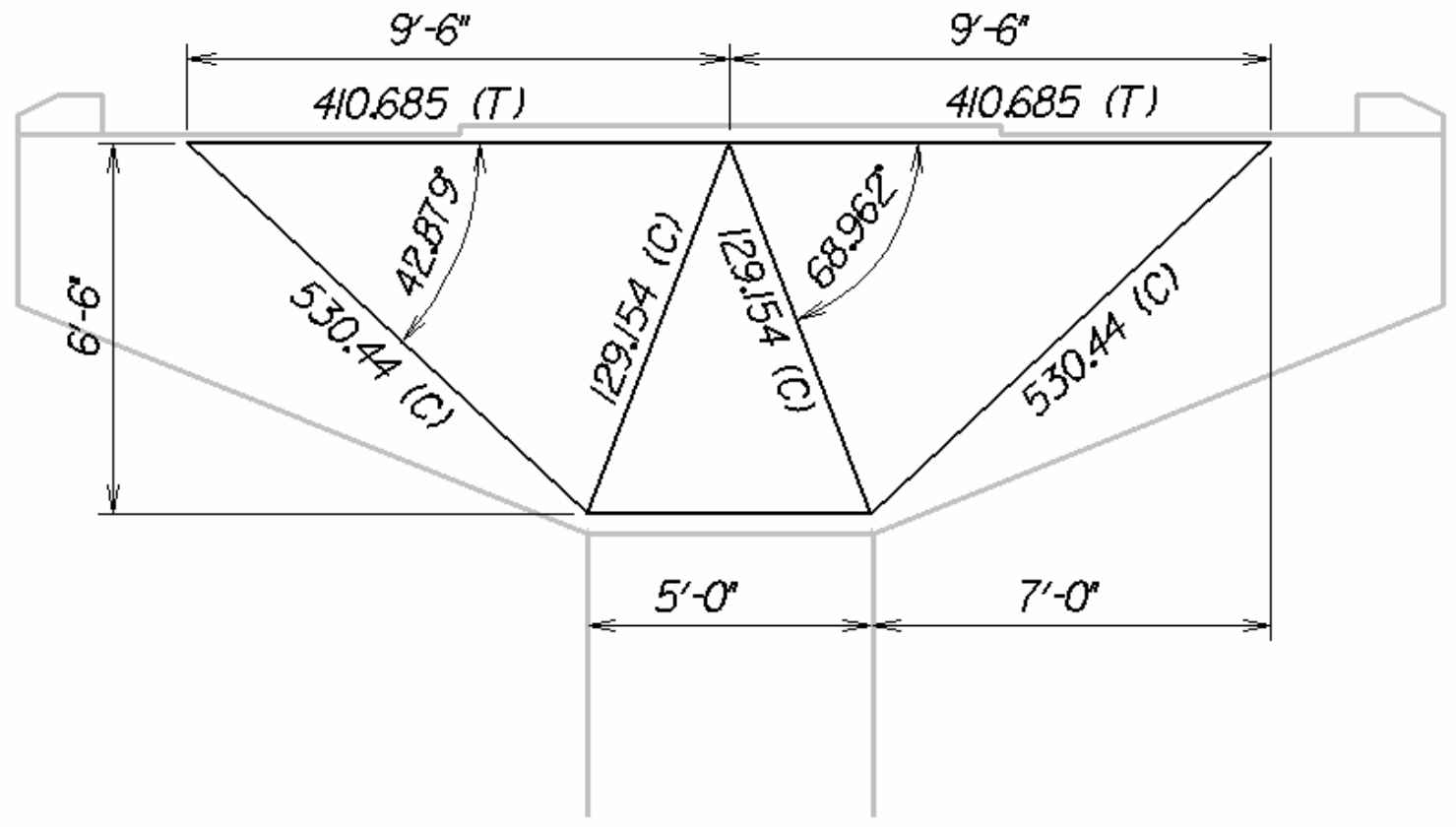

Figure 4.27. Shepherd Bridge Truss Model Dimensions and Solutions 


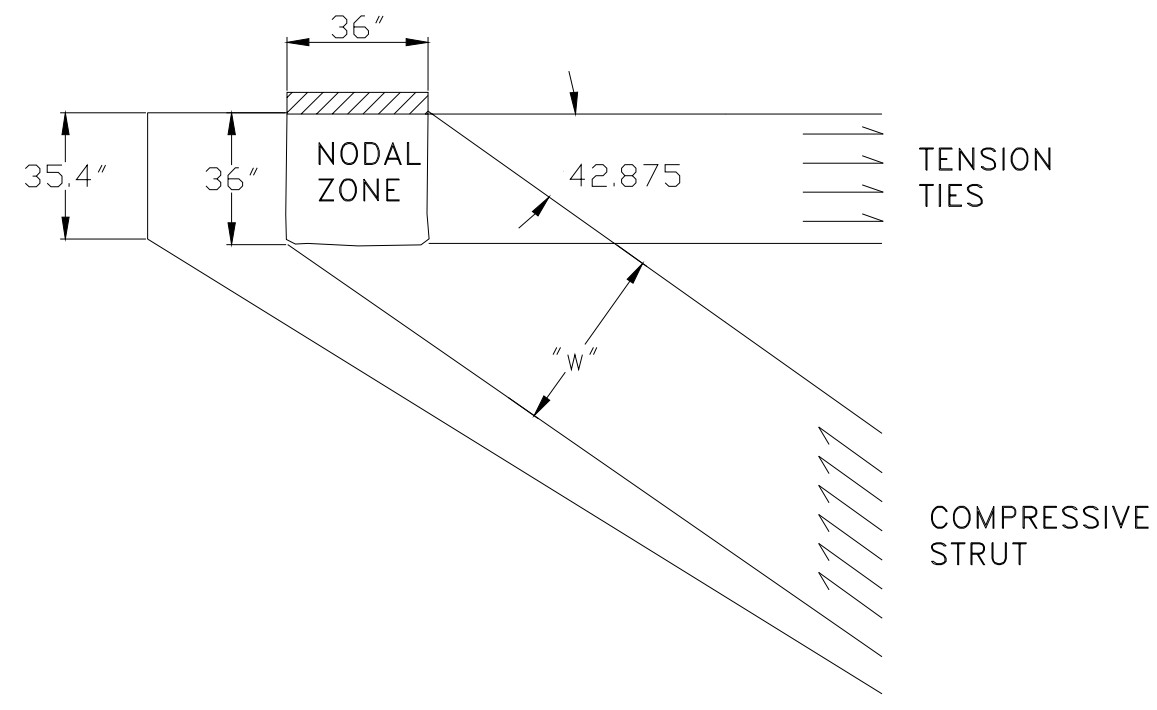

Figure 4.28 Effective Depth Calculation for Shepherd Bridge Pier Cap 


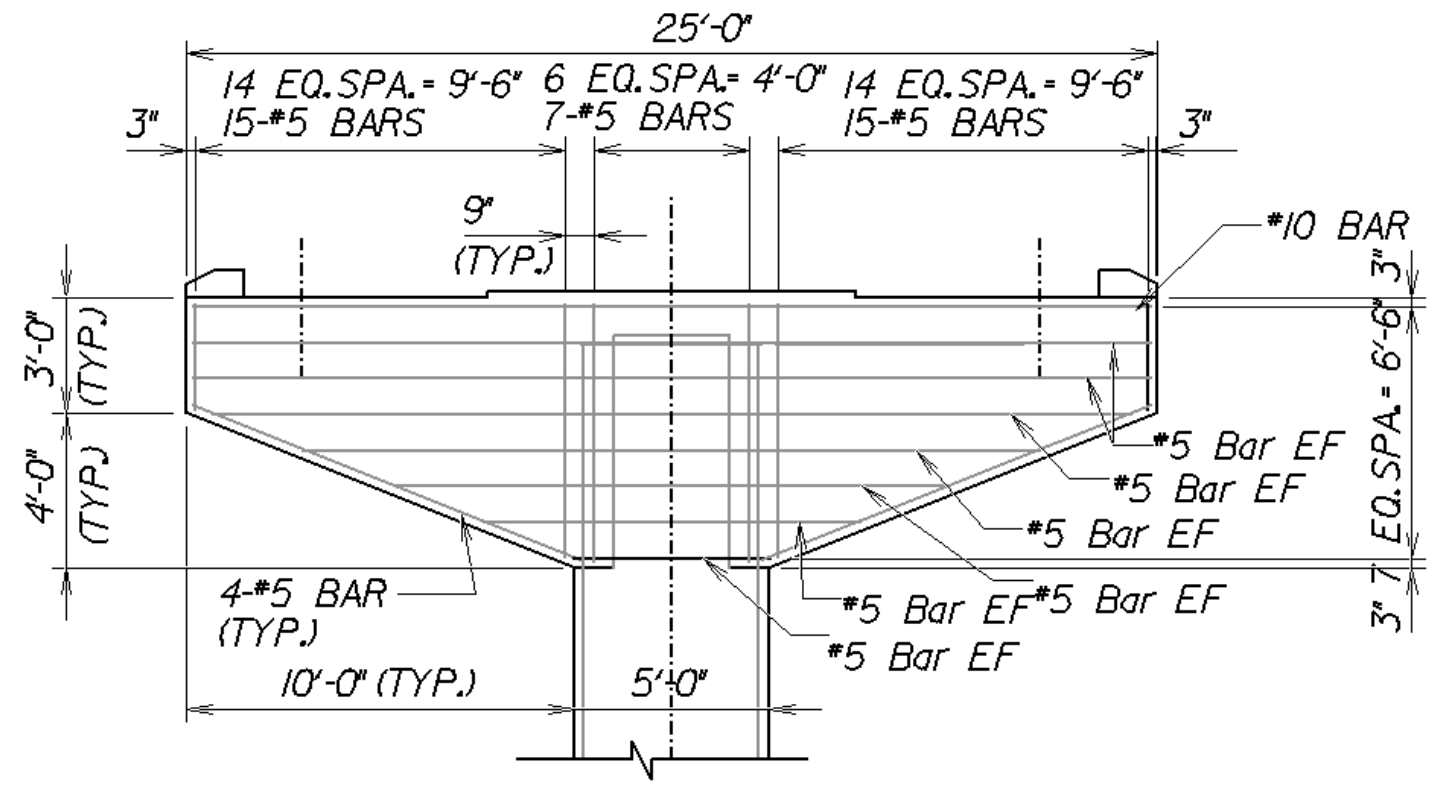

Figure 4.29. Shepherd Bridge Strut-and-Tie Modeling Reinforcing Details 


\section{Chapter 5}

\section{DESIGN RECOMMENDATIONS}

This chapter will address the differences in flexural and shear steel required by the Standard Specifications and the LRFD Specifications. Additionally, this chapter presents a concise procedure for the consistent design of hammerhead piers which addresses load generation, truss model definition, truss element dimensioning, and shear design.

\subsection{Recommended Strut-and-Tie Design Procedure For Hammerhead Piers}

\subsubsection{Determination of Loads}

The external loads acting on the pier at the nodal zone locations are the superstructure dead load and live load reactions. Members contributing to the dead load reactions are the beam, intermediate diaphragms, deck, pier diaphragm, parapet, and future wearing surface. The dead load reactions should be calculated for the interior and exterior beams separately due to the difference in effective slab widths. The live load reactions should consist of the HL-93 defined by the AASHTO LRFD Specifications (AASHTO, 1998). The live load reactions should be determined by considering the 
structure to be continuous. When placing the truck component of the HL-93 live load, the designer should place the second wheel directly over the pier to insure the maximum reaction is achieved. In turn, the HL-93 reaction should be placed so that to induce the maximum moment on the cantilever of the hammerhead pier. For the design study, the maximum moment is produced by placing the truck component of the HL-93 reaction two feet from the face of the curb or parapet. While the lane load component of the HL93 is placed at the face of the curb to produce the maximum moment. Additional superstructure load configurations may control and should be considered when applicable.

Furthermore, the load effects from water, wind, self-weight, and wind on the live load should be considered when applicable. The pressure loads, as well as the selfweight of the pier cap, are distributed evenly as point loads to each node by dividing the total pressure load by the total number of nodes.

\subsubsection{Defining the Truss Model}

The first step in defining the truss is locating the nodal zones. The nodal zones are defined where external loads, e.g. beam reactions, act on the pier cap and where the stress is transferred from the cap to the column. The location of the stress path can be assumed to be located where the reinforcing pattern transfers load from the cap to the column.

The tension ties should be modeled at the predicted location of the tension reinforcement while the compression struts represent the primary compressive stress and 
should be defined accordingly. Both the tension ties and compression struts should begin and terminate at the nodal zones. The final truss model should be represented by an acceptable truss model and have the least number of tensile ties possible.

The geometry of the tension tie is determined by the location of the tensile reinforcing pattern; therefore, care should be taken to insure that the final reinforcing pattern represents the tensile tie location in the truss model. For example, if the flexural reinforcing is assumed to be located three inches from the face of the concrete, then the tension tie should be modeled at a depth of three inches. If the location of flexural steel exceeds the three-inch depth, then the model should be resized based on the new centroid of the reinforcing mat. The diameter of reinforcing bars used also dictates the depth of the reinforcing centroid. Smaller reinforcing bars will normally produce a deeper centroid due an increase in the layers required to accommodate the number of bars, while the opposite occurs for larger diameter bars. However, care should be taken when specifying the larger diameter bars due to violating flexural steel distribution to control cracking.

\subsubsection{Dimensioning of Tensile Ties, Compressive Struts, and Nodal Zones}

The dimensioning of the compression strut, tension tie, and nodal zones are governed by Articles 5.6.3.2 through 5.6.3.6 of the AASHTO LRFD Specifications and were previously discussed in Section 3.3. 
The nominal resistance of a tensile tie in a hammerhead pier cap should be calculated using the following equation:

$$
P_{n}=f_{y} A_{s t}
$$

Using $P_{n}=P_{u} / \phi$ and solving for $A_{s t}$, the result of Eqn. 5-1 is the area of steel required to resist the tensile load. The area of required reinforcing can then be used to size rebar and calculate the spacing of rebar based on the requirements of AASHTO LRFD Specifications (AASHTO, 1998).

The first step in determining the capacity of the compression struts is calculating the limiting compressive stress, $f_{c u}$ :

$$
f_{c u}=\frac{f_{c}^{\prime}}{0.8+170 \varepsilon_{1}} \leq 0.85 f_{c}^{\prime}
$$

where:

$$
\varepsilon_{1}=\varepsilon_{s}+\left(\varepsilon_{s}+0.002\right) \cot ^{2} \alpha_{s}
$$

Utilizing $f_{c u}$ found in Eqn. 5-3, the nominal resistance can be calculated depending on the reinforcing pattern used in the hammerhead pier. For the unreinforced compressive strut, AASHTO gives the following equation for the nominal resistance:

$$
P_{n}=f_{c u} A_{c s}
$$


Using $P_{n}=P_{u} / \phi$ and solving for $A_{c s}$, the result of Eqn. 5-4 is the area of concrete required to resist the compressive load.

AASHTO provides the following equation for the condition where the compressive strut contains reinforcement that is parallel to the strut and detailed to develop its yield stress in compression. For case where reinforcement is present, the nominal resistance of the strut shall be taken as:

$$
P_{n}=f_{c u} A_{c s}+f_{y} A_{s s}
$$

Again, using $P_{n}=P_{u} / \phi$ and solving for $A_{c s}$, the result of Eqn. 5-5 is the area of concrete required to resist the compressive load. The value of the required $A_{c s}$ can then be compared to the available $A_{c s}$. The theory for the required and available compressive strut areas were discussed in Section 3.3; however, the procedure for calculating the compressive struts is as follows. Based on the calculated $A_{c s}$ required, a required effective depth of the compressive strut is calculated as:

$$
D_{R}=\frac{A_{c s}}{\text { Width Compressive Strut }}
$$

The width and the depth of the nodal zone can be taken as the width of the required bearing area (previously calculated in the superstructure design) (Oliva, 1997). Using the smallest angle between the compressive strut and adjoining tension ties $\alpha_{s}$, the available effective depth can be calculated as follows: 


$$
D_{A}=\left(W^{*} \sin \alpha_{s}\right)+\left(D * \cos \alpha_{s}\right)
$$

After the dimensioning of the tension ties and compression struts, the stress levels of the nodal zones must be checked. AASHTO LRFD Specifications require the concrete compressive stress in the node regions of the strut shall not exceed the following:

- $\quad$ For node regions bounded by compressive struts and bearing areas: $0.85 \phi$ $f_{c}^{\prime}$

- For node regions anchoring a one-direction tension tie: $0.75 \phi f_{c}^{\prime}$

- For node regions anchoring tension ties in more than one direction: $0.65 \phi f^{\prime}{ }_{c}$

By definition, the truss model does take into account shear and moment effects. However, it is the opinion of the author that it would not be prudent to forgo the addition of traditional shear stirrups. The shear design should be accomplished using a sectional approach provided by AASHTO LRFD Article 5.8.3.3. Additionally, distributed steel should be provided in accordance with State Transportation Department procedures and AASHTO LRFD Specifications. 


\section{Chapter 6}

\section{SUMMARY AND CONCLUSIONS}

\subsection{Summary}

Strut-and-tie modeling is an analysis and design tool for reinforced concrete elements where a truss model represents the internal force paths. The truss model is comprised of tensile ties, compressive struts, and nodal zones.

In the literature, Ritter (1899) and later Morsch (1920) conducted initial work on the truss type analogy to model the internal load carrying mechanism in a reinforced concrete beam. Kani et al. (1979) and Collins and Mitchell (1991) further developed strut-and-tie modeling for individual reinforced concrete members such as deep reinforced concrete members, prestressed concrete beams, and corbels. Realizing that if strut-and-tie approach was valid for parts of a structure then it should be valid for the entire structure, Schlaich et al. (1987) worked to combine individual research conducted on various reinforced concrete elements in such a fashion that strut-and-tie modeling could be used for the entire structure. Citing the inefficiency of the trial-and-error iterative process that is based on the designer's intuition and past experience, Liang, et al. (2002) developed a topology optimization procedure for reinforced concrete design using strut-and-tie modeling. 
The goal of the State Transportation Department survey is to assess the level of implementation of the AASHTO LRFD Specifications. The State Transportation Department survey was sent to all fifty states with 48 percent of the states responding. The results of the survey showed that the states are hesitant to implement the strut-and-tie modeling method.

The design study presents a procedure for developing the strut-and-tie model for hammerhead pier caps. The design procedure addresses the placement of the loads so as to induce the maximum moment in the cantilever section of the hammerhead pier. The design procedure also demonstrates the process for defining the tension ties, compression struts, and nodal zones. In summary, the following steps are used for the design of hammerhead pier caps by the strut-and-tie method.

- Determine the reactions of the superstructure based on the governing load combination.

- Define all nodal zones at the beam reactions and the cap to column reinforcing locations.

- Define the tension ties and compression struts from each nodal zone and at depths equal to the approximate location of the reinforcing pattern.

- Check truss continuity at each nodal zone.

- Solve truss internal forces for tension ties and compression struts.

- Determine reinforcing requirements for tension ties and check compressive strut regions.

- Check stress of nodal zones.

- Revise truss as required. 
- Provide shear stirrups and distributed steel for the hammerhead pier cap.

Furthermore, the design study compares the reinforcing requirements of the original (LFD) design with the results obtained in the strut-and-tie modeling method (based on LRFD). Based on the results of the design study and the procedure used in the modeling, recommendations are proposed for employing the strut-and-tie model to hammerhead piers. The recommendations include the revising of the truss model geometry, treatment of reinforcing bars and crack control, the repeating of truss model geometry, and the use of shear stirrups.

\subsection{Conclusions}

The AASHTO LRFD Design Code states in Section 5.6.3.1 "The strut-and-tie model should be considered for the design of deep footings and pile caps or other situations in which the distance between the centers of applied load and the supporting reactions is less than about twice the member thickness." The commentary further elaborates on the use of strut-and-tie models by pointing out the shortcomings of traditional design theory. Traditional design theory assumes that the shear distribution remains uniform and that the longitudinal strains will vary linearly over the depth of the beam. Furthermore, traditional design theory does not account for shear, moment, and torsional interaction, which the strut-and-tie model does take into account (AASHTO, 1998). 
The LRFD Specifications promote the strut-and-tie method as the design method of choice for deep reinforced concrete sections. However, no one has undertaken the task of developing a consistent approach to the design of hammerhead pier caps employing the strut-and-tie modeling method. The State Transportation Department survey supports the need for a design procedure for strut-and-tie modeling due to the reluctance of the majority of the states to implement the LRFD Code for substructure design.

The specific objectives of the study are to compare the reinforcing requirements of the strength design method (AASHTO LFD) for flexure and shear design with the strut-and-tie modeling method; ascertain the degree of strut-and-tie modeling implementation in State Transportation Departments; and to develop a procedure for modeling a hammerhead pier cap that can be applied by practicing engineers. This work presents a clear and concise procedure for utilizing the strut-and-tie model for the analysis and design of hammerhead piers. As was stated in section 4.5, an increase in tensile reinforcing was incurred by the LRFD strut-and-tie procedure. However, even though it was specified, shear reinforcing is implicitly not required. The strut-and-tie model design study results establish the method as a viable analysis and design tool in the design of hammerhead piers. 


\section{References Cited}

ACI Committee 318, Standard Building Code. Strut-and-Tie Models. ACI Concrete International Magazine, June 2001, pp. 125-132.

AASHTO LFD Standard Specifications, Sixteenth Edition, American Association of State Highway and Transportation Officials, Washington, D.C., 1996.

AASHTO LRFD Bridge Design Specifications, Second Edition, American Association of State Highway and Transportation Officials, Washington, D.C., 1998.

Adebar, P., and Zhou, Z., "Design of Deep Pile Caps Using Strut-and-Tie Models," ACI Structural Journal, Vol. 93, July/Aug 1996: p. 437-48

Collins, M. P., and Mitchell, D., Prestresed Concrete Structures, Prentice-Hall, Inc., Englewood Cliffs, New Jersey, 1991, 766 pp.

Collins, M. P., and Mitchell, D., "Rational Approach to Shear Design - The 1984 Canadian Code Provisions," ACI Journal, Proceedings, Vol. 83, No. 6, Nov-Dec 1986: pp. 925-933.

Collins, M. P., and Mitchell, D., "Shear and Torsion Design of Prestressed and NonPrestressed Concrete Beams," Journal of the Prestressed Concrete Institute, Vol. 25, 1980: pp. 32-100.

“Consys2000®@)”, LEAP Software Inc., 1997.

“Georgia Pier®C)”, Georgia Department of Transportation., 1984.

Huang, F. C., Lee, I. S., and Mo, Y. L., "Designing Pier Caps with Strut-and-Tie Models," Concrete International, Vol. 20, 1998: p. 43-7

Kani, M. W., Huggins, M. W., and Wittkopp, R. R., Kani on Shear in Reinforced Concrete, Department of Civil Engineering, University of Toronto, Toronto, 1979 $225 \mathrm{pp}$. 
Kuchma, D.A. and Tjhin, T. N., "Design of Discontinuity Regions in Structural Concrete Using a Computer-Based Strut-and-Tie Methodology," TRB Session Committee on Concrete Bridges, Nov 2001.

Liang, Q. Q, Uy, B., and Steven, G.P, "Performance-Based Optimization for Strut-Tie Modeling of Structural Concrete," Journal of Structural Engineering Vol. 128 June 2002: pp. 815-823.

MacGregor, J. G., and ACI Committee 318E (Shear and Torsion), Appendix X and CE49: Strut-and-Tie Models, draft of code and commentary to be considered for 2002 ACI Building Code, June, 2000, approx. 30 pp.

MacGregor, J. G., Reinforced Concrete: Mechanics and Design, Prentice-Hall, Inc., Englewood Cliffs, New Jersey, 3rd ed., 1997, 939 pp.

Marti, P., "Basic Tools of Reinforced Concrete Beam Design," ACI Journal, Proceedings, Vol. 82, No. 1, January-February 1985, pp. 45-56.

“Microsoft® Excel®(C), Microsoft Corporation, 1987-1999.

Morcsh, E., Der Eisenbetonbau-Seine Theorie und Anwendung (Reinforced Concrete Construction-Theory and Application), $5^{\text {th }}$ Ed., Wittwer, Stutgart, V.1, Part 1, 1920, Part 2, 1922.

Oliva, M., "Hammerhead Pier Design Using the Strut-and-Tie Modeling Method," Training for Wisconsin Department of Transportation, 1997.

“RISA2D®@”, RISA Technologies, 1999.

Ritter, W., "The Hennebique Design Method (Die Bauweise Hennebique)," Schweizerische Bauzeitung (Zurich), Vol. 33, No. 7, Feb 1899, pp. 59-61. 
Schlaich, J., Schäfer, K., and Jennewein, M., "Toward a Consistent Design of Structural Concrete," Journal of the Prestressed Concrete Institute, Vol. 32, No. 3, MayJune 1987, pp. 74-150.

Yun Y. M., and Ramirez, J. A., "Strength of struts and nodes in strut-tie model," Journal of Structural Engineering Vol. 122 Jan 1996: p. 20-9. 


\section{APPENDIX A}

STATE DEPARTMENT OF TRANSPORTATION SURVEY 
Please allow me to introduce myself, my name is Thomas Nicholas and I was a bridge engineer with the West Virginia Department of Highways. I am currently an instructor at Fairmont State College and a graduate student at West Virginia University. I am doing a study on the use of strut and tie modeling as it pertains to bridge substructures. It would be highly appreciated if I could ask for a moment of your time to answer a few questions and provide some information on how pier design is approached in your state.

1. Is your state currently using the AASHTO LRFD Design code, and if so, is the strut and tie analysis and design procedure being used for the design of bridge pier caps?

2. If the strut and tie procedure is currently not being employed, what design procedure is being used to design the bridge pier caps?

3. In addition to the two questions above, if you have a pier cap designed by strut and tie modeling could you please send a copy of the design calculations, a copy of the construction plans, and a copy of construction plans for an LFD Designed pier to the address below.

4. Any further information you could provide on the design of bridge pier caps in your state would be most helpful. 
Again, I would like to thank you for donating your valuable time in taking part in this study.

Sincerely,

Thomas Nicholas II 
APPENDIX B

NOMENCLATURE 
The following symbols are used in this paper:

$$
\begin{aligned}
& a=\text { depth of the compression block } \\
& A_{c s}=\text { effective cross-sectional area of strut as specified in Article 5.6.3.3.2 } \\
& A_{p s}=\text { area of prestressing steel } \\
& A_{s} \quad=\text { the required area of steel } \\
& A_{s s}=\text { area of reinforcement in the strut } \\
& A_{s t}=\text { total area of longitudinal mild steel reinforcement in the tie } \\
& b \quad=\text { width of concrete section } \\
& b_{w}=\text { the width of web } \\
& d=\text { depth from extreme compression fibers to reinforcing } \\
& D=\text { depth of the nodal zone } \\
& \mathrm{D}_{\mathrm{A}}=\text { available effective depth } \\
& \mathrm{D}_{\mathrm{R}}=\text { required effective depth } \\
& f^{\prime} c=\text { concrete cylinder strength } \\
& f_{c u}=\text { limiting compressive stress as specified in Article 5.6.3.3.3 } \\
& f_{p e}=\text { stress in prestressing steel due to prestress after losses } \\
& f_{y} \quad=\text { yield strength of mild steel longitudinal reinforcement } \\
& F_{i} \quad=\quad \text { force in strut or tie } \mathrm{i} \\
& l_{i}=\text { length of member } \mathrm{i} \\
& \mathrm{M}_{\mathrm{n}}=\text { nominal moment capacity } \\
& N_{u} \quad=\text { the factored tie force } \\
& P_{n} \quad=\text { nominal resistance of strut or tie } \\
& P_{u}=\text { ultimate capacity of strut or tie }
\end{aligned}
$$


$V_{c}=$ the nominal shear strength provided by the concrete

$V_{n}=$ the nominal shear strength

$V_{u}=$ the factored shear force at the section considered

$W \quad=$ width of the nodal zone

$\alpha_{s}=$ the smallest angle between the compressive strut and adjoining tension ties (deg)

$\beta_{s}=1.00$ for prismatic struts in uncracked compression zones

$\beta_{s}=0.40$ for struts in tension members

$\beta_{s}=0.75$ when struts may be bottle shaped and crack control reinforcement is included

$\beta_{s}=0.60$ when struts may be bottle shaped and crack control reinforcement is not included

$\beta_{s}=0.60$ for all other cases

$\beta_{n}=$ when nodes are bounded by struts and/or bearing areas

$\beta_{n}=0.80$ when nodes anchor only one tie

$\beta_{n}=0.60$ when nodes anchor more than one tie

$\epsilon_{m i}=$ mean strain of member $\mathrm{i}$

$\varepsilon_{s}=$ the tensile strain in the concrete in the direction of the tension tie (in/in)

$\gamma_{i}=$ angle between the axis of a strut and the bars

$\phi \quad=$ resistance factor

$\rho=$ the reinforcement ratio

$\rho_{b}=$ the balanced reinforcement ratio

$\rho_{v i}=$ steel ratio of the $i$-th layer of reinforcement crossing that strut 